\title{
Experimentelle Untersuchungen über die Wirkung rascher Veränderungen des Luftdruckes auf den Organismus.
}

\author{
Von \\ DDr. Richard Heller, Wilhelm Mager, \\ Hernann von Sehrötter
}

in Wien.

Mit 16 Textfiguren.

Ueberblickt man die zahlreichen Theorien, die bisher zur Erklärung der patholologischen Effecte, wie sie durch bedeutende Aenderungen des barometrischen Druckes, insbesondere durch den raschen Uebergang von einem bedeutend erhöh. ten Druck a uf den herrschenden Luftdruckgesetzt werden, so sind es hauptsächlich zwei grosse Gruppen von Auffassungen, die sich unterscheiden lassen.

Die eine Gruppe von Autoren erklärte die asphyctischen Zufälle, die Paralysen und Paraplegien, die einer raschen Decompression folgen können, als durch $\mathrm{mech}$ an is che Momente bedingte Folgezustände einer ab normen Blutvertbeilung: unter erhöhtem Druck.

Einige fassten direct eine $\mathrm{C}$ on $\mathrm{g}$ e sti on der inneren Organe (Pol und Watelle, Babington und Cathberth u. A.) oder eine solche gefolgt von Hämorrhagien als den ätiologischen Factor der Erscheinungen auf, andere zogen eine der Hyperämie in comprimirter Luft folgende reactive Anämie in den Kreis ihrer Erwägungen (amerikanische Autoren); wieder andere endlich machten die der Hyperämie folgenden Circulationsstör ungen verantwortlich (Smith). Aber auch die meisten Beobachter, welche die physiologischen Wirkungen der comprimirten Luft im pneumatischen Cabinet studirten, erklärten die Effecte des erböhten Luftdruckes durch die Annahme, dass Druckdifferenzen zwischen Körper- 
oberfläche und den inneren Organen mit ihren Folgen bestünden, eine Auffassung, gegen welche neben $\mathrm{G}$ i r a u $\mathrm{d}-\mathrm{T}$ e $\mathrm{ul}$ on, B ert und $\mathrm{Panum}$ jüngst insbesondere $\mathrm{Regnard}$ ibre Stimme erhoben baben.

Die andere Gruppe der Autoren, an deren Spitze H o ppeS e y ler, P. B ert und seine Schule stehen, erklärte, basirend auf ein reiches experimentelles Material, die Decompressionserscheinungen als die Folge von Circulationsstörungen und Embolien, die durch das Freiwerden der Blutgase, hauptsächlich von Stickstoff, bei rascher Druckabnahme zu Stande kommen.

Während nun von allen französischen Autoren die sogenannte Gastheorie zur Erklärung der bei Tauchern und Caissonarbeitern auftretenden Decompressionserscheinungen allgemein acceptirt wurde und sich auch bereits in Deutschland und Russland Eingang verschafft hatte, traten in den achtziger Jahren mebrere englische und amerikanische Autoren anf, Moxon, Twynam, Nixon, in den neunziger Jahren $\mathrm{Kn}$ a p $\mathrm{p}, \mathrm{H} u \mathrm{u}$ e $\mathrm{r}, \mathrm{C}$ orn ing, Thompson und neuerdings A. Smith (1894), eine in den genannten Fragen in Amerika maassgebende Autorität, welche alle wieder auf die mechanische Theorie, wenn auch in stark veränderter und erweiterter Form, zurückgriffen. Auch van Rensselae r (1891) and $\mathrm{Cl}$ ark (1893) ziehen, ersterer gestiitzt auf seine anlässlich eines amerikanisehen Tunnelbaues gemachten Erfahrungen, die Gastheorie wieder in lebhafte Diskussion und suchen zu zeigen, dass so manche Sätze P. B ert's und seiner Schule einer eingehenden Kritik nicht Stand halten, indem sie dabei vielfach $\mathrm{M}_{0}$ mente betonen, die auch $\mathrm{Smith}$ geltend zu machen sucht, ohne dass sich die Amerikaner, mit Ausnahme von Thom pson, die Mühe genommen hätten, die Experimente der französischen Schule nachzuprüfen oder zu wiederholen ${ }^{1}$ ).

Gerade diese Meinungsdifferenz der Antoren der letzten Jahre zu einer Zeit, in welcher die pnenmatische Fundirungsmethode, die

1) Nunmehr können wir dem Gesagten noch beifügen, dass $\mathrm{Hu} \mathrm{gh}$ Snell, mit dem wir bereits seit einem Jahre in wissenschaftlicher Correspondenz stehen, als erster von den englisch-amerikanischen Autoren in seinern eben erschienenen Buche "Compressed air illness" die B e r t'sche Gastheorie acceptirt hat. 
Anwendung von comprimirter Luft zu Bauzwecken immer mehr und mehr an Ausdehnung und Bedeutung gewinnt, veranlasste uns insbesondere mit Bezug auf die praktische Seite des Gegenstandes, die Wirkungen rascher Druckänderungen auf den Organismus neuerdings zu studiren und dabei mit jenen Druckdifferenzen zu arbeiten, welche fuir die Arbeiter in Pressluft in Betracht kommen. Wir bielten uns daher innerhalb der Grenzen von 1-5 A. Ue berdruck.

Nach dem Gesagten wird auch eine theilweise Wiederholung und Ergänzung der P. Bert'schen Experimente, wie sie nothwendiger Weise folgen musste, gerechtfertigt sein; im übrigen waren wir noch durch andere Gesichtspunkte, von denen wir uns bei den Untersuchungen leiten liessen, bemüht, die Gastheorie dureh unsere Versuche endlich zur herrschenden zu machen.

Vorzüglich aber war es die Präcisirung der Frage über Wirksamkeit und pathologische Bedentung der Luftembolie ${ }^{1}$ ), welcher wir unser besonderes Augenmerk geschenkt haben, um auf diese Weise die Aetiologie der einzelnen Symptome klarzustellen. Bevor wir nunmehr auf unsere Untersuchungen eingehen, wollen wir jener Autoren Erwähnung thun, welche gestiitzt auf Experimente füir die Gastheorie eingetreten sind. Wie wir an anderem Orte des Genaueren auseinandergesetzt haben, beobachteten schon im 17. und 18. Jahrhundert Robert Boyle um 1650 und van M u s s chenbroeck 1755 das Freiwerden von Blutgasen bei starker und rascher Luftverdùnnung, Entdeckungen, die erst wieder durch P. B e r t ans Licht gezogen und bekannt geworden sind. Bis in die dreissiger Jahre unseres Jahrhunderts wurde den genannten Fragen von Seite der Physiologen, mit Ausnahme von v. Haller nur untergeordnete Beachtung geschenkt, jedenfalls finden wir über diesbeziglich angestellte Thierversuche keine Aufzeichnungen. Erst im Beginn der 30er Jahre unseres Jahrhunderts sehen wir Poiss e uille experimental die Frage iber den Einfluss starker barometrischer Druckschwankungen auf die Circulation des Blutes studiren. Im Jahre 1857 folgte die bedeutsame Arbeit von $\mathrm{H}$ op pe-S e yler, der, angeregt durch die Berichte

1) Vergl. diesbezüglich auch unsere Publication: Ueber a rterielle Luftembolie von DDr. Heller, Mager, v. Schrötter. Zeitschrift für klinische Medicin. 32. Bd. Supplementheft. 1897. 
von Wa telle und $G$ u ér a r d über die Todesfälle von Arbeitern aus der Mine von Douchy, in Unkenntniss der Entdeckungen B oyle's und seines Nachfolgers die Thatsache des Freiwerdens der Blutgase bei raschem Absinken des barometrischen Druckes bei seinen Versuchsthieren beobachtete und als die eigentliche Todesursache hinstellte.

Unabhängig von Hop pe-Seyler nahm dann im Jahre 1871. P. Bert im grossen Maassstabe das Studium der Decompressionserscheinungen auf, das er dann gesammelt in seinem berühmten Werke „La pression barométrique“ (1878) niedergelegt hat. Aus dem Jahre 1873 liegt ein positives Experiment von S mith vor. Im Anschlusse an P. B ert haben A. Febure (1879), dann Bert's Schïler B l a n chard und Regnard (1881) dessen Versuche, insbesondere über die nach der Decompression gesetzten Läsionen des Rückenmarkes, wieder aufgenommen; 1883 studiren Frae n k l und Geppert die Erscheinungen an Thieren bei Druckverminderung, mit denen sich auch $\mathrm{R} 0$ senthal beschäftigt hat. Aus dem Jahre 1886 liegen Experimente von $\mathrm{Cats}$ a $\mathrm{r}$ s über die Verhältnisse, denen die Taucher unterworfen sind, sowie bemerkenswerthe Versuche von $\mathrm{C}$ a s s a ët, and Experimente von $\mathrm{Th}$ ompson vor. Im Jahre 1894 berichtet $\mathrm{Ph}$ ilippon iber seine Decompressionsversuche; endlich wurden im Anschlusse an den jüngst fertiggestellten Quaibau im Hafen von Bordeaux von dem dortigen Professor La y et (1895), dessen persönliche Bekanntschaft zu machen wir die Ehre hatten, Versuche angestellt ${ }^{1}$ ), in welchen er vorwiegend die praktische Seite der Frage verfolgte und bei denselben Bedingungen herstellte, wie sie thatsächlich für den Caissonarbeiter in Betracht kommen and kommen können. Eben durch die Gesichtspunkte, von denen er sich bei seinen Experimenten leiten liess, ist er uns in gewissem Sinne zuvorgekommen und wir anerkennen diesbeziglich seine Priorität, wenn wir anch betonen muissen, dass wir seine unter Hersent's Namen publicirten und in technischen Zeitungen abgedruckten Untersuchungen erst zu einer Zeit kennen lernten, za welcher wir bereits tiber eine grosse Zahl von Experimenten verfügten.

Die Möglichkeit, diese Versuche auszuführen, wurde uns durch 1) Auf seine wie auch auf die Experimente der vorgenannten Beobachter genaner einzugehen, wird an anderer Stelle Gelegenheit sein. 


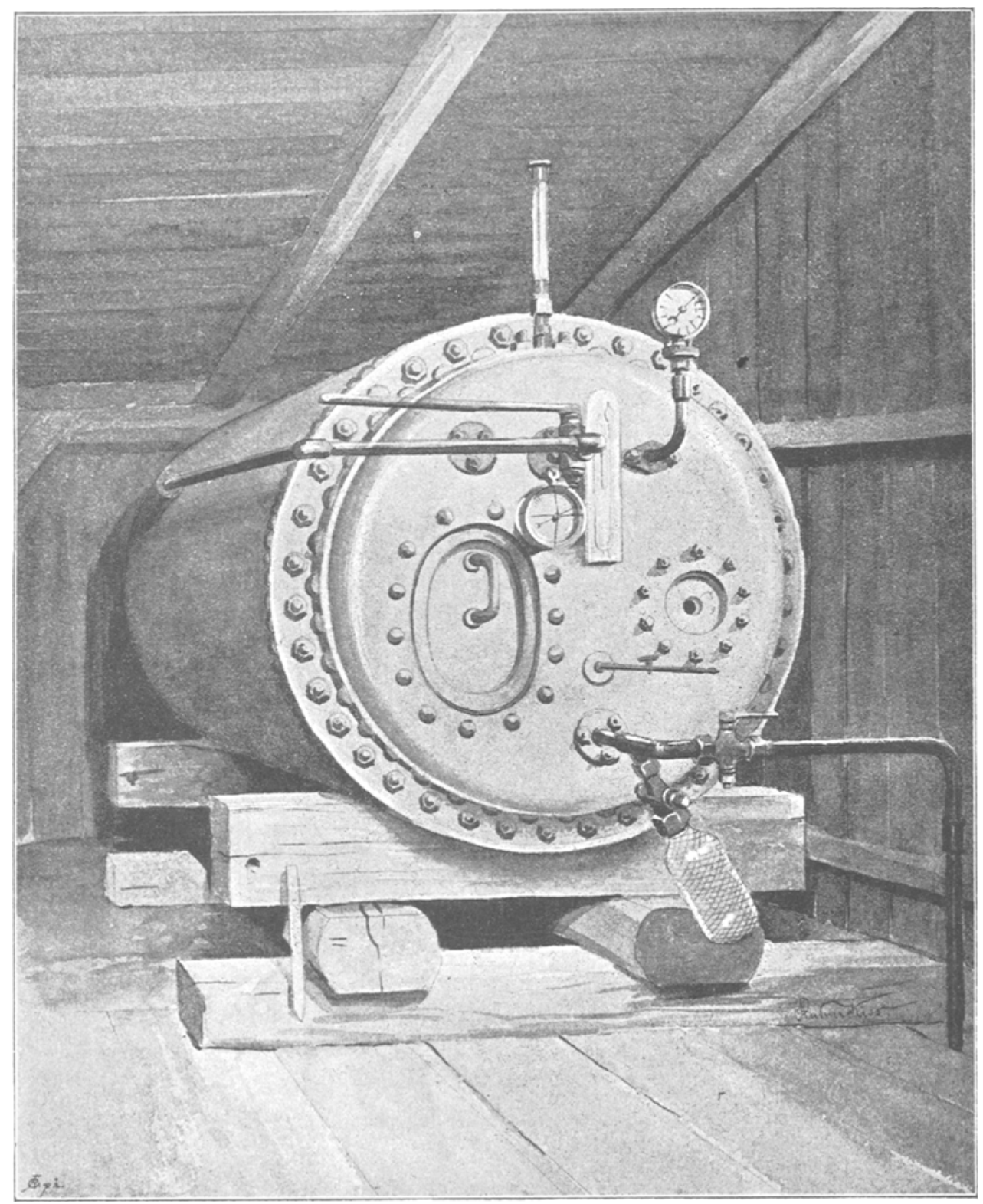

Figur 1.

die Liebenswürdigkeit und das freundliche Entgegenkommen des Herrn K. Redlich, Bauunternehmers in Wien, geboten, der den gleich näher zu beschreibenden Apparat eigens für unsere Zweeke 
herstellen liess. Ausserdem wurden die Experimente zum Theil in dem in Nussdorf bei Wien eben in Bau befindlichen Caisson (Object I der Schleusenarbeiten k. u. k. Donauregulirungseommission), sowie in der von L. v. Sehrötter und gleichzeitig unabhängig von einander von Oberbaurath $\mathrm{T}$ a u s s i g anlässlich des Nussdorfer Schleusenbaues vorgeschlagenen und im Besitz der Firma Gebrïder Redli ch and Berger befindlichen Sanitätsschleuse (Recompressionsschleuse für an „Pression" erkrankte Arbeiter) ausgeführt, bezüglich deren näherer Beschreibung wir hier auf eine demnächst

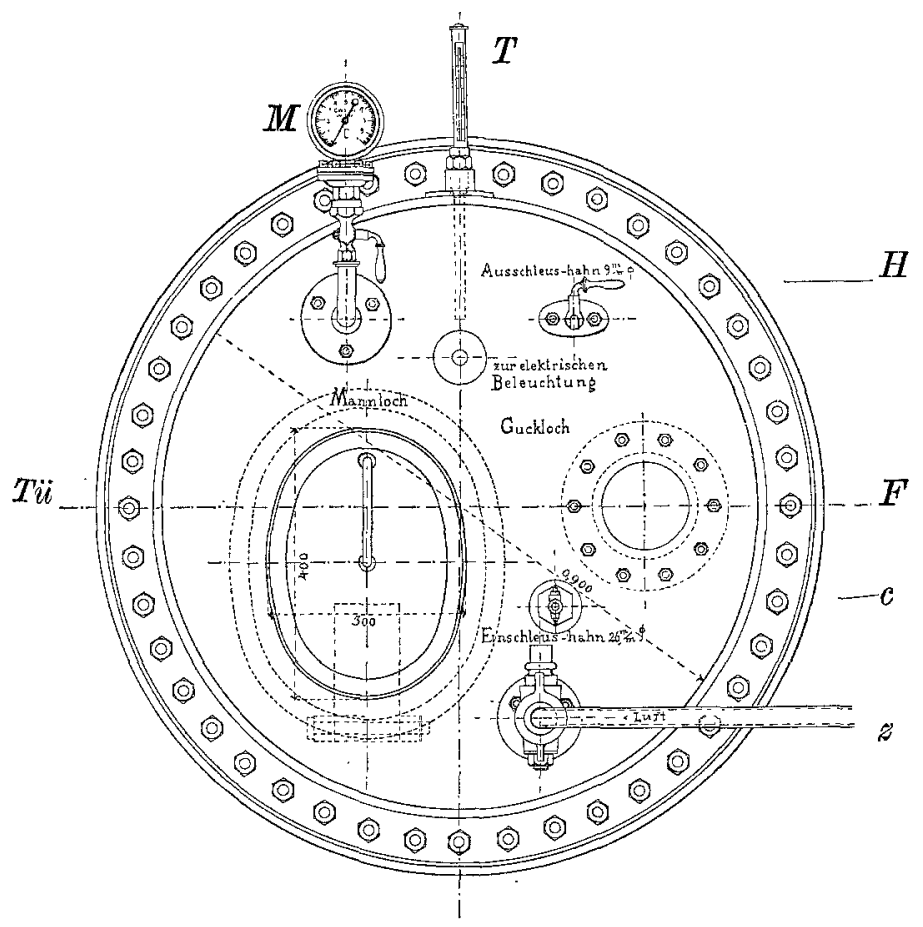

Fig. 2. Experimentirkammer, Vorderansicht.

erscheinende ausfïbrlichere Publikation verweisen müssen. Unsere Versuche begannen wir Anfang $\mathrm{Juni}$ 1894. Wenn im Caisson oder in der Sanitätsschleuse experimentirt wurde, so ist dies bei den betreffenden Versuchen stets ausdriicklich bemerkt. Die ibrigen Versuche wurden mittelst der Experimentirkammer angestellt. Dieselbe stellt der Hauptsache nach einen cylindrischen, ca. $16 \mathrm{cbm}$ betragenden Raum dar, in welchen durch Dampfmaschinen comprimirte Luft bis auf den maximalen Ueberdruck von $5 \mathrm{~A}$. einge- 


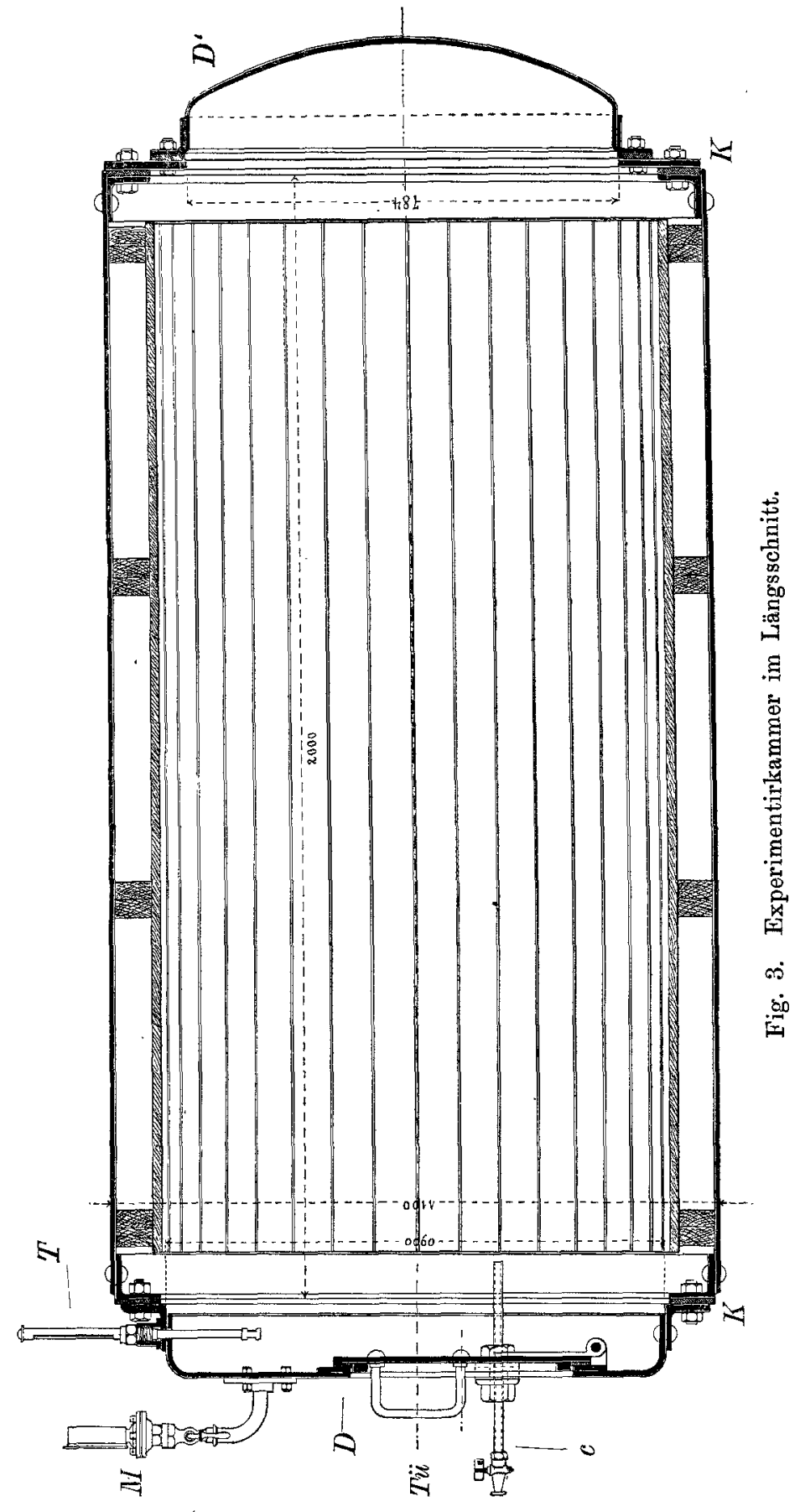


getrieben werden konnte und die Einrichtung getroffen war; den Druck durch Oeffnen eines Hahnes von grossem Querschnitt rasch auf den herrschenden Luftdruck zum Absinken zu bringen. Bezüglich der genaueren Beschreibung verweisen wir auf die beifolgenden Abbildungen. Fig. 1 stelit den Apparat in Vorderansicht in der heizbaren höIzernen Hütte, Fig. 2 die Construction des vorderen Deckels und Fig. 3 den constructiven Längsschnitt dar.

Zur Anfertignng der Kammer diente ein $2 \mathrm{~m}$ langes eisernes Schachtrohr von den Dimensionen, wie sie für die Einsteigrohre im Caisson (Durchm. 1,1 m) Verwendung fanden; an die beiden Enden desselben waren eiserne Deckel $\left(D, D^{\prime}\right)$ angeschraubt und durch Kautschukringe $(K)$ abgedichtet. Die innere Wand der Kammer war mit Holz ausgekleidet und waren zur Anbringung des Experimentirbrettes hölzerne Schemmel vorhanden. Der rückwärtige, nach aussen leicht convexe Deckel hatte keine weiteren Ansatzstiicke; der vordere besass eine vertical ovale Oeffnung (Dimens.: $h=40 \mathrm{~cm}, b=30 \mathrm{~cm}$ ), in welche ein als Schliessungsthür dienendes, mit einem Handgriff und einem Charnier versehenes Deckelstiick (Tii) von innen hineinpasste, welches mit einem Kantschukrand versehen bei steigendem Druck im Inneren der Kammer den Raum luftdicht abschloss, sowie eine zweite Oeffnung, in welche eine planparallele Glasplatte als Fenster $(F)$ eingesetzt war. Ansserdem waren an der Vorderwand noch mehrere Anschlussstücke für die zu- (z) und abfuhrende Luftleitung angeschraubt und die Hähne in der Weise angefertigt, dass alle Manipulationen leicht ausführbar waren; überdies waren Messinstrumente an denselben montirt.

Durch das Rohr $\approx$ (Durchm. $26 \mathrm{~mm})$ wurde die Luft direkt vom Luftsammler der Compressionspumpen der Experimentirschleuse zugeführt, wozu der untere Hahn diente. Wurde derselbe geschlossen, so konnte das Zweigstiick st mittelst des Ausströmungshahnes $H$ zur Decompression verwendet werden; es konnte an dieselbe auch eine Druckflasche angeschraubt werden, von welcher noch die Rede sein wird; sie ist aus Fig. 4 ersichtlich.

Das Rohr (Durchm. $9 \mathrm{~mm}$ ), welches gewöhnlich zur Druckverminderung benutzt wurde, besass einen bequem zu gebrauchenden Hahn, durch dessen vollständiges Oeffnen der Druek rasch zum Absinken gebracht werden konnte. Um den störenden Lärm und die Unannehmlichkeit der einem direkt entgegenströmenden 
kalten Luft $\mathrm{zu}$ vermeiden, war das Rohr bedeutend verlängert und in der Weise winkelig abgebogen, dass es erst entsprechend der hinteren Hälfte der Längswand nach aussen führte.

Aber noch eine kleinere, mit einem Hahn versehene kupferne Röhre $c$ sieht man in den vorderen Deckel eingesetzt, sie war für specielle Untersuchungen bestimmt und diente hauptsächlich zur Blatentnahme von einem in der Kammer unter Druck befindlichen Versuchsthiere (vergl. die Anwendungsweise desselben zur Blutgasanalyse pag. 33). Das Rohr ragte auf $25 \mathrm{~cm}$ in den Kammerraum und etwa in gleicher Länge nach aussen vor. Mittelst des Rohres und Hahnes $(H)$ wurde decomprimirt, wenn der Drackabfall nicht allzu rasch erfolgen sollte oder man allmäbliches $\mathrm{Ab}$ sinken desselben $z \mathfrak{u}$ erzielen beabsichtigte. Wollte man den Druckabfall sehr rasch bewerkstelligen, so wurden die Hähne sämmtlicher drei Rohre $(H, \approx, c)$ geöffnet, wodurch man den Druck innerbalb einer Minute auf den äusseren Luftdruck absinken lassen konnte. Wir waren so im Stande, ein Versuchsthier von 4,8 A. Ueberdruck auf den herrschenden Barometerstand in $30^{\prime \prime}-50^{\prime \prime} \mathrm{zu}$ decomprimiren. Langsames Entschleusen wurde durch starke Drosselung des oberen Hahnes erzielt und konnte dasselbe bei einem Druck von über $4 \mathrm{~A}$. auf die Zeit von über eine balbe Stunde ausgedehnt werden.

Das bereits erwähnte Fenster hatte nicht bloss den Zweck das Versuchsthier zu beobachten, sondern man konnte dureh dasselbe auch Instrumente (Blutdruckmesser und Hygrometer) ablesen.

Ein Thermometer $T$ war in der Weise in den Deckelrand eingedichtet, dass dessen Kugelende im Kammerinneren sich befand und ausserhalb die Temperaturänderungen während der Compression und Decompression anzeigte. Das Manometer $M$ (Sehaeffer und B udenberg) hatte eine Theilung in Zehntel-Atmosphären, sodass innerhalb dieser Grenzen stattfindende Drnckschwankungen abgelesen werden konnten. Bei $c l$ waren die elektrischen Leitungsdrähte eingefügt, die eine Glühlampe zur Beleuchtung der Druckkammer versorgten. Zur Beobachtung des Hygrometerstandes diente ein sehr handliches Präzisions-Instrument von $\mathrm{C}$ a p elle $\mathrm{r}$ in Wien, an welchem man direkt den Feuchtigkeitsgehalt in Prozenten ablesen kann und das in der Druckkammer gegenüber dem schon besprochenen Fenster $F$ in der Weise neben einem MaximalMinimalthermometer aufgehängt wurde, dass man die Scalen bequem beobachten konnte. 
Will man nun ein Thier dem erhöhten Luftdruck aussetzen, so geht man in folgender Art vor: Man hat dann das Thier in die Kammer zu bringen, die Thüre zu schliessen und den unteren Hahn zu öffnen; der Druck steigt dann rascher oder langsamer, wie man es wïnscht, im Kammerraume an, wie man dies an dem Manometer controliren kann. Während das Thier sich nun in der Experimentirschleuse befindet, kann man dasselbe durch das Fenster, ebenso wie verschiedene Instrumente bequem beobachten. Oeffnet man dann, um die Decompression zu bewerkstelligen, den oberen Hahn, so ist die Beobachtung der Vorgänge im Inneren durch den frei werdenden und oft dichte Nebelbildung verursachenden Wasserdampf, insbesondere bei raschem Druckabfall, erschwert, dem man einigermaassen dadurch begegnen kann, dass man auf wenige Augenblicke die Decompression unterbricht, wodurch die Nebel schwächer werden.

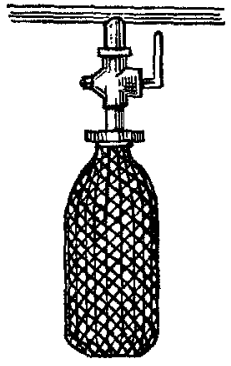

Fig. 4. Dickwandige von einem Drahtnetz umsponnene Glasflasche; $a$ das Luftzufïhrungs- resp.

Abströmungsrohr.

Die Druckflasche (vgl. die beistehende Fig. 4), welche ursprünglich zu den Experimenten mit kleinen Versuchsthieren benutzt werden sollte, fand später nach Herstellung unseres grossen Apparates keine Verwendung mehr, doch kann sie in jenen Fällen, in welchen man über nicht genügendes technisches Material verfügt, zweckmässig zu den gleichen Experimenten verwendet werden ${ }^{1}$, und wir haben sie deshalb hier wiedergegeben. Ihre Construktion ist ohne weiteres verständlich, die Compression und Decompression sind sehr rasch zu bewerkstelligen.

Von den Apparaten sowie der Versuchsanordnung zum Zwecke der Blutgasgewinnung wird zusammenhängend bei den betreffenden Experimenten die Rede sein. Wenn in den folgendeu Aufzählungen der Experimente von 1, 2, 3 etc. Atmosphären Druck die Rede ist, so ist damit stets Ueberdruck gemeint, so dass der Gesammtdruck defacto 2, 3, 4 etc. Atmosphären beträgt.

1) Ebenso benützten wir sie zum Studium der Frage der Gasentbindung aus Flüssigkeiten, wovon an anderer Stelle noch weiter die Rede sein wird. 
Wir gehen nunmehr an die ausfiuhrliche Mittheilung unserer Experimente und wollen, um die Uebersicht über dieselben zu erleichtern, gleich an dieser Stelle kurz die Fragen angeben, um deren experimentelle Beantwortung es sich uns hauptsächlich handelte. Die Versuche sind nach bestimmten Gesichtspunkten angeordnet, die vor jeder Gruppe von Experimenten des Genaueren erörtert werden.

Erstens: Kam es uns darafan, zu untersuchen, obthatsächlich, wie diesdie Anhänger der mechanischen Theorievermutheten, die Blutvertheilung des Organismus in comprimirter Luft aus mechanischen Ursachen eine Veränderungerfahre.

Zweitens: Wann und unter welehen Bedingungen kann man Gasblasen im Gefässystem nach der Decompression nachweisen?

Drittens: Welche chemische Zusammensetzung: besitzen die im lebenden Thiere frei gewordenen Gase?

Viertens: Unter welchen Bedingungen werden pathologische Effecte durch diese Vorgänge gesetzt und welcher Natur sind dieselben?

Fünftens: Wie gestalten sich diese Verhältnisse, wenn man einer raschen Decompression neuerliche Compression (Recompression) folgen lässt?

\section{I.}

Um die Frage nach einer abnormen Blutvertheilung unter erhöhtem Druck endgültig zu lösen, war es das Natürlichste, eine Section der Versuchsthiere in comprimirter Luft vorzunebmen, womit sich die Versuche 1 und 2 beschäftigen. Gegen die Behauptung einer vermehrten Blutfülle des Gehirns, einer Congestion gegen dasselbe unter Druckerhöhung, als gegen ein von unnachgiebigen knöchernen Wänden eingeschlossenes Organ, wurde Versuch 4 angestellt, um den Druck gleichsam direct auf dasselbe wirken zu lassen und diesen Effect klarlegen zu kömneu.

Zur Beobachtung der Blutcirculation unter erhöhtem Luftdrucke diente Versuch 3, Versuch 5 sollte über den mechanischen Einfluss des Druckes auf den Abdominalinhalt Aufschluss geben 
und Versuch 6, ebenfalls zur Klärung mechanischer Einflüsse unternommen, sollte die Blutvertheilung im todten Thier beleuchten. Versuch 7 war in der Absicht angestellt, über die unter erhöhtem Luftdruck erfolgende Aufnahme von Gasen ins Blut Aufschluss zu geben.

Endlich mögen hier noch anbangsweise Versuche folgen, die angestellt wurden, um die Wirkung sehr rascher Drucker öhung auf den Organismus kennen zu lernen. Durch die besondere Construction unseres Recompressionsapparates waren wir in der Lage, mittelst der "Medicamentenschleuse" (kleiner Cylinder mit Luftzuleitungsrohr von relativ grossem Durchmesser) Thiere in $3-4 \mathrm{~S} \mathrm{e}-$ c u $\mathrm{n}$ de $\mathrm{n}$ auf einen Ueberdruck von 2,2 A. zu comprimiren.

\section{Versueh 1 .}

Kaninchen. (Versuch in der Sanitätsschleuse.)

Zeit der Compression: 27 Minuten.

Druck: 2,1 A tm.

Dauer des Aufenthaltes: $3 / 4$ Stunden.

Zeit der Decompression: 50 Minuten.

Eine halbe Stunde nach erreichtem Maximaldrucke wird das Kaninchen durch Schläge auf den Kopf getödtet und secirt. Sowohl während des weiteren Aufenthaltes in comprimirter Luft, als auch beim Ausschleusen und nach der Decompression zeigten sich keine Veränderungen am getödteten Thiere; keine Congestion der inneren Organe oder des Gehirnes und Rückenmarkes.

\section{Vers a ch 2.}

Kaninchen. (Versuch in der Sanitätsschleuse.)

Zeit der Compression: 20 Minuten.

Druck: 2,0 Atm.

Dauer des Aufenthaltes: $3 / 4$ Stunden.

Zeit der Decompression: 50 Minuten.

Bevor das Thier in die Sanitätsschleuse mitgenommen wird, wird das specifische Gewicht des Blutes, aus der Pfote entnommen, mit 1056 bestimmt; Trepanation des Schädels und Entfernung einer ca. $1 / 2 \mathrm{~cm}$ im Durchmesser betragenden Knochenplatte; lockerer Verband.

Nachdem das Thier eine halbe Stunde im Druck geathmet hat, wird es durch Schläge auf den Kopf getödtet und im Apparate secirt.

Bei der Section zeigt sich keine Veränderung an den inneren 0rganen, keine Aenderung der Blutvertheilung. Während der Druckverminderung blähen sich die Eingeweide des getödteten Thieres auf, sonst trat keine Veränderung ein. - Es ergiebt sich keine Hyperämie der inneren Organe; das venöse Blut unterscheidet sich durch sein dunkleres Roth wie unter 
normalen Barometerstand vom arteriellen. Eine heller rothe Färbung des Venenblutes wird nicht gefunden. Die Blutfüllung der Meningen gleich der des Thieres beim Versuch Nr. 1. Die neuerliche Prüfung des specifischen Gewichtes des Blutes in der Schleuse ergiebt den gleichen Werth wie vor dem Versuche.

\author{
Versuch 3 . \\ 3 Frösche. (In der Sanitätsschleuse.)
}

Compressionszeit: 27 Minuten.

Druck: 2,1 Atm.

Dauer des Aufenthaltes: $3 / 4$ Stunden.

Decompressionszeit: 50 Minuten.

Nachdem der Druck die Höhe von 2,1 Atm. erreicht hatte, wurden an den Fröschen die Capillaren der Schwimmhäute und des Peritoneums beobachtet und auch während der Decompression die Beobachtung fortgesetzt. Das Blut circulirte in allen sichtbaren Gefässen während dieser Zeit sowie auch während und nach dem Entschleusen normal.

\title{
Versue h 4 .
}

Kaninchen. (Caisson. Druck: 2,55 Atm.)

Einem Kaninchen wird in schwacher Chloroformnarkose eine ca. $3 \mathrm{~mm}$ grosse Oeffnung ins linke Schädeldach gemacht und die Hautwunde darüber vernäht.

Um $2 \mathrm{~h} \mathrm{Nachm.} \mathrm{wird} \mathrm{es} \mathrm{eingeschleust} \mathrm{und} \mathrm{um} 6 \mathrm{~h} \mathrm{Nachm.} 20$ Min. lang ausgeschleust. Es ist sehr niedergeschlagen, hat die Ohren zurückgelegt, versucht nicht wegzulaufen und reagirt nur schwach auf äussere Reize. Athmung etwas ersehwert. - Nach $1 \frac{1}{2}$ Stunden wird es wieder lebhaft, sieht um sich und bewegt sich; die Athmung wird besser. Watteverband.

Am andern Tage früh ist das Kaninchen munter und frisst. Wird durch Chloroforminhalation getödtet. Die Section ergab:

Kleine Ecchymosen an der linken Lunge und im Pericardium.

Am Gehirn, der Stelle der Knochenlücke entsprechend, die Hirnrinde blutig suffundirt. Sonst keine Veränderungen.

\author{
Versueh 5 . \\ Hund Nr. II, ,Lion“, $8 \mathrm{~kg}$, Männchen. \\ (Hernia umbilicalis.)
}

Vor dem Versuche wird das Thier gefüttert und befindet sich im ärztlichen Inspectionszimmer. 
14 Richard Heller, Wilhelm Mager, Hermann von Schröter:

\begin{tabular}{|c|c|c|c|c|c|}
\hline Z. & $\begin{array}{l}\text { Dr. } \\
\text { i. A. }\end{array}$ & A. T. & Sch. T & $\begin{array}{l}\mathrm{Hg} . \\
\text { Sch. }\end{array}$ & Bar. $\left.{ }^{1}\right)$ \\
\hline $\begin{array}{l}9 \mathrm{~h} 40^{\prime} \\
945^{\prime}\end{array}$ & $\begin{array}{l}0 \\
90\end{array}$ & $-6^{0}$ & $-4^{0}$ & $80 \%$ & $764 \mathrm{~mm}$ \\
\hline $946^{\prime}$ & 3,0 & & $\begin{array}{r}+8 \\
+80\end{array}$ & 95 & \\
\hline $947^{\prime}$ & 4,0 & & & & \\
\hline $950^{\prime}$ & 4,7 & $\theta^{\prime}$ & & & \\
\hline $1040^{\prime}$ & 4,7 & & $+11^{0}$ & & \\
\hline $1041^{\prime}$ & 0 & & $0^{0}$ & 80 & \\
\hline
\end{tabular}

Bei 4,7 Atm. Druck bellt der Hund laut. Die Hernie zeigt keinerlei Veränderungen.

Sowohl unter Druck als knapp nach dem Anssehleusen befindet sich das Thier vollkommen wohl, kein Meteorismus, keine Auftreibung an der Hernie. - Nach $1 / 4$ Stunde tritt leichte S te if heit der Hinter beine auf, die bis $12 \mathrm{~h}$ Vorm. völlig schwindet.

\section{Versuch 6.}

\section{Katze.}

Eine eben durch Stich in die Medulla getödtete Katze wird in die Experimentirkammer eingeschleust und durch eine Stande in einem Ueberdruck von 4,5 Atm. belassen. Rasche Decompression in 52. Sec. Das Abdomen des Thieres erscheint stärker aufgetrieben. Bei der Section zeigen sich die Darmschlingen star'k gebläht; sonst allenthalben normaler Befund; keine Gasblasen in den Gefässen, keine abnorme Blutvertheilung.

\section{Versuch 7.}

\section{$\mathrm{Z}_{w}$ ei Kaninchen. (In der Sanitätsschleuse.)}

Zwei Kaninchen werden durch Schlag auf den Kopf getödtet. Nach 10 Minuten wird das eine in den Recompressionsapparat mit eingeschleust und einem Ueberdruck von 2,1 Atm. ausgesetzt; nach eiver balben Stunde wird es daselbst secirt. Es zeigt sich keine abnorme Blutvertheilung; weder die Lungen und die Abdominalorgane, noch das Gehirn zeigen eine vermehrte Blutfüllung. Decompression in 35 Min.

Das Thier mit jenem bei dem herrschenden Barometerdruck mittlerweile secirten verglichen, zeigt gleichen Befund.

1) In diesen Tabellen bedeuten:

Z, Zeit des Versuches;

Dr. i. A., Ueberdruck in Atmosphären;

A. T., Aussentemperatur in ${ }^{0} \mathrm{C}$.;

Sch. T., Temperaturen im Apparate;

Hg. Sch., Prozentualer Feuchtigkeitsgehalt in demselben;

Bar., Aeusserer Barometerstand. 


\section{Versuch 8.}

\section{Hund Nr. LXII.}

Nach entsprechender Präparation wird das Thier in den Compressions. apparat gebracht; die in die rechte Vena jugularis eingebondene Canüle wird mittelst eines Kautschukschlauches mit dem inneren Antheil des Messingrohres $c$ in Verbindung gesetzt, nachdem Canüle, Schlauch und Rohr bis zum Hahne mit 4 proc. oxalsaur. Natronlösung gefüllt sind. Das Thier wird nunmehr auf $2,5 \mathrm{Atm}$. eingeschleust; nach $1 / 2$ Stunde wird der Hahn geöffnet und nach Abfluss der Oxalsäure das ausfliessende reiue Blut aufgefangen ${ }^{1}$ ). Die Blutprobe, mit einer vor dem Versuch entnommenen verglichen, ergiebt keine Differenz im Farbentone; das specifische Gewicht einzelner Blutstropfen, die jedoch nicht alle gleich hoch im Chloroformbenzolgemisch schwimmen, wird im Mittel etwas geringer (1046) als vor dem Versuch (1050) gefunden.

Das Thier wird in einer halben Stunde vorsichtig entschleust, Canüle und Schlauch sodann in derselben Weise adjustirt wie früher und der Hund hierauf neuerdings auf $4,5 \mathrm{Atm}$. eingeschleust. Nach $3 / 4$ stïndigem Verweilen wird wieder der Hahn geöffnet und die nach Abfluss der oxalsaur. Natronlösung gewonnene, rasch $\mathrm{sch}$ a u $\mathrm{mg}$ werdende Blutprobe wieder mit den vorigen verglichen. Auch jetzt zeigt sich kein heller rother Farbenton des Blutes; das specif. Gewicht wie nach dem früheren Versuche vermindert (1046 für die meisten Tropfen); auch spectroscopisch keine Veränderung.

Nunmehr wird die 1. Art. carotis mittelst Canüle mit dem Rohr in Verbindung gebracht und der Hund zum dritten Male und zwar auf $4 \mathrm{Atm}$. comprimirt. Die nach hallsstündigem Zuwarten entnommenen Blutproben zeigen ein eigenthümliches Verhalten. Auf eine bereitgehaltene Schale ausgegossen, bilden sich im Blute allenthalben grössere und zahlreiche kleinere Blasen und Bläschen, so dass das Blut bald zu einem rothen Schaume geworden ist; noch schöner kann man das Phänomen beobachten, wenn man eine grössere Blutquantität in einen Messcylinder strömen lässt, wobei, während das Blut das Gefäss erfüllt, ein immer reichlicher werdender Schaum emporsteigt. Die Fibringerinnsel, die sich in den Blutproben bilden, fühlen sich luftkissenartig an und erweisen sich bei genauer Betrachtung von feinsten Gasbläschen allenthalben durchsetzt; ebenso beschaffen sind auch die im

1) Man muss dabei vorsichtig zu Werke gehen und die Flüssigkeit nicht allzu rasch abströmen lassen, da sonst leicht die Kautschukröhre, die unter Druck im Apparate sich befindet, comprimirt wird und auch nach der Decompression bei geschlossenem äusseren Hahn comprimirt bleibt, wenn das Nachströmen von Blut aus dem Thier nicht rasch genug erfolgen kann; man hat auf diesen Umstand auch bei Entnahme arteriellen Blutes behufs Gasanalyse desselben zu achten. 
Rohr zurückbleibenden cylindrischen Gerinnsel. Von in Chloroformbenzolmischung aufgefangenen Blutstropfen kann als das niedrigste specifische Gewicht 1039 erhoben werden; die grösseren Tropfen erweisen sich als specifisch leichter als die kleinen.

\section{Versueh 9 .}

- Zwei Kaninchen (Sanitätsschleuse).

2 Kaninchen werden in die Medicamentenschleuse gebracht und durch Oeffnen des Luftzuleitungsrohres fast momentan auf den Druck von 1,8 Atm. comprimirt. Die Thiere wexden dann in den Innenraum der Sanitätsschleuse hereingelassen und durch 1 Stunde beobachtet. Die Thiere zeigen keinerlei Veränderungen in ihrem Verhalten; sie werden dann langsam entschleust und bieten auch nach der Decompression nichts Abnormes.

\section{Versuch 10.}

Zwei Meerschweinchen.

Einschleuszeit: 3 Secunden.

Druck: 2,2 Atm.

Aufenthalt: 1 Stunde.

Decompressionszeit: 30 Minuten.

Zwei Meerschweinchen werden mittelst der Medicamentenschleuse in 3 Sec, auf einen Druck von 2,2 Atmosphären comprimirt; nachdem sie in den Innenraum des Recompressionsapparates hereingenommen waren, zeigen sie keinerlei Störungen ihres Wohlbefindens und hören scheinbar vollkommen gut; sie werden nach ca. einer Stunde langsam in 30 Minuten decomprimirt. Beide Thiere befinden sich vollkommen wohl.

Die nach 8 Tagen vorgenommene Section ergiebt normale Verhältnisse; der Befund des Gehörorganes an anderer Stelle.

\section{Versu.ch 10a. \\ Hund Nr. XVI.}

Ein kleiner Hund wird in 3-4 Secunden auf dieselbe Weise wie in den beiden vorigen Versuchen auf den Druck von 1,9 Atmosphären gebracht. In der Sanitätskammer zeigt er keine Störung des Allgemeinbefindens; er hört jedoch schlechter und gehorcht erst nach mehrmaligem lauten Anrufen. Das Thier wird nach einstündigem Verweilen in 35 Minuten entschleust und zeigt am nächsten Tage keinerlei Erscheinungen.

Fassen wir die durch die Versuche gewonnenen Resulta t e zusammen, so zeigt sich, dass die Erhöhung des Luftdruckes mechanisch in keiner Weise die Vertheilung des Blutes in den Gefässen zu Gunsten einer Vermehrung der Blatfüllung in den inneren Orgauen beeinflusst, wie aus den Sectionsbefunden lebender 
und todter Thiere unter Druck hervorgeht. Auch die Druckverhältnisse im Abdomen bleiben in Bezug auf den übrigen Organismus dieselben wie unter normalem Barometerstand ${ }^{1}$ ). Die Blatfüllung des Hirns beim trepanirten und nicht trepanirten Thier erwies sich als gleich.

Ebenso wenig wird auch keine Veränderung der capillären Blutcirculation dureh die Zunahme des äusseren Luftdruckes hervorgebracht.

Der letzte Versuch der ersten Gruppe lehrte uns, dass unter erhöhtem Druck eine Vermehrung der Blutgase im lebenden Thier stattfindet, die aus dem Blute in Form von Blasen frei werden, wenn man das Blut plötzlich unter den normalen Luftdruck bring $\mathrm{t}^{2}$ ). Die maximale Druckdifferenz in unserem Versuche betrug 4 Atmosphären.

Ausserdem ergaben die weiteren Untersuchungen, dass im Gegensatz zu den frïheren Autoren, P o l-W a telle u. A., das Venenblut keine vermehrte Röthe zeigt und auch nicht die gleiche Farbe besitzt, wie das arterielle; es ergab sich vielmehr keine Farbenänderung.

Das specifische Gewicht des ausgeströmten Blutes wảr in Folge der Bildung von Gasblasen bedeutend geringer geworden, und konnte man eben aus dieser Ursache keine exacte gleichmässige Bestimmung vornehmen, da ja nothwendiger Weise die grossen, an Gasbläschen reicheren Tropfen specifisch leichter sein mussten, als die kleinen; unter Druck wie auch nach langsamer Decompression (s. Vers. 83, 85, 86) bleibt, wie zu erwarten stand, das specifische Gewicht unverändert. Durch nahezu momentane Druckerhöhung (Vers. 9, 10 und 10 a) auf 2,2 Atmosphären findet keine Schädigung des Gesammtorganismus statt; das Gehörorgan, wie insbesondere durch das Experiment 10 beobachtet werden konnte, wird durch mechanische Momente geschädigt.

Die nächste Versuchsreihe wird nunmebr, wie Eingangs angedeutet wurde, zu untersuchen haben, ob es auch in den Ge-

1) Wie auch aus Messungen des Bauchumfanges am Menschen hervorgeht.

2) Auch mit unter erhöhtem Lufdruck vom Menschen gewonnenen Blutproben wurden diesbezïglich Versuche angestellt, von denen noch in anderem Zusammenhang die Rede sein wird. 
fässen des Thieres nacb der Decompression zur Gasblasenbildung aus dem Blute kommt, und in welcher Abhängigkeit vom Druck, in welchen Mengen sowie in welcher Vertheilung dieselben nachgewiesen werden.

II 1).

A. Versuchsthiere in comprimirter Luft getödtet.

Versuch 11.

Kaninchen.

(Versuch in der Sanitätsschleuse. Maximaler Druck: 1,5 Atm.)

Ein Kaninehen wird in die Saritätsschleuse mitgenommen und in einer halben Stunde auf den Druck von 1,5 Atm, comprimirt. Nachdem das Thier durch eine Stunde anter diesem Druck geathmet hat, wird es durch Schläge auf den Kopf getödtet und durch die Medicamentenschleuse momentan de. comprimirt.

Die nach 5 Minuten vorgenommene Section ergiebt folgonden Befund:

Die Körpervenenstämme, insbesondere aber die Vena cava superior reichlich, von grossen und kleinen Gasblasen, desgleichen die rechte Auricel von grossblasigem schaumigen Inhalt erfüllt, freie Gase im rechten Herzen, in den Lungenarterien und Lungenvenen; Gasbläschen auch im linken Vorhof und in der linken Herzkammer. Gasblasen in den Coronarvenen, einzelne auch in den Coronararterien nachweisbar. In der Aorta sowie den Arteriae renales und femorales ein Blutluftgemisch allenthalben vorhanden. In den Mesenterialgefässen nirgends freie Gase nachzuweisen; von der Schnittfläche der Leber fliesst nur reines, heller rothes Blut ab. - Im Uebrigen keine Hämorrhagien oder sonstige pathologische Veränderungen.

\section{Versuch 12.}

Kaninchen.

(Caisson. Druck: 2,38 Atm.)

Ein starker Hase wird um $10 \mathrm{Uhr}$ Vorm. bis anf den Grund des Caissons gebracht. Um $12 \mathrm{~h}$ wird das Thier durch Schläge ins Genick im Cai sson getödtet und hierauf ausgeschleust.

Unter Wasser wird der Thorax geöffnet und das Herz angeschnitten.

Das Wasser färbt sich blutig und es steigen ganz feine Gasbläschen auf.- - Bei der weiteren Section erweisen sich die Lungen lufthaltig, mässig mit Blut gefüllt. Die übrigen Organe normal.

1) Cm das Vorhandensein von Gasblasen im Gefässsystem einwandsfrei festzastellen, wurden die Thiere der ersten Versuche, einem Vorschlag Prof. Gärtuer's in Wien folgend, unter Wasser secirt. Wo diese Methode angewerdet wurde, ist dies in den betreffenden Experimenten besonders angegeben. 


\section{Versuch 13.}

\section{Kaninchen.}

(Caisson. Druck: 2,38 Atm.)

Zwei Kaninchen wurden um 6 Uhr eingeschlenst, bleiben vier Stunden im Caisson. Um 10 Uhr wurden sie durch Schläge auf den Kopf getödtet und ausgeschleust.

Section unter Wasser. Eröffnung des Thorax. Nachdem das Herz an den grossen Gefässen abgebunden und abgeschnitten war, schwebte es nach sorgfältiger Entfernung des pericardialen Fettgewebes im Wasser. Es wurde bierauf rasch abgetrocknet ${ }^{1}$ ) und in Chloroformbenzolmischung gebracht. Unter der Flüssigkeit wurden die Ventrikel angeschnitten. Es entwickelten sich kleine Gasblasen, die theils allein als helle Bläschen emporstiegen, theils an Blutkügelchen adhärirten; daneben bildeten sich noch hellroth gefärbte, auf der Flüssigkeit schwimmende oder sich in verschiedenen Höhen haltende Blutklïmpchen. Das specifische Gewicht des auf der Flüssigkeit schwimmenden Blutes war geringer als 1035. (Eine genane Bestimmung war unmöglich, da das Aräometer nur bis 1035 graduirt war.) - Das abgebundene Herz des zweiten Kaninchens scheint leicht im Wasser zu schweben. Beim Einschneiden unter Chloroformbenzol erfolgt in Form von zwei Stössen das Entweichen relativ grosser Gasblasen, dann steigen zahlreiche kleinere feine Bläschen auf. Im Herz sehr wenig Blut, dessen specifisches Gewicht nicht bestimmt werden konnte; doch nehmen die einzelnen ganz kleinen Blutstropfen eine verschiedene Lage in der Chloroformbenzolmischung ein. Nachdem das Herz noch im Thorax abgeschnürt worden war, wurde die Vena cava angestochen. Aus dieser quoll reichlich sehr schaumiges Blut.

\section{Versuch 14.}

\section{Kaninchen.}

\section{(Caisson. Druck: 2,56 Atm.)}

Ein männliches Kaninchen wurde um 12 Uhr Mittags in den Caisson eingeschleust und in einem Behälter an der Decke der Arbeitskammer aufgehängt. Um $2 \mathrm{~h} 30^{\circ} \mathrm{Nachm}$. wurde der Caisson gesenkt, wobei eine Druckschwankung von 2,56 auf $1,2 \mathrm{Atm}$. stattfand.

Gleich nach der abermaligen Druckerhöhung stiegen zwei Mann in den Caisson und fanden das Thier lebend. Es wurde hierauf sofort daselbst durch Schläge auf den Nacken getödtet und nach dem Ausschleusen unter Wasser gebracht. Der Druck nach der Senkung betrug 2,9 Atm.

1) Diese Vorsichtsmaassregel des Abtrocknens ist bei jedem Versuche angewendet worden, um das anhaftende Wasser zu entfernen und so Täuschungen vorzubeugen. Ebenso wurden die Instrumente stets vorher mit Benzolchloroform gereinigt. 
Nach Eröffnung des Thorax unter Wasser wurde das Herz an den grossen Gefässen unterbunden and abgeschnitten; es sinkt im Wasser unter. Eröffnung des Herzens unter Oel: Es entleert sich wenig hellrothes Blut; aus dem Herzen steigen feine Gasblasen auf, ebenso aus der unter Wasser ausgeschnittenen Vena cava. Bei der weiteren Section zeigen sich die Lungen nicht blutreicher, Magen und Därme gebläht, Leber und Nieren bormal. Nach längerem Stehen ist der Boden des Gefässes, in welchem das Herz in Oel liegt, mit sehr vielen kleinen Gasblasen bedeckt, die theils frei sind, theils die einzelnen kleinen Blutkugeln umhüllen.

\section{Versuch 15.}

\section{Kaninchen.}

(Caisson. Druck: 2,4 Atm.)

Um $10 \mathrm{~h}$ Vorm. wird ein Kaninchen eingeschleust und um $2 \mathrm{~h}$ Nachm. ausgeschleust, nachdem es im Caisson durch Schläge auf den Kopf getödtet wurde. Es wird der Thorax eröffnet und das Herz an den grossen Gefässen abgebunden und ausgeschnitten. Das Herz schwebt, ohne unterzusinken. Hierauf werden die Ventrikel eingeschnitten und aus beiden steigen grosse Gasblasen auf; beide Ventrikel blutleer. Aus der angeschnittenen Vena cava entleert sich schaumiges Blat und grössere Gasblasen.

\section{Vers u eh 16.}

\section{Kaninchen.}

(Caisson. Druck: 2,49 Atm. Decompressionszeit: 3 Min.)

Ein Kaninchen wird eingeschleust und im Materialkübel in den Caisson herabgelassen. - Das Thier wurde nach 2 Stdn. im Caisson getödtet. Nach der Decompression wurde es sofort unter Wasser in der gewohnten Weise secirt, indem der Thorax eröffnet, das Herz leicht vorgezogen . und an den Gefässen unterbunden wurde. Das abgeschnittene Herz schweht im Wasser. Hierauf wird es sorgfältig abgetrocknet, damit keine Luft oder Wasserblasen ins Chloroform gezogen werden, und in Chloroformbenzol gebracht. Die Coronargefässe enthalten kleine Gasblässchen, so dass die Blutsäule in denselben perlschnurartig unterbrochen erscheint. Aus dem rech= ten Ventrikel, der angeschnitten wurde, entleeren sich Gas- und Blatblasen von wechselnder Form und Grösse; das specifische Gewicht des Blutes geringer als 1035. Das Herz wird hierauf durch einen Holzstab unter der Mischung gehalten und eine Stunde später der linke Ventrikel eingeschnitten, aus welchem ebenfalls mehrere grössere Gasblasen ruckweise entweichen, denen kleinere Gasbläschen folgen; daneben eine geringe Menge rothen Blutes; das Blut des linken Ventrikels hat das specif. Gewicht 1042. - Lungen blass, wenig blutreich. 


\section{Versuch 17. \\ Kaninchen.}

(Versuch in der Sanitätsschleuse.)

Ein Kaninchen wird in der Sanitätsschleuse auf einen Druck von 1,5 Atm. comprimirt und eine Stunde im Drucke belassen. - Danach wird es durch die Medicamentenschleuse momentsn entschleust.

Es zeigt keinerlei Frscheinungen, sitzt ruhig da; nach circa fünf Minuten hat sich mit Ausnahme der Athmung, die leicht dyspnoisch geworden war, nichts geändert. Es wird hierauf, 10 Minuten nach der Decompression, durch einen Schlag auf den Kopf getödtet.

Section: Die rechte Auricel sowie die Stämme der Vena cava supe. rior und inferior mit grossen Gasblasen erfüllt. Das rechte Herz dilatirt, Gasblasen durch die Wand der Arteria pulmonalis durchscheinend. In den Coronarvenen die Blutsäule von Gasbläschen unterbrochen. Der linke Ventrikel stark contrahirt; im linken Vorhofe keine freien Gase sichtbar. Beim Einschneiden in den linken Ventrikel entleert sich eine geringe Menge Blut; aus dem rechten treten Gasblasen und blutiger Sohaum aus. Die Lungen bieten nichts Abnormes. In den Gefässen des Mesenteriums keine freien Gase. Die Arterien erscheinen blass blutleer contrahirt. Im abdominalen Theile der Vena cava inferior feine Gasperlen zu sehen; die Aorta enthält keine freien Gase.

Leber und Milz von normaler Beschaffenheit; auf der Schnittfläche zeigt das austretende Blut keine Veränderung, keine Bildung von Gasbläschen. Därme von normalem Aussehen.

\section{B. Versuehsthiere nach der Decompression getödtet.}

Versuch 18.

Zwei Kaninchen.

(Caisson. Druck: 2,52 Atm.)

Um $11 \mathrm{~h}$ Vorm. wurden zwei Kaninchen eingeschleust. Um $12 \mathrm{~h}$ Mittags wurden sie mit dem Materiale plötzli ch entschleust und sofort nach der Decompression durch einen Schlag auf den Kopf getödtet.

1. Section des ersten Thieres: Eröffnung des Thorax; das Herz wurde an den grossen Gefässen abgebunden. Die linke Auricel contrahirte sich noch. Nach dem Abbinden sah man durch die dünne Vorhofswand im Herzen grosse Gasblasen. Das Herz wurde ausgeschnitten und unter Benzolchloroform eröffnet; neben dem Blute steigen ruckweise grössere Gasblasen auf, und aus dem Blate entbinden sich grössere und kleinere Gasbläschen. Die Lungen zeigen deutliche Ecchymosen. In:den Gefässen des Zwerchfelles ist die Blutsäule durch Gasbläschen an mehreren Stelken unterbrochen. In der Vena cava ascendens eine grosse Menge von Gasblasen und schaumiges Blut. In der linken Arteria cruralis Gasblasen; rechts keine nacbzuweisen. Die Bauchgefässe stark mit Blut gefüllt. Leber, Milz und Nieren zeigen 
makroscopisch keine Veränderungen; mikroscopisch am Zupfpräparat kann man erkennen, dass die Blutsäule aus vielen Capillaren völlig verdrängt ist; auch in den kleineren Venen sind Gasbläschen nachweisbar.

2. Die Section des zweiten Kaninchens ergab: Nach Eröffnung des Thorax wird das Herz unterbunden, ausgeschnitten und unter Benzol eröffnet. In den Vorhöfen und den Ventrikeln reichliche Mengen von Blut. Es entwickeln sich eine grosse Anzahl von Gasblasen, die in der Flüssigkeit aufsteigen. In der Aorta descendens sowie in den grossen Venenstämmen viele grössere Gasblasen. In der Arteria renalis rechts eine grössere Blase. Die linke Lunge zeigt zahlreiche bis linsengrosse Hämorrhagien. An den Nieren ausser einer leichten Hyperämie der Rinde nichts Abnormes wahrzunehmen. Därme nicht besonders gebläht. In den grösseren Gefässen der Extremitäten ebenfalls Gasblasen.

\section{Versuch 19.}

\section{Hund Nr. XXIII.}

Caisson. Compressionszeit: 10 Minuten.

Druck: 2,5 Atm.

Decompressionszeit: 20 Minuten.

Fin mittelgrosser Hund wird durch $0,22 \mathrm{gr}$ Morphium subcutan narcotisirt. In die linke Arteria carotis wird der zur Blutgasanalyse bestimmte Apparat, Fig. 5, eingebunden und das Thier um $3 \mathrm{~h}$ Nachm, eingeschleust. Um $1 / 26 \mathrm{~h} \mathrm{Nachm}$. wird das Thier aus dem Caisson in unsere Baracke gebracht. Der Hund war aus der Narcose erwacht und hatte herumgeschlagen und sich so den Apparat aus der Arterie gerissen. In der Baracke wurde das Thier chloroformirt, der Apparat in das freiliegende Gefäss abermals eingebunden und Blut entnommen. Man kann die Bildung feinster Gasbläschen aus dem Blute beobachten, die sich an der Oberfläche ansammein. Der Hund wurde dann durch Chloroform getödtet.

Section: Thorax eröffnet, das Herz an den grossen Gefässen abgebunden und unter Chloroformbenzol eröffnet. Es entleeren sich hierbei eine grosse Menge von Gasblasen. Die übrigen Organe normal. Im Rückenmark makroscopisch nichts Abnormes.

Versueh 20.

Hund Nr. XXII.

Caisson. Finschleuszeit: 15 Minuten.

Druck: 2,6 Atm.

Ausschleuszeit: 15 Minuten.

Der mittelgrosse Hund wird durch $0,12 \mathrm{gr}$ Morphin subcutan narcotisirt, der Apparat, Fig. 5, in die linke A.rteria carotis eingehunden. Der Hund bleibt 2 Stunden unter Druck. Na ! der Blutentnahme der Apparat vollständig gefüllt. Hähne intact. Bei der ‘bnahme des Apparates von der 
Arterie reisst dieselbe ab. Der Hund verblutet sich im Caisson und kommit todt heraus.

Nach der Herausnahme bietet das Blut, das um den Hund anf dem Brette zum Theil schon geronnen sich befindet, einen ungewöhnlichen Anblick, indem zahlreiche kleine Gasblasen in demselben sichtbar sind und ganze Partien des zähen Blutes in Form fast nussgrosser Blasen emporgehoben sind:

Die sofort vorgenommene Section des Hundes ergab:

In den Jugularvenen sowie in der Vena cava die Blutsäule von verschieden grossen, perlschnurartigen Gasblasen unterbrochen. Am Herzen sieht man dasselbe an den Coronargefässen, und man sieht an beiden Herzohren deutlich beim Verschieben und Drücken das Vorhandensein von reichlich mit Gasblasen gemengten schaumigen Blutes. Die Herzventrikel erscheinen schlaff, aufgetrieben. Das Herz wird an den grossen Gefässen abgebunden und in Benzolchloroform eröffnet. Es wird zuerst der linke, dann der rechte Ventrikel mit der Scheere angeschnitten. Aus beiden steigen sehr grosse und massenhafte Gasblasen auf. Daneben entleert sich wenig Blut, welches in Form von Kugeln an die Oberfläche steigt. Die cinzelnen Blutkügelchen erscheinen an ihrer Oberfläche von einer Gaskuppe gekrönt, die zum Theil aus einzelnen sehr feinen Gasbläschen zusammengesetzt ist.

Die Aorta abdominalis sowie die grossen Venen lassen beim Einschneiden Blut austreten, das theils schon schaumig ist, oder aus dem nach einigen Secunden reichlich Gasblasen aufperlen, wodurch die Oberfläche ein schimmerndes, silberglänzendes Aussehen erhält. Auch in den Arterien und Venen der beiden hinteren Extremitäten ist die Blutsäule reichlich durch Gasblasen unterbrochen. Lungen anämisch, Leber, Milz und Nieren normal. Auf Gehirn und Rückenmark musste verzichtet werden. Analyse der Blatgase siehe pag. 33 u. d. folg.

Vers u e h 21.

$\mathrm{Hund} \mathrm{Nr}$. XXI.

Caisson. Druck: 2,5 Atm.

Einschleuszeit: 15 Minuten.

Ausschleuszeit: 35 Minuten.

Der mittelgrosse Hund wird durch 0,2 gr Morphin subcutan narcotisirt.

Der Blutapparat, Fig. 2, in die linke Art. carotis eingebunden. Der Hund blieb drei Stunden im Caisson.

Der Apparat ist nach der Blutentnahme ganz mit Blut gefüllt, vollständig intact.

Gasanalyse siehe pag. 33 .

Der Hund wird rasch durch Chloroform getödtet.

Section: Lungen mässig blutreich; in Blute des rechten Ventrikels hie und da Gasbläschen; die übrigen Organe zeigen nichts Pathologisches. 


\section{Versuch 22. \\ Hund Nr. XX.}

Caisson. Compressionszeit: 10 Minuten.

Druck: 2,5 Atm.

Decompressionszeit: 30 Minuten.

Der mittelgrosse Hund wird durch $0,12 \mathrm{gr}$ Morphin subcutan narcotisirt. Der Blutapparat, Fig. 5, in die linke Arteria carotis eingebunden. Der Hund blieb vier Stunden unter Druck. Nach der Blutentnahme der Apparat vollständig mit Blut gefüllt, Hähne intact.

Nach einiger Zeit bilden sich im Blute ganz feine Gasblasen. Der Hund durch Chloroformnarkose getödtet.

Gasanalyse siehe pag. $33 \mathrm{u}$. d. folg.

Section: Lungen von normalem Blutgehalt; das Blut des rechten Herzens enthält feine Gasblasen, ebensolche vereinzelt zwischen den Trabekeln; hie und da Gasblasen in den erweiterten grossen Venenstämmen; mässige Hyperämie der Abdominalorgane.

Vers uch 23.

Zwei. Kaninchen.

\begin{tabular}{|c|c|c|c|c|c|}
\hline $\mathrm{Z}$. & $\begin{array}{l}\text { Dr. } \\
\text { i. A. }\end{array}$ & A. T. & Sch. T. & $\begin{array}{c}\mathrm{Hg} . \\
\text { v. Sch. }\end{array}$ & Bar. $\mathrm{Hg}$. \\
\hline $\begin{array}{l}10 \mathrm{~h} 10^{\prime} \\
1013^{\prime} \\
1023^{\prime} 30^{\prime \prime} \\
1024^{\prime}\end{array}$ & $\begin{array}{l}0 \\
2,8 \\
2,8 \\
0\end{array}$ & $0^{0}$ & $\begin{array}{l}+1^{0} \\
+7^{0} \\
+6^{0} \\
-1^{0}\end{array}$ & $\begin{array}{l}80^{\circ} \% \\
90 \% \\
88 \% \\
78 \%\end{array}$ & $760 \mathrm{~mm} 80 \%$ \\
\hline
\end{tabular}

Beide Kaninchen werden 15 Minuten nach dem Ausschleusen, während welcher Zeit sie keinerlei Erscheinungen gezeigt hatten, durch Schläge auf den Kopf getödtet.

Sectionsbefund: In den Coronargefässen des Herzens die Blutsäule von Gasblasen unterbrochen. Die rechte Kammer dilatirt enthält neben spärlicher Menge von Blut Gasblasen; in der linken contrahirten Herzkammer feinschaumiges Blut zwischen den Trabekeln. Die Lungen anämisch. In den Arterien und Venen des Zwerchfelles, sowie den Gefässen der Extremitäten schaumiges Blut. - In der Aorta, der Cava ascendens und descendens Gasblasen und schaumiges Blut.

Versuch 24.

$\mathrm{H}$ u nd Nr. XVIII.

\begin{tabular}{|c|c|c|c|c|c|}
\hline Z. & Dr. i. & A. T. & Sch. T. & Sch.H. & Bar. Hg. \\
\hline $\begin{array}{rr}9 \mathrm{~h} & 30^{\prime} \\
9 & 40^{\prime} \\
10 & 58^{\prime} \\
10 & 59^{\prime}\end{array}$ & $\begin{array}{l}0 \\
4,5 \\
4,5 \\
0\end{array}$ & $+3^{0}$ & $\begin{array}{l}+3^{0} \\
-80 \\
- \\
-20\end{array}$ & $\begin{array}{l}90 \% \\
\overline{95} \\
88 \%\end{array}$ & $757 \mathrm{~mm} 90 \%$ \\
\hline
\end{tabular}


Zeigt nach dem Ausschleusen keine Erscheinungen. Das Thier wird rasch durch Bulbusstich getödtet.

Section. Im rechten Herzen Gasbläschen in geringer Menge dem Blute beigemischt. Ebenso freie Gasbläschen im rechten Vorhof und in der Vena cava ascendens. Die Lungen anämisch; sonst keine pathologischen Veränderungen.

\section{$\mathrm{Versuch} 25$.}

H und Nr. XXXVIII.

Ein mittelgrosser Hund wird in zwei Minuten auf den Druck von 2,5 Atm. eingeschleust und 5 Minuten in dem Druck belassen; Decompres* sion in 50 Sec. Das Thier zeigt keine Erscheinungen.

Nach einer Stunde wird das Thier neuerdings auf denselben Druck gebracht und durch 30 Sec. im Apparate belassen; rasche Decompression. Das Thier zeigt keine Erscheinungen.

Section nach 10 Minuten ergiebt Gasblasen in einzelnen venösen Ge. fässstämmen.

$$
\begin{gathered}
\text { Versuch } 25 \mathrm{a}^{1} \text { ). } \\
\text { Hund Nr. XIII. }
\end{gathered}
$$

(Versuch in der Sanitätsschleuse.)

Ein mittelgrosser Hund wird in ca. 15 Minuten auf einen Ueberdruck von 1,2 Atmosphären comprimirt und durch $3 / 4$ Stunden in der Kammer belassen. Nach dieser Zeit wird das Thier mittelst der Medicamentenschleuse nahezu momentan decomprimirt.

Der Hund zeigt keinerlei Erscheinungen, er befindet sich wohl und läuft herum.

Ungefähr 10 Minuten nach Verlassen des Apparates wird das Thier durch Chloroforminhalationen getödtet.

Die Section ergiebt: Lungen von normalem Blutgehalt. In der linken Vorkammer flüssiges Blut; die linke Kammer contrahirt, enthält nur eine spärliche Menge rothen Blutes; in der rechten Auricel sowie im rechten Ventrikel feinschaumiges Blut; in der Cava ascendens, mehr in der Vena cava descendens, freie Gasblasen von verschiedener Grösse im Blute nachweisbar. Im Bereich der Mesenterialgefässe nirgends freie Gase vorhanden; an den übrigen Organen nichts Pathologisches.

\section{Vers u c h 26.}

\section{Hund Nr. XL und Nr. XIIII.}

Zwei Hunde werden in 3 Minuten auf den Druck von 4,5 Atm. gebracht und durch 15 Minuten in der Druckkammer belassen; rasche Decom-

1) Das Ergebniss dieses Versuches ist insbesondere gegenüber den Ansichten Smith's und seiner Anbänger von Wichtigkeit, die das Freiwerden von Gasen nach einer Decompression von so geringem Ueberdruck bestreiten. 
pression; beide Thiere befinden sich wohl und zeigen keinerlei Erscheinungen. Die Section des einen Hundes zeigt vereinzelte Gasblasen im Gebiet der beiden Hohlvenen und des rechten Vorhofes; Lungen blutreich, im übrigen normale VerhäItnisse,

\section{Versuch 27.}

\section{H u n d Nr. XXXIX.}

Mittelgrosser Hund rasch auf 3,5 Atm. eingeschleust; wird durch fünf Minuten in der Experimentirkammer belassen; nach dieser Zeit Decompression in 50 Secunden; keine Erscheinungen. Die sofort vorgenommene Section ergiebt keine freien Gasblasen in den Gefässen.

\section{Vers u e h 28.}

\section{Hund Nr. XLI und ein Kaninchen.}

Ein Hund sowie ein Kaninchen werden in einer Minute auf den Druck von 4,7 Atmosphären gebracht, durch 5 Minuten im Apparate belassen und rasch entschleust. Nach der Herausnahme der Thiere aus dem Apparat zeigen dieselben keine Veränderungen; die rasch danach vorgenommene Section beider Thiere lässt keine freien Gase in den Gefässen derselben crkennen.

\section{Versuch 29.}

Hund Nr. XIX.

Caisson. Compressionszeit: 10 Minuten.

Druck: 2,37 Atm.

Decompressionszeit: 30 Minuten.

Dem mittelgrossen Hunde werden $0,22 \mathrm{gr}$ Morphin in die Bauchdecken injicirt. In der dadurch bewirkten Narcose wird die linke Arteria carotis aufgesucht, peripher unterbunden, central durch einen Schieber abgeklemmt und der Apparat, Fig. 5, eingebunden. Der Fund wurde um $3 / 4^{3} \mathrm{~h}$ eingeschleust, um $3 / 4^{5} \mathrm{~h}$ erfolgte die Blutentnahme. Der Hund kam lebend heraus und wurde durch Chloroformnarcose getödtet. Der Apparat war vollständig intact und ganz mit Blut gefüllt. Allmählich bildet sich ein kleiner Luftraum und Gasblasen steigen in Form von feinen Perlen aus dem Blute auf.

Section ergiebt allenthalben normale Verhältnisse.

Die Analyse der Blutgase siehe pag. 33 u. d. folg.

Versuch 30.

Kaninchen.

(Caisson. Druck: 2,4 Atm.)

Ein Kaninchen wird in die Materialkammer eingeschleust und daselbst 2 Stunden belassen. Hiereuf in einer Zeit von 30 Minuten mit den Arbeitern ausgeschleust und knapp vor dem Oeffnen der Thüre des Vorraumes durch Sobläge ins Genick getödtet, also nach beendeter Decompression. 
Das todte Thier wird unter Wasser gebracht und der Tborax unter Wasser eröffnet; das Herz an den grossen Gefässen abgebunden und unter einer Chloroformbenzolmischung geöffnet. Es steigen keine Luftblasen auf. Im Gefässsystem nirgends Gasblasen. An den inneren Organen allenthalben normaler Befund.

\section{Versuch 31 .}

H u n d Nr. XLII.

Das Thier wird rasch comprimirt und 3 Stunden in einem Luftdruck von 2,8 Atm. belassen. Decompression in 20 Minuten; das Thier befindet sich wohl und läuft herum. Es wird durch Chloroform getödtet. Bei der Section lassen sich nirgends Gasblasen nachweisen.

\section{Beobachtnng an lebenden Thieren.}

\section{Vers a e b 32 .}

H u n d Nr. XLIII.

Einem Hunde wird unter Cocainanaesthesie die Bauchhöhle in der linea alba eröfnet, die Darmschlingen freigelegt und mit Compressen, die mit warmer physiologischer Kochsalzlösung getränkt sind, bedeckt.

Das Thi $\in$ r wird rasch eingescbleust und $3 / 4$ Stunden unter einem Drucke von 4,5 Atmosphären belassen, hierauf in 35 Secunden decomprimirt.

Nach der Decompression zeigen sich die Darmschlingen stärker injicirt; Puls an den Gefässen derselben allenthalben sichtbar, nirgends Gasblasen.

Herzaction frequent, keine Krämpfe oder paraplegische Erscheinungen.

Die Darmschlingen werden nun hervorgezogen, um auch die Gefässe an der Radix mesenterii zur Anschauung zu bringen.

Bei weiterer Präparation, nunmehr unter Chloroformnarcose, zeigen die Gefässe der Vena portae nirgends Gasblasen, jedoch einzelne grössere und kleinere Gasblasen in der Vena cava und der linken Arteria renalis; in den übrigen Arterien freies Gas nicht erkennbar. Nach 10 Minuten Eröffnung der Thorax; das Herz contrahirt sich noch, jedoch unregelmässig, man gewahrt im oberen Abschnitt der Vena cava ascendens sowie in der Cava descendens und durch die Wand des rechten Atriums grössere und kleinere, an vereinzelten Stellen gehäuft, feinere Bläschen; ebenso Blasen in der Vena iliaca dextra und sinistra. Die Herzcontractionen haben aufgehört; in den Arterien sowohl jetzt, wie auch nach 10 Minuten keine Index gazeuses; in den Venenstämmen ist das Bild dasselbe geblieben. Schaumiges Blut im rechten Herzen. Lungen blass; keine Ecchymosen in denselben vorhanden; im übrigen keine Veränderungen.

\section{Versuch 33.}

H un d Nr. XLIV.

Ein mittelgrosser fetter Hund wird in Morphinnarkose in 3 Minuten bis zu einen Druck von 4,5 Atmosphären comprimirt und verbleibt eine 
Stunde in comprimirter Luft. Das Thier verhält sich im Drucke vallkommen ruhig. Athmung regelmässig.

Es wird hierauf in 30 Secunden decomprimirt und sofort nach der Decompression die Bauchhöhle eröffnet, zugleich werden die Arteria und Vena cruralis linkerseits sowie die Arteria carotis und Vena jugularis freigelegt.

Bei der Beobachtung der Gefässe zeigt sich im circulirendem Blute keine Veränderung. Die Circulation in den Gefässen der freigelegten Darmschlingen hat aufgehört; kein Puls an den Arterien derselben sicht- und fühlbar; in der Blutfüllung zeigt sich keine Veränderung, keine Hyperämie.

Nach 5 Minuten treten bei dem Thiere Streckkrämpfe in den hinteren Extremitäten, dann auch gleichzeitig in allen vier Extremitäten auf. Nach weiteren zwei Minuten bilden sich in den Gefässen des Mesenteriums anfänglich ganz kleine lichtroth gefärbte Parthien aus, die bei näherem Zusehen als ganz feine Gasbläschen sich von der sonst dunklen Blutfüllung der Venen abheben. Diese Frscheinung, zuerst nur in ganz wenigen Venen sichtbar, bildet sich bald in fast sämmtlichen venösen Gefässen des Mesenteriums, jedoch in wechselnder Weise aus. Man kann das Neuauftreten solcher Stellen sowie das Wachsen bereits vorhandener deutlich verfolgen; oft ertüllt das feinstschaumige Blutgasgemisch gleich den ganzen Querschnitt des Gefässes, in anderen und zwar in den grösseren Venen sieht man die Randzonen des Blutes sich gleichsam verfärben und feinschaumig werden; besonders ist dies an einigen Theilungsstellen deutlich zu sehen. Eine messbare Dilatation des Gefässrohres an den von dem Blutgasgemisch erfüllten Stellen ist nicht zu beobachten: In der schmalen Blutsäule der Arterien des Netzes keine Gasblasen. Zahlreiche über linsengrosse Hämorrhagien im Mesenterium treten während der Beobachtung anf und sind vorwiegend im Bereich der Randschlingen vorhanden; sie zeigen ein gestreiftes Aussehen.

Abermals Streckkrämpfe in den hinteren Extremitäten von sehr kurzer Dauer. Das Thier liegt dann ruhig; regelmässige langsame Herzaction, tiefe Athemzüge, zeitweilig aussetzend. Kein Gargouillement über dem Herzen. An den freigelegten, voll und kräftig pulsirenden Arterien sieht man anfänglich keine Veränderung. Auch zeigt Blut, welches man aus der Arteria carotis ausströmen lässt keine Gasblasen. Nach einigen Minuten erscheinen dieselben blässer und man kann nach vorsichtiger Entfernung der Gefässscheidenreste grössere, das Lumen ganz einnehmende, sowie kleinere Gasblasen in ruckweiser Bewegung erkennen. Bald darauf wird die Athmung sehr unregelmässig, ebenso unregelmässige Herzaction.

Der Hund wird rasch recomprimirt. Wie man sich durch das Glasfenster des Apparates iiberzengen kann, athmet das Thier in der comprimir: ten Luft regelmässig fort. Es wird 5 Minuten im Apparate belassen; Decompression von 3,5 Atmosphären in 10 Minuten. Das Thier athmet mit tiefen Inspirationen; voller, kräftiger Puls an den Arterien; Herztöne nicht rein, wie von schnurrenden Geräuschen begleitet. An den Gefässen des Netzes lseine Veränderung erkennbar, wenn es auch den Anschein hat, als 
ob an einigen Stellen sich das beschriebene feinste Blutgasgemisch in etwas grössere Bläschen umgewandelt hätte. Es wird nunmehr die rechte Arteria femoralis freigelegt und man kann Gasblasen am pulsirenden Gefässe nachweisen. Eröffnung des Thorax. Unregelmässige wellenförmige Herzcontractionen; die Blutsäule der beiden Arteriae coronariae cordis von Gasindices unterbrochen, die sich jedoch nicht bewegen; in dem Venensystem des grossen Kreislaufes, ganz besonders im Gebiet der Vena cava grossblasiger und feinblasiger Inhalt, ausserdem auch einzelne im Blute schwimmende Gasblasen. Aus der Aorta und den grossen Arterien fliesst belm Einschneiden kein Blut aus; erst durch Druck kann man grosse Gasblasen und spärliches Blut herauspressen; das Blut des hellen rosarothen Schaumes zeigt aus dem angeschnittenen Mesenterialvenen herausquellend dieselbe Farbe wie das nicht veränderte Blut. Die Leber verhält sich wie eine oedematöse Lunge; am Schnitt dunkelrother Schaum reichlich abfliessend; Lungen blass, anaemisch, nicht ecchymosirt. Herz: Der rechte Ventrikel dilatirt von schäumigem Blute erfüllt; der linke Ventrikel nahezu blutleer; im übrigen der Befund wie er bereits bei anderer Gelegenheit besprochen wurde.

Versuch 34 .

$\mathrm{Zwei}$ Kaninchen.

Zwei Kaninchen werden ans Experimentirbrett gebunden. Das eine wird schwach narcotisirt und die Bauchböhle in der Medianlinie eröffnet. Die herausgetretenen Darmschlingen werden mit warmen, feuchten Compressen bedeckt.

Hierauf werden beide Thiere in drei Minuten comprimirt und eine Stunde lang in einem Drucke von 4,2 Atmosphären belassen. Nach dieser Zeit werden sie in 30 Secunden decomprimirt. Beide Thiere zeigen sowohl gleich nach dem Ausschleusen, als auch nach 8 Minuten, bis zu welcher Zeit zugewartet wird, keine Erscheinungen; bei dem Kaninchen mit eröffneter Bauchböhle konnten in den noch deutlich pulsirenden Mesenterialgefässen keine Gasblasen nachgewiesen werden. Auch die weitere Section dieses Thieres ergab nirgends im Circulationssystem freies Gas. Dem zweiten Thiere, das während dieser Zeit schwach narcotisirt wurde, wird nunmehr ebenfalls die Bauchhöhle eröffnet; auch hier finden sich in den Gefässen keine Gasblasen.

Dieses Thier wird nunmehr nochmals und zwar durch eine halbe Stunde in den Druck von 4,2 Atmosphären gebracht, dann in 30 Secunden decomprimirt und lebend unter Chloroformnarkose secirt. Nirgends freie Gase, die auch nicht nach dem Tode des Thieres auftraten. Bei beiden Thieren keine Lungenecchymosen.

Versueb 35.

Vier Kaninchen.

Vier Kaninchen werden zusammen auf einen Druck von 4,5 Atmosphären comprimirt. 
Zeit der Compression 3 Minuten.

Dauer des Aufenthaltes in comprimirter Luft: 1 Stunde.

Zeit der Decompression: 30 Secunden.

Die Thiere sind nach dem Ausschleussen munter und zeigen keinerlei Erscheinungen, springen herum, hören gut, und beschnuppern bereitgehaltene Nahrung. Nach 8 Minuten wird das Kaninchen a durch einen Schlag auf den Kopf getödtet.

Dem Kaninchen b wird in schwacher Narcose die Bauchhöhle eröffnet and werden die Gefässe der unteren Extremität freigelegt. In den Gefässen nirgends Gasblasenbildung sichtbar.

Nach ca. 5 Minuten feine Gasbläschen (feinster Schaum) jedoeh nur in der Vena iliaca dextra und sinistra sowie in einigen retroperitonealen Venen erkennbar. In den Arterien überall normale Füllung. Eröffnung des Thorax.

Section: Im Herzen keine freien Gase, auch kein Blutgasgemisch in demselben vorhanden. Lungen und die übrigen Organe zeigen normalen Befund; Hyperämie der Abdominalorgane.

Section des getödteten Kaninchens a, das ebenfalls keinerlei Frscheinungen geboten hatte: Gasblasen in den Venen und Arterien des gesammten Gefässsystems in der bekannten Vertheilung; ferner Sclaum im rechten Herzen. Der linke Ventrikel contrahirt, enthält nur wenig feinstschaumiges Blut.

Eine halbe Stunde nach der Decompression wird das Kaninchen c durch einen Schlag auf den Kopf getödtet und das Kaninchen a in Narcose wie das Thier $b$ lebend secirt. Bei beiden Thieren vollständig negativer Befund rücksichtlich freier Blutgase.

Betrachtet man die Ergebnisse dieser Versuchsreihe uibersichtlich, so konnten wir, was die Sectionsbefunde anlangt, in den Versuchen 11-26 inclusive Gasblasen im Gefässsystem nachweisen 1 ); in den Versuchen 27-31 inclusive wurden keine freien Gase im Blute gefunden; in den Versuchen $32-35$ endlich konnten wir die Zeit und Art der Entstehungsweise der Gasblasen am lebenden Thiere beobachten.

Bei den Versuchen 11-16 inclusive wurden die Thiere in dem Druck getödtet, in dem sie geathmet hatten; die En tbin $\mathrm{d} u \mathbf{n g} \cdot \mathrm{der}$ Gase aus dem Blute erfolgte daher im todten Thiere; sie erfolgte im Venen- und Arteriensystem a us der ruhenden Blat masse.

Bei den Versuchen $17-26$ wurden die Thiere mehr oder minder rasch nach erfolgter Decompression getödtet, zu einer Zeit

1) Vergleiche hierzu auch Versuch 71: Nachweis freier Gasblasen nach der Decompression von 1 Atmosphäre. 
also, wo das Thier wieder unter gewöhnlichem Luftdruck athmen konnte. Die Vertheilungsart der Gase im Gefässsystem des hierauf getödteten Thieres musste dann, mit einiger Reserve allerdings, diejenigen Verbältnisse zur Anschaung bringen, wie sie einige Zeit nach der Decompression im lebenden $\mathrm{T}$ hie re vorhanden waren.

Alle diese Versuchsthiere befanden sich mit Ansnahme der in den Experimenten 23, 25 und 26, iber eine Stunde in comprimirter Luft.

In den Versuchen 17 und 24 erfolgte die Decompression sehr rasch, in den Versucben 19 bis 22 wurde der Druckabfall langsam in einer Zeit bis zu 30 Minuten bewerkstelligt. In dem Experimente 25 betrug der Aufenthalt im Drucke 10 Minuten, im Versuche 26 war er 15 Minuten; die Decompression in dem einen Falle von 2,5 Atm., in dem andern von 4,5 Atm. erfolgte sehr rasch innerhalb einer Minute. Auch hier konnten noch, wein auch spärlich, freie Gase im Venensystem nachgewiesen werden. Mit Ausnahme von Versuch 23, der Kaninchen betraf, waren es Hunde, die verwendet wurden.

Die Experimente 27 (Hund) und 28 (Hund und Kaninchen) zeigten uns, dass nach dem kurzen Aufenthalte von 5 Minuten unter erböhtem Drucke (3,5 und 4,7 Atm.) trotz sehr rascher Decompression keine Gase im Blute aufgetreten waren.

In den drei folgenden Versuchen 29-31, wovon 29 und 30 Hunde betrafen, während in 31 ein Kaninchen verwendet wurde, waren die Bedingungen so angeordnet, dass die Thiere $2-3$ Stunden unter Drücken von 2,4-2,8 Atm. verblieben, um dann in 35 Minuten ausgeschleust zu werden. Wie in den beiden vorbergehenden Versuchen zeigten sich anch hier keine Veränderungen im Gefässinhalt.

Die nun folgenden Experimente $32-35$ wurden so angestellt, dass wir die Thiere durch längere Zeit, bis za einer Stunde in einer Atmosphäre von 4,5 Atm. Druck verweilen liessen und dann so rasch als möglich decomprimirten, um die Gasblasenbildung im lebenden Thiere beobachten za können.

Wenn wir also die Thiere einebestimmte $\mathrm{Z}$ eit lang, als deren untere Grenze wir 15 Minuten anseben miissen, unter einem Druck vou $2,5 \mathrm{Atm}$. beliessen, sokonnten wirselbst nocb bei einer 
Decompressionszeit ron 30 Minuten Gasblasen im Gefässystem nachweisen. Ist aber der Aufenthalt ein zu kurzer oder die der jeweiligen Druckerhöhung entsprechende Decompressionszeit eine zn lange, so beobachtet man kein Freiwerden von Gas aus dem Blute $^{1}$ ).

Was nun Form und Vertheilung der Gasblasen betrifft, so ist folgendes zu sagen.

Bei den Thieren, welche unter erhöhtem Luftdruck getödtet worden waren, fanden sich freie Gasblasen sowohl im arteriellen, als auch im venösen Gefässsystem; in beiden Ventrikeln des Herzens, in Arterien und Venen, und zwar in reichlicher Menge, so dass es schwer hält, anzugeben, ob stärkere Gasentbindung im Venen- oder Arteriensystem stattgefunden hat. Nur rücksichtlich der Vertheilungsart und Form der Gasblasen fallen insbesondere bei Vergleichung der kleineren Arterien und Venen deutliche Unterschiede auf. Ohne in Bezug auf diese Versuchsreihe auf eine genauere Beschreibung einzugehen, kann man im Allgemeinen sagen, dass es in den Venen mehr zur Bildung grösserer und kleinerer Gasbläschen kommt, während in den Arterien die Blutsäule durch die freien Gase stellenweise ganz verdrängt ist and sodureh Gasindices unterbrochen erscheint.

Rücksichtlich der Versuche 17-26 wollen wir hervorheben, dass der Sectionsbefund ein verschiedenes Resultat ergab, indem einmal das ganze Gefässsystem (Arterien und Venen), sowie auch das System der Vena portae von freien Gasen erfuillt war, während in anderen Fällen (21, 22 und 26) nur das System des rechten Herzens, sowie dieses selbst den Befund von frei gewordenen Blutgasen darbot. In Bezug auf die am lebenden Thiere, gewomenen Erfahrungen beben wir die Beobachtung der primären Entstehung der Gase im Venensystem, sowie den Umstand hervor, dass dieselben in Form feinster Bläschen, und zwar erst einige Zeit nach der Decompression (in Vers. 44 nach ca. $8^{\prime}$ ) sichtbar auftreten ${ }^{2}$ ).

1) Bei dem unter Druck getödteten Thier ist die Decompressionszeit natïrlich innerhalb gewisser Grenzen ohne Belang.

2) In Untersuchungen über das Freiwerden von Gasen aus dem Blut bei $L$ uft verdü $n \mathbf{n} u n g$ werden wir auch vom Verein für Luftschifffahrt durch Dr. Berson unterstïtzt. 


\section{III.}

\section{Analyse der Blatgase.}

Bevor wir auf die Methode und die Resultate unserer Blutgasanalysen eingehen, müssen wir zunächst auf einen Umstand aufmerksam machen, welcher die Anstellung der in Rede stehenden Untersuchungen für uns äusserst schwierig gestaltete, und dadurch auch die Zahl der gemachten Analysen beschränkte, indem vielfach mit Mühe gewonnene Blutproben später, als za einer einwandsfreien Untersuchung nicht geeignet, keine Verwendung finden konnten. Dieser die genannten Beobachtungen störende Umstand war die räumlicbe Trennung des Laboratorinms von dem Orte, wo wir über comprimirte Luft verfügten, so dass die gewonnenen Proben über eine Stunde weit vorsichtig transportirt werden mussten. Günstiger gestaltete sich die Sache für uns, als wir über einen eigenen, lediglich für experimentelle Zwecke bestimmten Apparat verfügten. Vor Herstellung desselben waren wir bemiiht, die comprimirte Luft eines eben im Bau befindlichen $\mathrm{C}$ a is sonobje ctes zu benutzen, indem wir trotz aller Schwierigkeiten nicht auf die so seltene Gelegenheit verzichten wollten, Blat von unter bedeutend erhöhtem Luftdrack athmenden Thieren bezüglich des Gasgehaltes zu untersuchen.

Die sämmtlichen chemischen Analysen wurden von Herrn Dr. von Zeynek, Assistenten am Wiener K. u. K. pathologisehchemischen Institut, nach der Methode von $\mathrm{P}$ fl ìg er ausgefithrt, und ergreifen wir an dieser Stelle die Gelegenheit, Herrn Dr. von Zey n ek für seine freundliche, werthvolle Mithülfe unseren besten Dank auszusprechen.

Zunächst konnten wir uns nur die Aufgabe stellen, die Blutgasverhältnisse an Thieren zu studiren, die wir im $\mathrm{C}$ a is s o $\mathrm{n}$ unter denselben Druck brachten, unter welchem eben Menschen arbeiteten.

Zur Gewinnung des Blutes dieser Thiere bedienten wir uns der folgenden Maassnahmen.

Verwendet wurden Hunde von $5-6 \mathrm{kgr}$ Gewicht, die in Morphinnarcose nach der gleich näher zu beschreibenden Operation in den Senkkasten eingeschleust wurden, und nach mehrstündigem Verweilen daselbst unter einem Ueberdruck von 2,5 Atmosphären innerbalb 10 bis 30 Minuten decomprimirt wurden. 
34 Richard Heller, Wilhelm Nager, Hermann von Schrotter:

Das angewandte Verfahren musste nothwendiger Weise so eingerichtet werden, dass das zu untersuchende Blut dem Thiere in comprimirter Luft entnommen wurde, da wir unter diesen Umständen kein Mittel besassen, selbst unter normalem Barometerstand hantirend, Blut von einem unter erhöhtem Luftdruck athmenden Hunden zu gewinnen, wie wir dies später zu thun im Stande waren.

Nach Präparation der Arteria carotis, Unterbindung ihres peripheren Endes und Durchschneidung des Gefässes wurde in das Ende des abgeklemmten centralen Stumpfes das Robr a des Glasgefässes $A$ oder $B$ (Fig. 5) eingebunden, der Hahn $b$ geschlossen und das Thier sammt dem gehörig befestigten Apparate in den Caisson gebracht. Das Gefäss wurde vor dem Gebrauch mit oxalsaurem Natron durchgespült und eine kleine Menge desselben zur Vermeidung von Gerinnung im Gefitisse belassen.

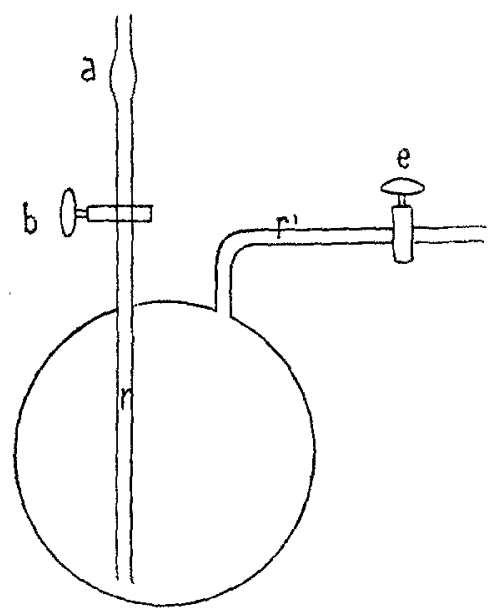

A

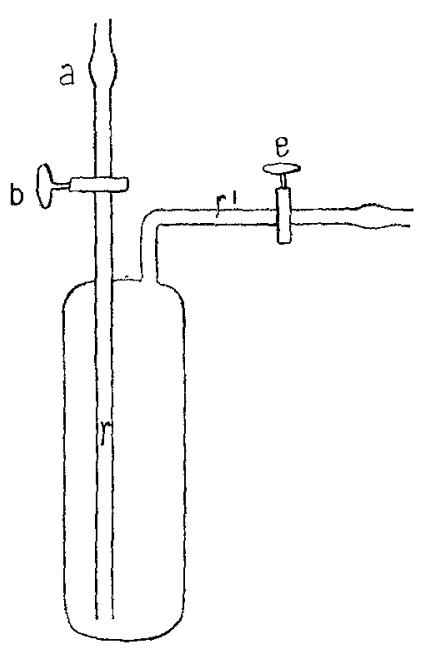

B

Apparate zur Gewinnung von Blut in comprimirter Luft.

$A$ : Balionartiges Gefäss mit zwei eingeschmolzenen Glasröhren, $r^{\prime}$ und $r$, wovon letztere nahezu bis auf den Boden des Gefässes reicht.

B: Eprouvettenartiges Gefäss, dessen Glasröhren ebenso angeordnet sind, wie im Gefässe $A$. $r$ und $r^{\prime}$ sind an ihren beiden Enden zur besseren Befestigung an der Arterie etwas aufgetrieben.

Das Glasgefäss $B$ hatte den Vortheil, dass die einströmende Blutmenge die Luft mit einer nur geringen Oberfläche auszutreiben hatte. 
Die Blutentnahme unter erhöhtem Luftdruck wurde in der Weise bewerkstelligt, dass die an der Arterie befestigte Sperrpincette, sowie der Hahn $b$ und $e$ geöffnet wurden, sodass das arterielle Blut in den Apparat einströmen konnte. Nach Füllung desselben, sowie des Rohres $r^{\prime}$ bis $e$ wurden beide Hähne geschlossen. Nach der Decompression wurde das Gefäss von der Arterie abgenommen und ins Laboratorium gebracht.

Durch Verbindung der Röhre $r^{\prime}$ mit der Quecksilberluftpumpe durch einen Kautschukschlauch konnten nach Oeffnung des Hahnes $e$ die Blutgase ausgepumpt werden ${ }^{1}$ ). Dass dieses Verfahren gewisse Mängel besitzt, braucht wohl nicht besonders betont zu werden. Die Entgasung konnte leider erst etwa 1 Stunde nach der Blutentnahme stattfinden, ebenso war eine Einkühlung der Blutprobe nicht durchführbar ${ }^{2}$ ); es ist somit nicht nöthig zu erklären, warum trotz scheinbar vollkommen dichten Scbliessens der Hähne von einer grösseren Zahl von Proben nur eine verwendbar war.

Die Analyse dieser Blutprobe $\left(32,88 \mathrm{~cm}^{3}\right.$ von einem Hund, der in einem Ueberdruck von 2,53 Atmosphären geathmet hatte) ergab $11,64 \mathrm{~cm}^{3}$ Gas von der Zusammensetzung:

$$
\begin{aligned}
\mathrm{CO}_{2} & =26,15 \text { Vol. } \% \\
\mathrm{O} & =6,35 \quad " \quad " \\
\mathrm{~N} & =2,90 ",
\end{aligned}
$$

Vergleicht man den Stickstoffwerth dieser Analyse mit den Stickstoffzahlen, die bei gewöhnlichem Atmosphärendruck ermittelt wurden, so ergiebt sich bei Bericksichtigung des von $\mathrm{Zuntz}$ bestimmten Mittelwerthes von 2,7 Volum \% eine nur sehr geringe Steigerung, bei Vergleichung mit den Zahlen Pflüger's eine Zunahme um 11 Vol. \% gegenüber seiner Mittelzahl, eine solche von 1,7 Vol. $\%$ gegenuiber seiner Minimalzahl, ebenso eine Zunahme von 1,5 Vol. \% gegentuber dem höchsten Werth, den Sczelk ow ermittelt hat; die von Pfliiger angegebene Maximalzahl wird jedoch von unserer N-Zahl nicht erreicht. Rücksichtlich des von P. Bert gefundenen Mittelwerthes von 2,2 Vol. $\%$ ergiebt sie eine Zunahme von 0,6 Vol. $\%$, ebenso wie sie gegen einen aus Pflï-

1) Die Entgasung der Probe wurde mit einer Geissler'schen Pumpe ausgeführt, die einen grossen Recipienten hatte, so dass die Gasgewinnung fast momentan erfolgte. Zum Blute wurde kein weiterer Zusatz gegeben.

2) Zunahme des $\mathrm{CO}_{2}$-Gehaltes auf Kosten des $\mathrm{O}$. 
ger's und Bert's Angaben gezogenen Werth von 2,15 Vol. $\%$ eine Vermehrung von 0,85 Vol. $\%$ anfweist, jedoch nur $0,5 \mathrm{Vol} . \%$ geringer ist, als die von dem letzteren Autor für 2,5 Atmosphären angegebene Zahl.

Nach dieser vergleichenden Zusammenstellung dürfen wir wohl eine Vermehrung des Stickst of fgehaltes der analysirten Blutprobe annehmen, wenn dieselbe auch geringer ist, als wir erwartet hatten; leider verfïgten wir nicht tiber eine Controlprobe von demselben Thier unter gewölnlichern Atmosphärendruck ${ }^{1}$ ).

Bevor wir eine weitere Methode der Gewinnung des Blutes von einem Thiere, das unter erhöhtem Atmosphärendruck geathmet hatte, mittheilen, durch welche wir eine Vermehrung des Stickstoffgehaltes im Blute sicher constatiren konnten, wollen wir noch einer Untersuchung Erwähnung thun, durch welche festgestellt werden sollte, dass im Blute des Mensehen, welcher entsprechend langsam decomprimirt wurde, kein Ueberschus an Stickstoff mehr vorhanden is t.

Leider war es, wie leieht begreiflich, aus äusseren Gründen nicht möglich, diesbezùglich zahlreichere und genauere Angaben zu gewinnen.

Die bier mitgetheilte Analyse stammt von der Blutprobe eines Menschen, der eine Stunde unter einem Ueberdruck von 2,5 Atm. gearbeitet hatte und in 40 Minuten ausgeschlenst worden war.

Das Blut wurde dann nach ca. 3 Minuten in der Weise entnommen, dass in die eröffnete Vena mediana eine Canüle eingeschoben wurde, die mittelst eines dicht schliessenden Kautschukschlauches mit einem Gefässe in Verbindung stand, das auf ähnliche Weise, wie die bereits beschriebenen Apparate construirt war.

Entnommen wurden $108,0 \mathrm{~cm}^{3}$ Blut, die $43,30 \mathrm{~cm}^{3}$ Gas ergaben. Die Zusammensetzung desselben war folgende.

1) Eine weitere Analyse sei hier nur nebenbei erwähnt; bei derselben war der N-Gehalt auffallend gering, wohl in Folge der leider nicht vollkommenen Methode der Gewinnung der Blutprobe.

$84,56 \mathrm{~cm}^{3}$ Blut gaben $27,79 \mathrm{~cm}^{3}$ Gas. (Das Thier befand sich eine halbe

Für $100 \mathrm{~cm}^{3}$ Blut, 24,87 $\mathrm{cm}^{3} \mathrm{CO}_{2} \quad$ Stunde in 2,4 Atm. Ueberdruck.)

$$
\begin{array}{ccc}
6,17 & & 0 \\
1,82 & & \\
N &
\end{array}
$$


Experimentelle Untersuchungen etc. des Luftdruckes auf den Organismas.

$$
\begin{aligned}
\mathrm{CO}_{2} & =34,92 \mathrm{Vol} . \% \\
\mathrm{O} & =3,74 \quad " \quad, \\
\mathrm{~N} & =1,43 \quad " \quad,
\end{aligned}
$$

Wie man sieht, ist der gefundene Stickstoffwerth eher noch etwas geringer, als der von Sets chenoff für das Menschenblut bei normalem Atmosphärendruck bestimmte Werth, 1,6 Vol.\%. Wir können also sagen, dass in diesem Falle der Stickstoffgehalt des Blutes nach der Decompression jedenfalls kein erhöhter mehr war.

Nachdem wir tuber eine eigene Experim e $\mathrm{n} \mathrm{tirk} \mathrm{a} \mathrm{m} \mathrm{mer}$ geboten, waren wir im Stande, Blut von einem in hoch comprimirter Luft befindlichen Thiere zu gewinnen, obne sich selbst

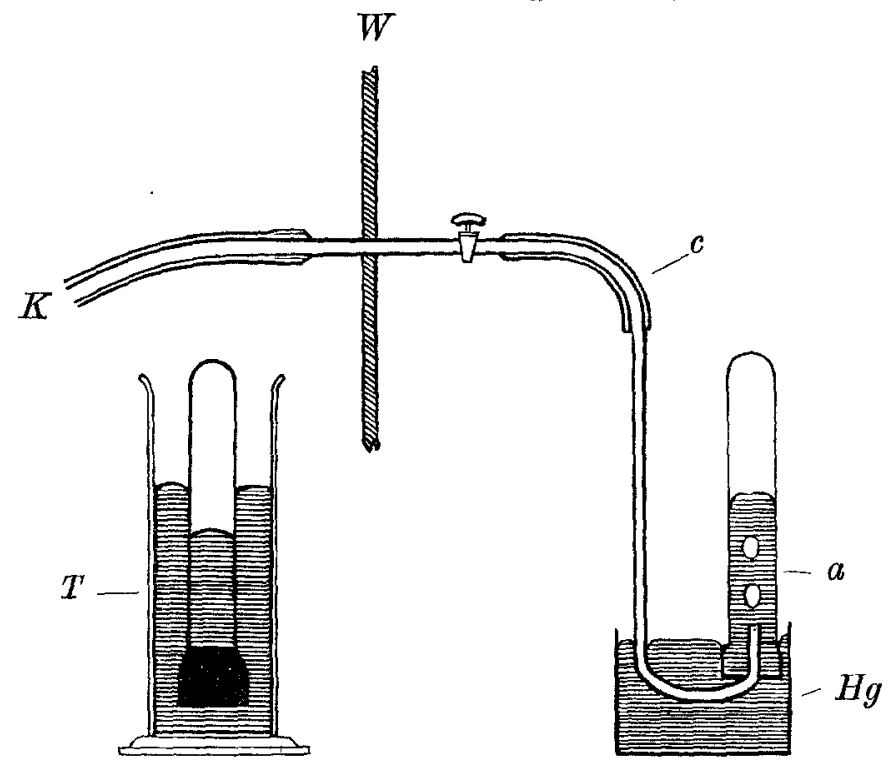

Fig 6 (schematisch).

Gewinnung von Blut eines in einem Medium von $5 \mathrm{Atm}$. athmenden Hundes behufs Analyse der Blutgase.

$W$ Vordere Wand der Experimentirkammer.

$C$ In dieselbe eingefügte Messingröhre.

$K$ Kautschukschlauch mit der Arteria earotis des Thieres durch eine Canüle in Verbindung.

Hg Gefäss mit Quecksilber.

A Eudiometerrohr, in welches man das ausströmende Blut aufsteigen sieht.

$T$ Das Eudiometerrohr, an seinem unteren Ende durch einen Kautschukstopfen geschlossen, befindet sich in einem mit Quecksilber gefüllten Cylinder zum Transport ins Laboratorium. 
in derselben aufhalten zu müssen. Die von uns angewandte Methodik ist aus der Beschreibung des nachfolgenden Versuchs, sowie aus der demselben beigegebenen schematischen Figur 6 ohne Weiteres verständlich.

\author{
Versuch I. \\ Hund Nr. LXXIII.
}

Bei einem Hunde wird die Arteria carotis mittelst Caniile und einem dicht schliessenden kurzen Schlauch mit dem Messingrohre $C$ in Verbindung gebracht; Canüle, Schlauch und Rohr werden bis za dem an dem letzteren befindlichen äusseren Hahn mit $1 \%$ oxalsaurem Natron gefüllt, um die Gerinnung des Blutes za verhüten. Nach Abnahme der Sperrpinzette von dem Gefässe wird der Hahn geschlossen.

Nachdem der Hund in 5 Minuten unter einen Druck von im Ganzen $5,8 \mathrm{Atm}$. gebracht worden und 30 Minuten in demselben verblieben war, während welcher Zeit stets für genügende Lufterneuerung im Apparate Sorge getragen wurde, wird der bezeichnete Hahn geöffnet. Als nach Abfluss des oxalsauren Natrons reines Blut ausfliesst, wird dasselbe mittelst Kautschukrohr durch eine früher aussen angebrachte Glasröhre unter Quecksilber aufgefangen ${ }^{1}$ ). An der Oberfläche des Blutes bilden sich nach kurzem Stehen feinste Gasbläschen, die sich an der Kuppe des Endiometerrohres zu einzelnen grösseren Blasen sammeln; nach einiger Zeit hat sich eine geringe Menge freien Gases im obersten Theile des Rohres angehäuft. Das nicht aufgefangene ausgeflossene Blut füblt sich in geronnenem Zustande wie ein Stückchen emphysematöser Lunge an und zeigt mikroscopisch und auch schon mit blossem Auge ganz feine Bläschen von freiem Gas. - Das Eudiometerrohr wird in dem mit Quecksilber gefüllten Cylinder $T$ ins Laboratorium gehracht und das im Messrohre gesammelte Blut mittelst der Luftpumpe behufs Analyse entgast.

\title{
Ver s u c h II. Hund LXXIII.
}

Anordnung des Versuches wie im Experiment I.

Einschleusszeit: $4^{1 / 2}$ Minuten.

Atmosphärendruck: 5,5 Atm.

1) Nach der weiteren Entnahme einer grössenen Blutmenge wird das Thier in 10 Minuten decomprimirt; nach circa 20 Minuten erbricht der Hund, Puls sehr schwach, Athmung sehr verlangsamt. Während der nunmehr vorgenommenen Recompression stirbt das Thier rasch nach Erreichung des höchsten Manometerstandes. Bei der Section zeigen sich makroscopisch nirgends Gasblasen in den Gefässen; Organe blass anämisch. Im Gehörorgan beiderseits die Bulba mit dunkelrothem, zum Theil flüssigem, zum Theil coagulirtem Blute erfüllt. Die mikroscopische Untersuchung des Gehörorganes in anderem Zusammenhange. 
Zeit des Verweilens bis zur Blutentnahme: 45 Minuten.

Nach dieser Zeit werden ca. $40 \mathrm{~cm}^{3}$ Blut im Eudiometerrohr aufgefangen, welches dasselbe Verhalten wie nach dem Versuche zeigt.

Bedauerlicher Weise konnte diese zweite Blutprobe wegen Gerinnselbildungen nicht verwerthet werden, da sich ein Coagulum vor das zur Pumpe führende Rohr legte; die erhaltene geringe Gasmenge wurde zwar der Untersuchung unterzogen, ergab aber keine verwerthbaren Resultate.

E'benso gelang es nicht, eine dritte und vierte Probe einwandsfrei ins Laboratorium zu schaffen.

Analyseder Blutprobe ${ }^{1}$ ) des Versuches No. I.

$46 \mathrm{~cm}^{3}$ Blut ergaben für $0^{0} \mathrm{C}$. und $760 \mathrm{~mm}$ Quecksilberdruck 24,5 $\mathrm{cm}^{3}$ Gas von der Zusammensetzung :

$$
\begin{aligned}
\mathrm{CO}_{2} & =33,8 \text { Vol. } \% \\
\mathrm{O} & =10,2 \quad, \quad " \\
\mathrm{~N} & =9,2 \quad, \quad,
\end{aligned}
$$

also im Ganzen 53,2 Vol.\% Gas.

Die Vermehrung des Stickstoffgehaltes im untersuchten Blute ist somit eine bedeutende und übertrifft sogar die von P. B e r t für 6 Atmosphären Druck ermittelte Stickstoffzahl von 6,5 um 2,7 Vol. $\%$. Wir milssen da wohl annebmen, dass das Blut des Versuchsthieres auch unter gewöhnlichem Luftdruck bereits einen hohen Stickstoffgehalt hatte.

Wenn wir uns somit auch über die Aenderung der Blutgase in comprimirter Luft durch eigene Untersuchungen überzengen wollten, um auf diese Weise einen Schluss auf die Zusammensetzung der nach rascher Decompression freigewordenen Gasblasen ziehen zu können, so waren wir insbesondere bestrebt, die Natur und Zusammensetzung derselben direkt zu ermitteln, wie dies vor uns P. Bert gethan hat. Wenn wir auch das Blut einem Thiere entnommen haben, welches in der Kammer einem erhöhten Luftdruck ausgesetzt ist und wir dann unter dem herrscbenden Barometerdrucke Gasblasen aus dem Blute frei werden sahen, deren chemische Zusammensetzung wir dann feststellen konnten; so glaubten wir nicht ohne weiteres annehmen zu dürfen, dass die Gase in derselben quantitativen Zusammensetzung nach der Decompression auch im Circulationsapparat des lebenden Thieres frei werden.

1) Das specifische Gewicht des Blutes konnte nach dem bei Versuch 8 diesbezüglich Gesagten nicht genau bestimmt werden. 
Wir suchten daher die i m lebenden $\mathrm{T}$ biere freigewordenen Gase direkt a u f u fangen und zu untersuchen, um die Natur dies er Gasblasen kennen zu lernen und $z u$ sehen, ob die Annahme berechtigt war, der zu Folge dieselben der Hauptmasse nach aus Stickstoff bestehen mnssten. Die insbesondere in der Versuchsreihe IV mitzutheilenden Experimente bei Compression auf einen Druck von über 4 A., entsprechendem Aufenthalt (durch ca. eine Stunde) in diesem Drucke mit nachfolgendem raschen Druckabfall $\left(30-50^{\prime \prime}\right)$ werden uns zeigen, dass die Thiere entweder fast momentan sterben oder nach wenigen Minuten von den schwersten aspbyctischen Erscheinungen befallen werden, wozu wir auf die hochgradige Dyspnoe, den frequenten unregelmässigen Puls und die glucksenden Geräusche über dem Herzen hinweisen, welche wir bei Beschreibung der einzelnen Versuche mittheilen werden.

Die raseh vorgenommene Section dieser Thiere hatte uns ferner gelehrt, dass in solchen Fällen das Circulationssystem von Gasblasen iiberfuillt und das Herz, insbesondere dessen rechte Kammer, von Gas stark dilatirt ist, ja dass man häufig, besonders im rechten Ventrikel neben dem Gas fast gar kein Blut oder nur zwischen den Trabekeln desselben befindlich nachweisen kann.

Wir suchten nun die im Herzen, vorzugsweise im rechten Ventrikel angesammelten Gase von Thieren, die auf die geschilderte Weise decomprimirt.worden waren behufs Analyse zu gewinnen.

Auch für diese Untersuchung machte sich der Umstand der örtlichen Trennung von Experimentirkammer und chemischen Laboratorium unangenehm fühlbar, indem wir nicht, wie dies P. Bert im Stande war, das Herz mittelst Spritze zu punktiren oder durch eine in die Vena jugularis eingefübrte Canüle seines Gas- und Blutgasgemisches zu entleeren in der Lage waren, welches dann sofort zur Analyse weiter verwendet werden konnte; wir mussten vielmehr eine eigene Methode in Anwendung bringen, welche es gestattete, den gewonnenen, der Hauptsache nach gasförmigen Inhalt zur chemischen Untersuchung nach dem entfernten Laboratorium $\mathrm{zu} \cdot$ schaffen.

Wir gingen in folgender Weise vor.

Entweder starben, wie gesagt, die Versuchshunde nach wenigen Augenblicken (Exp. 37, 38, 39 u. 40) und dann wurden 
sie sofort secirt, der Thorax eröffnet und das Herz an den grossen Gefässen abgebunden, um in der gleich näher zu beschreibenden Art weiter verwendet za werden; oder die Thiere wurden auf der Höhe der asphyctischen Erscheinungen, nach deren Eintritt wir den günstigen Zeitpunkt zur Gewinnung der Herzgase, voraussetzen konnte, somit erst einige Minuten nach der Decompression durch Stich in die Medulla oblongata (Exp. 41 u. 42), ein anderer durch Erdrosseln (Exp. 43) getödtet. Hierauf wurde rasch der Thorax eröffnet, die grossen Gefässstämme ligirt und das Herz abgeschnitten. Dasselbe wurde dann gehörig abgetrocknet in eine Wanne unter Quecksilber gebracht, durch sorgfältiges Abwischen von den etwa adhärirenden Luftblasen befreit und in der Weise unter einem in das Quecksilber tauchenden Trichter eröffnet, dass die austretenden Gasblasen in das mit Quecksilber gefüllte Eudiometerrohr anfsteigen mussten. Die schematische Figur 7 zeigt den hierzu verwendeten Apparat; die Art und Weise des Vorganges ist aus Fig. 8 ohne Weiteres verständlich, in welcher

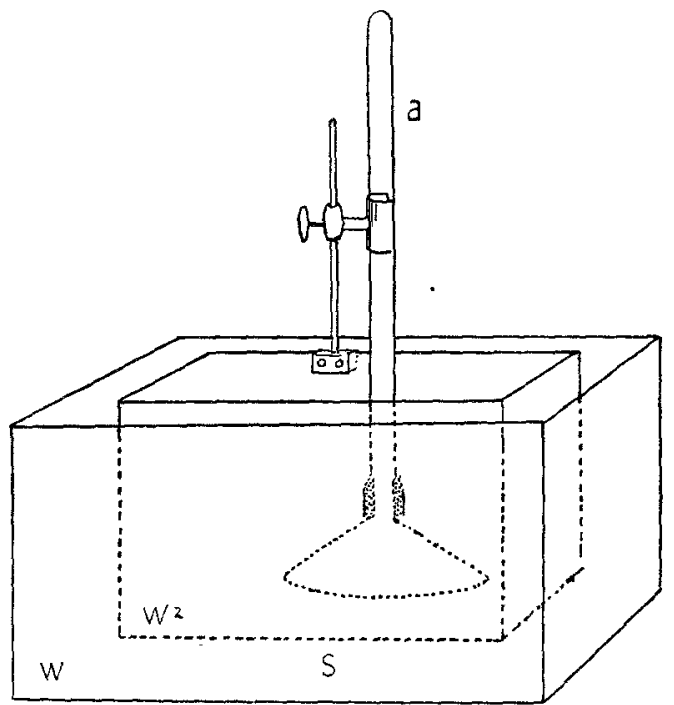

Fig. 7.

Schematische Abbildung des Apparates zur Gewinnung der Herzgase.

a Eudiometerröhre mit umgekehrtem Trichter.

$W$ Aeussere mit Sand (S),

$W_{2}$ innere mit Quecksilber gefüllte Glaswanne, stark genug um den Druck von 2,5 Liter $\mathrm{Hg}$ aushalten zu können (Dimensionen: $l=21 \mathrm{~cm}, b=$ $13 \mathrm{~cm}, h=13 \mathrm{~cm}$ ). 
42 Richard Heller, Wilhelm Mager, Hermann von Schrötter:

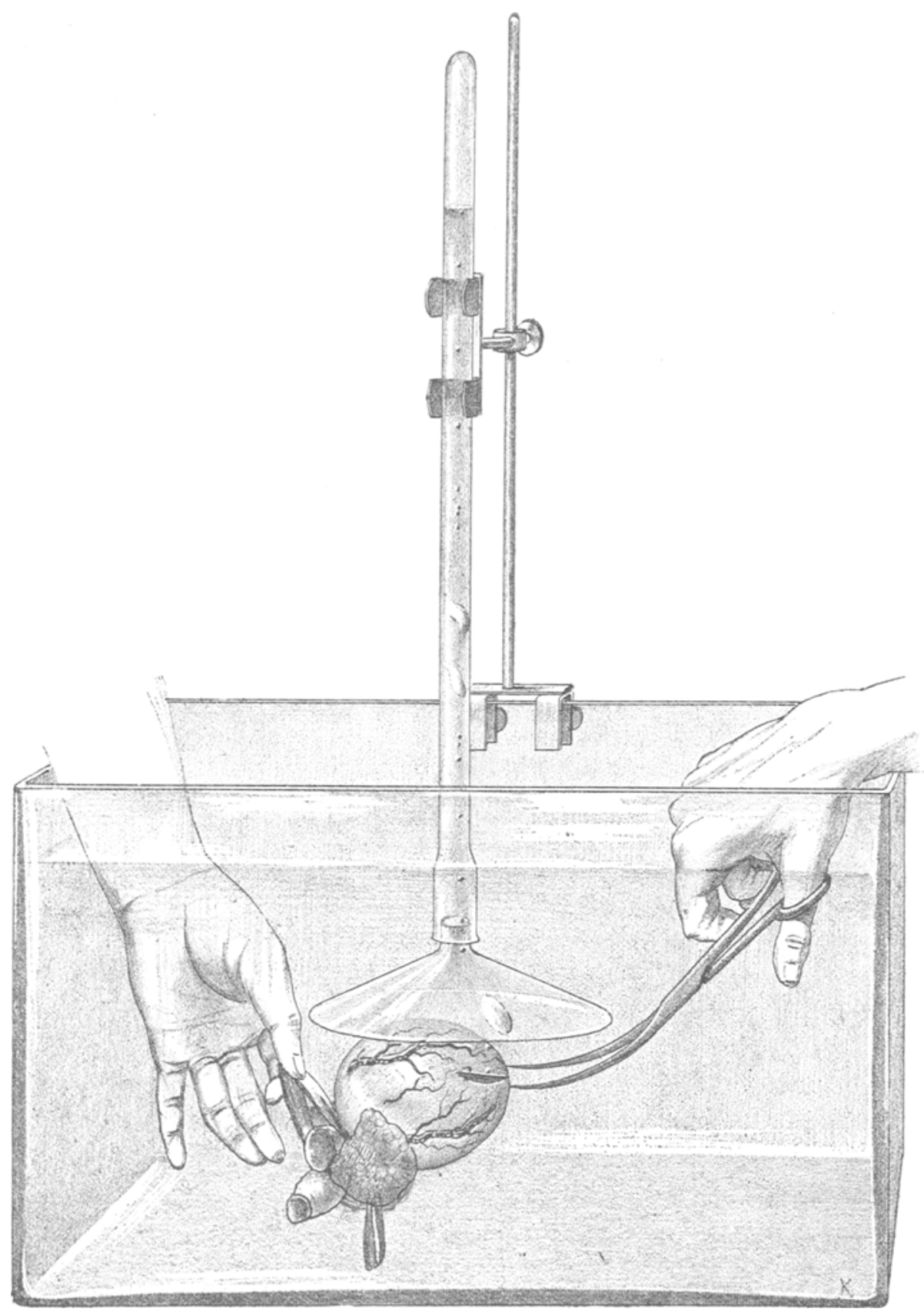

Fig. 8.

Vorgang bei der Gewinnung der Herzgase.

Beide Ventrikel des Herzens gebläht; in den Coronargetässen desselben freie Gasblasen wahrnehmbar. 
zur besseren Anschaulichkeit der Inhalt der Glaswanne Quecksilber durchsichtig gedacht ist.

Das Eudiometerrohr wurde dann an seinem unteren Ende mit einem Kautschukstöpsel geschlossen, in dem bereits genannten Cylinder $T$ (Fig. 6) in Quecksilber gebracht und auf diese Weise in das Laboratorium geschafft.

Aber nicht bloss das freigewordene Gasgemisch steigt nach dem Einschneiden in das Eudiometerrohr auf, immer, wie dies ja aus dem früher Gesagten verständlich ist, gelangen neben dem Gas noch geringe Blutmengen in die Glasröhre, deren Gasgehalt den des freien Gasgemisches beeinflussen konnte. Wir glauben jedoch die dadurch gesetzten Fehlerquellen vernachlässigen zu dürfen, da eine hierdurch bedingte Zunahme der untersuchten Gasmenge der Hauptsache nach wohl anf die Gase Sauerstoff nnd Kohlensäure entfällt. Man wird daher zu der Annahme berechtigt sein, dass der Stickstoffgehalt der analysirten Gasmenge nahezu jenem gleichkommt, wie er in dem im Herzen vorbandenen frei gewordenen Gasgemische enthalten ist. Vor der Analyse wurde das letztere vom Blute getrennt und in ein anderes Eudiometerrohr übergeleitet.

Des ferneren wird man es nicht als einen groben Fehler bezeichnen können, dass wir, um eine möglichst grosse Gasmenge zur Analyse zu bekommen, das Gas von mehreren Versuchsthieren in einem Rohr gesammelt und untersucht haben, werden doch jedenfalls die gefundenen Zallen brauchbare Mittelwerthe darstellen, welche uns über die Zusammensetzung der nach raschem Druckabfall im Gefässsysteme auftretenden freien Gasblasen Aufschluss geben. Die seböne Uebereinstimmung der gefundenen Stickstoffwerthe mit den vor uns nur von P. Bert bestimmten Zahlen spricht für die gewonnenen Resultate ${ }^{1}$ ).

1) Die Gase aus den beiden Ventrikeln getrennt zu bestimmen, um auf diese Weise vielleicht eine Anschauung über die Thätigkeit der von einem BIutluftgemisch durchströmten Lunge zu gewinnen, scheiterte bis jetzt an der bedeutenden Schwierigkeit dieser Untersuchung. Aus äusseren Gründen mussten wir uns auch zufrieden geben, über bloss zwei sichere Gasanalysen zu verfügen. - Tobieseu hat nur d n specifischen Sauerstoffgehalt des Blutes nach Decompression von zwei Atmosphären bestimmt. 
44 Richard Heller, Wilhelm Mager, Hermann von Schrötter:

$$
\text { An alyse I. }
$$

Herzgase von den Hunden.

No. XVI Versuch 37 gestorben

$\begin{array}{rrrr}" & \text { XXXIV } & , & 38 \\ " & \text { XII } & " & 41 \text { getödtet } \\ " & \text { XIII } & " & 42\end{array}$

ca. $45 \mathrm{~cm}^{3}$ Gas

$$
\begin{aligned}
& \text { ergab } \mathrm{CO}_{2}=4,71 \\
& 0=15,31 \\
& \mathrm{~N}=79,98
\end{aligned}
$$

Analyse II ${ }^{1}$ ).

Herzgase von den Hunden.

$$
\begin{aligned}
& \text { No. XXXII und XXXIII Versuch } 40 \text { gestorben } \\
& " \quad \text { XIV } \\
& \text { ergab } \left.\mathrm{CO}_{2}=12,45^{2}\right) \\
& \mathrm{O}=7,18 \\
& \mathrm{~N}=80,37 \text {. }
\end{aligned}
$$

Vergleichsweise seien hierzu die Resultate der diesbezüglichen drei Gasanalysen von P. Bert angefuhrt, welche sich auf Versuchsthiere beziehen, die rasch von einem Drucke von 9,5-10 A. decomprimirt wurden.

P. Bert's Nr. DLVIII. Hund gleich nach der Decompression todt. Das rechte Herz von Gasblasen geb]äht, keine freien Gase im linken Herzen.

In Volumprocenten $\mathrm{CO}_{2}=15,2$

$$
\begin{aligned}
& \mathrm{O}=2,0 \\
& \mathrm{~N}=82,8 .
\end{aligned}
$$

P. Bert's Nr. DLXIX. Katze. j Minuten nach der Decompression todt. Das aus dem rechten Herzen gewonnene Gas, $23,8 \mathrm{~cm}^{\mathbf{3}}$, hat die $\mathrm{Zu}$ sammensetzung wie folgt:

$$
\text { In Volumprocenten } \quad \begin{aligned}
\mathrm{CO}_{2} & =15,9 \\
0 & =0 \\
\mathrm{~N} & =84,1 .
\end{aligned}
$$

1) Zwei weitere Proben konnten wegen der geringen Gasmenge nicht genau analysirt werden.

2) Der verhältnissmässig hohe $\mathrm{CO}_{2}$-Gehalt erklärt sich vielleicht aus der Todesart, Strangulation des Thieres. 
P. Bert's Nr. DXXVIII. Hund. Gleich nach Verlassen des Apparates wird mittelst Canüle durch die rechte Vena jugularis $33,9 \mathrm{~cm}^{3}$ Gas gewonnen, dasselbe ergiebt:

$$
\text { In Volumprocenten } \begin{aligned}
\mathrm{CO}_{2} & =20,8 \\
O & =\text { in Spuren 1) } \\
\mathrm{N} & =79,2 .
\end{aligned}
$$

Die in diesem Abschnitt mitgetheilten Versuche haben ergeben, dass das Blut des lebenden Thieres unter erhöhtem Luftdruck mehr Stickstoff absorbirt und dass das nach der Decompression im lebenden Thierefreigewordene Blutgasgemisch der Hauptsache nach aus Stickstoff besteht.

IV.

\section{Decompressionserscheinungen.}

A. Asphyctische Symptome.

\begin{tabular}{|c|c|c|c|c|c|}
\hline Z. & Dr. i. & A. T. & Sch. T. & $\begin{array}{l}\mathrm{Hg} . \\
\text { Sch. }\end{array}$ & $\begin{array}{l}\text { Bar. } \\
\mathrm{Hg} .\end{array}$ \\
\hline $\begin{array}{rr}9 & \mathrm{~h} \\
3 & 30^{\prime} \\
9 & 35^{\prime} \\
10 & 35^{\prime} \\
10 & 35^{\prime}\end{array}$ & $\begin{array}{l}0 \\
4,2 \\
4,2 \\
0\end{array}$ & $+18^{\circ}$ & $\begin{array}{r}+180 \\
+250 \\
+160\end{array}$ & $\begin{array}{l}87 \% \\
93 \% \\
84 \%\end{array}$ & \\
\hline
\end{tabular}

Vers ue h 36 .

Hund Nr. XXXI.

Der Hund stürzt 5 Minuten nach Verlassen des Apparates unter hochgradigster Dyspnoë zusammen. Ueber dem Herzen gurgelnde Gerüusche zu hören, Puls kaum fühlbar, unregelmässig. Zunahme der asphyctischen Ersclueinungen; nach 5 Minuten stirbt das Thier.

Section. Panniculus adiposus gut entwickelt; schon beim Durchschneiden der Muskulatur quillt aus den kleinen Muskelarterien und Venen schaumiges Blut hervor. Die Lungen blass, fast blutleer, keine Ecchymosen.

Das Herz ballonförmig gebläht. Beim Einschneiden in den rechten Ventrikel entweicht in einen bereitgehaltenen Messcylinder eine bedeutende Menge (ca. $20 \mathrm{~cm}^{3}$ ) Gas; nur spärliche Mengen schaumigen Blutes zwischen den Trabekeln. Der linke Ventrikel sowie der Vorhof dilatirt; beide

1) Die im Vergleich zu P. Bert's Resultaten gefundenen höheren Werthe für 0 erklären sich wohl aus der Mitbestimmung von Gasen der Blutmenge, die in das Eudiometerrohr aufgestiegen, war. 


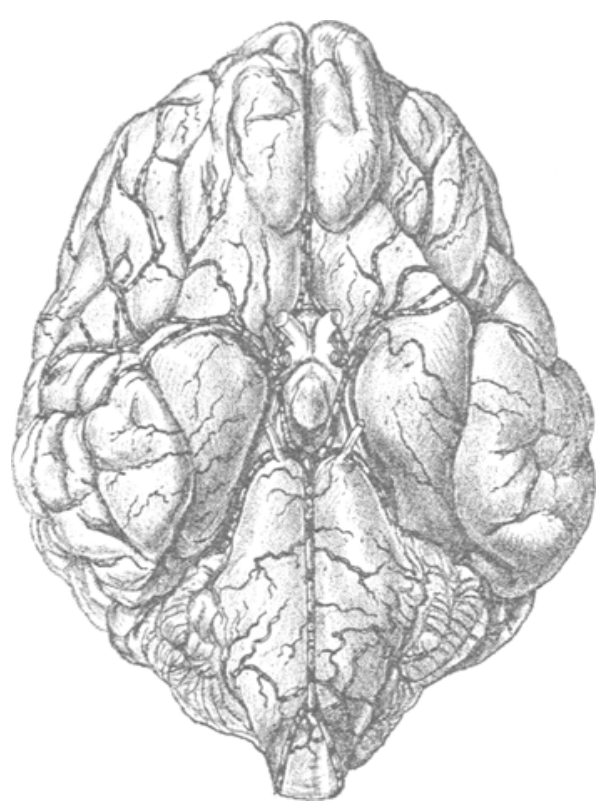

Fig. 9.

Gehirn eines Hundes nach der Decompression. Man sieht die Blutsäule der Arterien allenthalben von Gasblasen unterbrochen.
Atrien von schaumigem Blut prall gefüllt; in der linken. Kammer reichlich grossblasiges schaumiges Blut. In der Cava ascendens und descendens sowie dem venösen Schädelsinus schaumiges, mit grösseren Gasblasen untermischtes Blut. Die Leber verhält sich nach dem Einschneiden wie eine ödematöse Lunge. In den Mesenteriajgefüssen, dem System der Vena azygos., den Gefässen der Hirnhäute feine Gasblasen ; ebensolche reichlich in den Arterien des Gehirnes, wie beistehende Abbildung zeigt (Fig. 9), sowie in allen peripheren Gefässen. Abdominalorgane blass; Nieren leicht cyanotisch.

\section{Versuch 37.}

Hund Nr. XVI, „Rouge“ (Männchen, 6 Kilo).

\begin{tabular}{|c|c|c|c|c|c|}
\hline Z. & $\begin{array}{c}\text { Dr. } \\
\text { A. }\end{array}$ & A. T. & Sch. T. & $\begin{array}{l}\text { Sch. } \\
\text { Hg. }\end{array}$ & Bar. Hg. \\
\hline $\begin{array}{rr}9 \mathrm{~h} & 30^{\prime} \\
9 & 40^{\prime} \\
10 & 58^{\prime} \\
10 & 59^{\prime}\end{array}$ & $\begin{array}{l}0 \\
4,5 \\
4,5 \\
0\end{array}$ & $+3^{0} \mathrm{C}$ & $\begin{array}{l}+3^{0} \\
+8^{0} \\
+5^{0} \\
-2^{0}\end{array}$ & $\begin{array}{l}90 \% \\
95 \% \\
-88 \%\end{array}$ & $757 \mathrm{~mm} 90 \%$ \\
\hline
\end{tabular}

Stürzt nach dem Ausschleusen unter hochgradiger Dyspnoë zusammen und stirbt mit einem Schrei fast momentan; Thorax in maximaler Inspirationsstellung; Herz durch freie Gase ballonförmig gebläht. Das Herz wird zur Gasgewinnung verwendet. Gasblasen allenthalben in den Gefässen. Organe des Unterleibes blass cyanotisch; Lungen blass, auch aus grösseren Gefässen derselben entleert sich kein Blut auf die Schnittfläche. 
Versuch 38.

Hund Nr. XXXIV (8 Kilo).

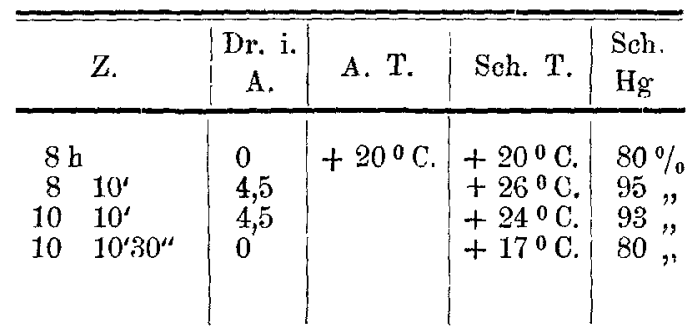

Nach Verlassen der Schleuse stürzt das Thier mit einem Sch rei zusammen und ist sofort todt. Thorax in maximaler Inspirationsstellung.

Section. Herz sowohl im linken als auch im rechten Ventrikel ballonförmig gebläht, ausser Luft nur ganz geringe Mengen schaumigen Blutes iı beiden Ventrikeln enthaltend; das gesammte arterielle und yenöse Gefässsystem reichlich von Gasblasen erfüllt. Aus der Leber, Niere und Milz quillt beim Einschneiden schaumiges Blat. Lungen blass, anämisch. - Die Herzgase werden behufs Analyse aufgefangen.

\section{Versuch 39 .}

Hund Nr. XIV, „Spitz" (8 Kilo).

\begin{tabular}{|c|c|c|c|c|c|}
\hline $\mathrm{Z}$. & $\begin{array}{c}\text { Dr. i. } \\
\text { A. }\end{array}$ & A. $\mathrm{T}$. & $\operatorname{Sch} . \mathbf{T}$. & Sch. H. & Bar. Hg. \\
\hline $\begin{array}{ll}2 & \\
2 & 5^{\prime} \\
3 & 15^{\prime} \\
3 & 16^{\prime}\end{array}$ & $\begin{array}{l}0 \\
4,5 \\
4,5 \\
0\end{array}$ & +13 & $\begin{array}{l}+13^{\circ} \\
+17^{\circ} \\
+16^{0} \\
+50\end{array}$ & $\begin{array}{l}86 \% \\
96 \% \\
90 \% \\
86 \%\end{array}$ & $740 \mathrm{~mm} 86 \%$ \\
\hline
\end{tabular}

Der Hand stirbt 2 Minuten nach dem Ausschleusen unter asphyctischen Erscheinungen.

Section: Herz ballonförmig gebläht, der rechte und linke Ventrikel stark dilatirt. Lungen blass, leicht gedunsen, in den Mesenterialgefässen massenhaft Gasblasen, Leber auf der Schnittfäche wie eine ödematöse Lunge, reichlich schaumiges Blut entleerend. - Die Herzgase wurden zur chemischen Untersuchung aufgefangen. 
Vers u c b 40.

Hund Nr. XXXII, XXXIII.

\begin{tabular}{|c|c|c|c|c|}
\hline$Z$. & $\mid \begin{array}{c}\text { Dr. i. } \\
\text { A. }\end{array}$ & A. T. & Sch. T. & Bar. $\mathrm{Hg}$ \\
\hline $\begin{array}{c}9 \mathrm{~h} 30^{\prime} \\
9 \mathrm{~h} 35^{\prime} \\
10 \mathrm{~h} 35^{\prime} \\
10 \mathrm{~h} 35^{\prime} 39^{\prime \prime}\end{array}$ & $\begin{array}{l}0 \\
4,2 \\
4,2 \\
0\end{array}$ & $+17^{\circ} \mathrm{C}$ & $\begin{array}{l}+17^{\circ} \mathrm{C} . \\
+24^{0} \mathrm{C} . \\
+16^{0} \mathrm{C} .\end{array}$ & $\begin{array}{l}80 \% \\
90 \% \\
89 \% \\
80 \%\end{array}$ \\
\hline $\begin{array}{l}11 \mathrm{~h} \\
11 \mathrm{~h} 3^{\prime} \\
11 \mathrm{~h} 35^{\prime} \\
11 \mathrm{~h} 35^{\prime} 30^{\prime \prime}\end{array}$ & $\begin{array}{l}0 \\
4,2 \\
4,2 \\
0\end{array}$ & $+19^{\circ} \mathrm{C}$ & $\begin{array}{l}+19^{\circ} \mathrm{C} . \\
+25^{0} \mathrm{C} \\
+16^{\circ} \mathrm{C} .\end{array}$ & $\begin{array}{l}90 \% \\
97 \% \\
79 \%\end{array}$ \\
\hline
\end{tabular}

Beide Thiere wurden ca. zwei Minuten nach Verlassen des Apparates an den hinteren Extremitäten geläbmt, zugleich schwere asphyctische Symptome, die aber nach $15 \mathrm{Min}$. vollkommen schwinden.

Neuerdings eingeschleust, bessern sich die Lähmungen soweit, dass die Thiere, wenn auch mübsam, in der Schleuse umhergehen.

Nach der zweiten Decompression stürzen Beide hochgradig asphyctisch zusammen und sind bew usstlos. Der Hund Nr. XXXII stirbt innerhalb 10 Minuten, Nr. XXXIII in 20 Minuten, nachuem er an allen vier Extremitäten gelähmt am Boden lag.

Die Section beider Thiere ergiebt fast den gleichen Befund wie beim Thiere des Versuches 36 .

Die Herzgase wurden behufs chemischer Analyse aufgefangen.

\section{Versueb 41 . \\ Hund Nr. XII.}

$\mathrm{D}_{\text {as }}$ Thier ist vollkommen normal.

\begin{tabular}{|c|c|c|c|c|c|}
\hline $\mathrm{Z}$. & $\begin{array}{c}\text { Dr. i. } \\
\text { A. }\end{array}$ & A. T. & Sch. T. & $\begin{array}{l}\text { Sch. } \\
\text { Hg. }\end{array}$ & Bar. Hg. \\
\hline 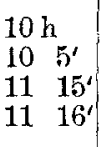 & $\begin{array}{l}0 \\
4,5 \\
4,5 \\
0\end{array}$ & $+13^{\circ}$ & $\begin{array}{l}+130 \\
+170 \\
+60\end{array}$ & $\begin{array}{l}86 \% \\
92 \% \\
82 "\end{array}$ & $740 \mathrm{~mm} 86 \%$ \\
\hline
\end{tabular}

Der Hund stürzt nach dem Ausschleusen auf dem Wege zum ärztlichen Inspectionszimmer mit hochgradiger Dyspnoë zusammen; das Thier kriecht keuchend am Boden umher; glucksende Geräusche über dem Herzen zu hören. Es wird zum Zwecke der Gewinnung der im Herzen freigewordenen Gase behufs ehemischer Untersuchung nach $10 \mathrm{Min}$. durch Bulbusstich getödtet. 
Sectionsbefund: Lungen blass, mit vereinzelten stecknadelkopfgrossen Härnorrhagien, auf der Schnittfläche nur aus den grösseren Gefässen Blut entleerend. Das geblähte Herz wird an den grossen Gefässen abgebunden, dann losgetrennt und unter Quecksilber geöffnet. Es steigen grosse Gasinengen in das Eudiometer, daneben einige spärliche Blutstropfen. In den Mesenterialgefässen, sowie in allen grösseren Venen massenhaft Gasblasen; dje Blutsäule der Arterien von Gasindices allenthalben unterbrochen. Rücksichtlich der Gasblasenbildung in den Mesenterialgefässen vergleiche beistehende Skizze (Fig. 10) ${ }^{1}$ ).

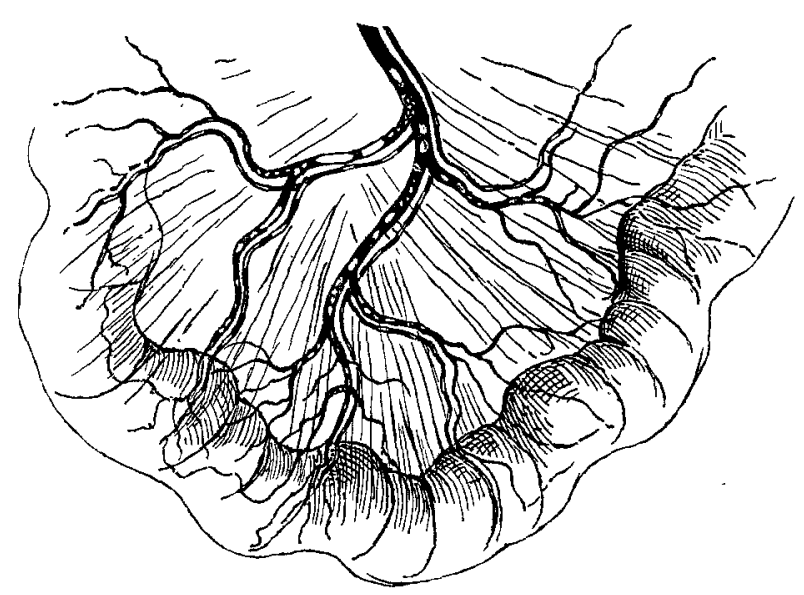

Fig. 10.

Freie Gasblasen in den Mesenterialgefässen.

Links an der Abgangsstelle der Vene von einem Hauptstamm mehrere kleinere Gasbläschen; in den Arterien die Blutsäule durch Gasindices stellenweise ganz unterbrochen.

Des Genauerendeckt sich der Befund im Gefässsystem des Mesenteriums sowieanden Coronargefässen in jeder Beziehung so vollständigmitdemjenigen, wie wir ihn nach küntlicher Lufteintreibung ins Arteriensystem erhalten haben, dass wirhiervorläufigauf unsere bereits citirte Abhandlung ${ }^{2}$ ) und die derselben beigegebenen Abbildungen verweisen.

1) Eine genaue Wiedergabe dieses Befundes wird in einer ausführlichen Publication erfolgen.

2) l. c. pag. 3 . 
Versueb 42.

Hund Nr. XIII, "Zigeuner" (Männchen, $12 \mathrm{Kilo}$ ).

\begin{tabular}{|c|c|c|c|c|c|}
\hline $\mathrm{Z}$. & $\begin{array}{c}\text { Dr. i. } \\
\text { A. }\end{array}$ & A. $\mathrm{T}$. & Sch. T. & Sch, H. & Bar. $\mathrm{Hg}$. \\
\hline $\begin{array}{ll}10 \mathrm{~h} \\
10 & 5^{\prime} \\
11 & 15^{\prime} \\
11 & 16^{\prime}\end{array}$ & $\begin{array}{l}0 \\
4,5 \\
4,5 \\
0\end{array}$ & $+13^{0}$ & $\begin{array}{l}+13^{0} \\
+16^{\circ} \\
+15^{0} \\
+60\end{array}$ & $\begin{array}{l}86 \% \\
90 \% \\
86 \%\end{array}$ & $740 \mathrm{~mm} 86 \%$ \\
\hline
\end{tabular}

Der Hund stürzt nach dem Ausschleusen sofort unter schwerster Dyspnoё zu Boden; mühsame, langsame, maximale Inspirationen, die Hinterbeine gelähmt. Reflexe gesteigert; Stuhl und Urin gehen unwillkürlich ab.

Das Thier wird zur Gewinnung der Herzgase nach 10 Minuten durch Bulbusstich getödtet; Sectionsbefund wie beim Versuche 36.

Ver s u c h 43.

Hund Nr. XVII „Noir“ (Männchen, 6 Kilo).

\begin{tabular}{|c|c|c|c|c|c|}
\hline Z. & $\begin{array}{c}\text { Dr. i. } \\
\text { A. }\end{array}$ & A. T. & Sch. T. & Sch. H. & Bar. $\mathrm{Hg}$. \\
\hline $\begin{array}{rr}9 \mathrm{~h} & 30^{\prime} \\
9 & 40^{\prime} \\
10 & 58^{\prime} \\
10 & 59^{\prime}\end{array}$ & $\begin{array}{l}0 \\
4,5 \\
4,5 \\
0\end{array}$ & $+3^{0}$ & $\begin{array}{l}+3^{0} \\
+8^{0} \\
+5^{0} \\
-2^{0}\end{array}$ & $\begin{array}{l}90 \% \\
95 \% \\
88 \%\end{array}$ & $757 \mathrm{~mm} 90 \%$ \\
\hline
\end{tabular}

Nach dem Ausschleusen hochgradige Dyspnoë sowie Lähmung đer hinteren Extremitäten; Stulıl und Urin gehen unwillkürlich ab. Der Hund wird strangulirt, das Herz behufs Gewinnung der freien Herzgase verwendet.

Im geblähten Herzen freie Gase in grosser Menge. (Das specifische Gewicht des Blutes aus dem linken Vorhof 1020.) Lunge blass anämisch; im Gefässsystem allenthalben Gasblasen.

Vers u e h 44.

Hund Nr. XXVI, XXVII, XXVIII.

\begin{tabular}{|c|c|c|c|c|c|}
\hline Z. & $\begin{array}{l}\text { Dr. i. } \\
\text { A. }\end{array}$ & $\begin{array}{l}\text { Aussen- } \\
\text { temp. }\end{array}$ & $\begin{array}{l}\text { Temp. incl. } \\
\text { Schleuse }\end{array}$ & Hygr. & Bar. Hg. \\
\hline \begin{aligned} & \multicolumn{2}{c}{$9 \mathrm{~h}$} \\
& 9 $10^{\prime} \\
& 9 15^{\prime} \\
& 11 15^{\prime} \\
& 11 15^{\prime} 30^{\prime \prime}\end{aligned}$ & $\begin{array}{l}0 \\
4,5 \\
4,7 \\
4,7 \\
0\end{array}$ & \multicolumn{4}{|c|}{ nicht gemessen. } \\
\hline
\end{tabular}


Alle 3 Thiere starben mehr oder minder rasch kurz nach dem Ausschleusen unter asphyctischen Erscheinungen.

Section: Bei, allen 3 Thieren nahezu derselbe Befund. Herz bei Percussion tympanitisch schallend. Aus dem linken, mehr jedoch aus dem rechten Ventrikel entleeren sich beim Anschneiden Gasblasen unter hörbarem Geräusch.

Die rechte Herzkammer fast vollständig blutleer, nur Gas enthaltend. In den grossen Venenstämmen ist die Blutsäule von Gasblasen erfüllt, in den Arterien sowie im Uebrigen der bereits geschilderte Befund.

Versuch 45.

Hund Nr. XXIV (6 Kilo).

Das Thier war vor dem Versuch vollkommen gesund.

\begin{tabular}{|c|c|c|c|c|c|}
\hline Z. & $\begin{array}{c}\text { Dr. i. } \\
\text { A. }\end{array}$ & A. T. & Sch. T. & $\begin{array}{l}\text { Sch. } \\
\text { Hg. }\end{array}$ & Bar. \\
\hline $\begin{array}{ll}8 \mathrm{~h} & 30^{\prime} \\
8 & 35^{\prime} \\
9 & 20^{\prime} \\
9 & 21^{\prime}\end{array}$ & $\begin{array}{l}0 \\
4,3 \\
4,3 \\
0\end{array}$ & $+20^{\circ}$ & $\begin{array}{l}+20^{\circ} \\
+26^{\circ} \\
+18^{\circ}\end{array}$ & $\begin{array}{l}80 \% \\
90 \% \\
78 \%\end{array}$ & - \\
\hline
\end{tabular}

Wenige Minuten nach der Decompression zeigt das Thier plötzlich schwere asphyetische Erscheinungen; überdies tritt häufiges Gähnen sowie Würgbewegungen auf, die von Erbrechen eines leicht blutig tingirten Schleimes gefolgt sind. Allmählich bessert sich der Zustand des Hundes, die Dyspnoë schwindet; Nachmittags hat sich das Thier vollkommen erholt.

Fassen wir die Versuchsergebnisse dieser Reihe zusammen, so haben wir gesehen, dass die Thiere der Experimente $36-40$ inclusive, sowie des Versuches 44 innerhalb 5 Minuten unter den sebwersten a sph yetisehen Erschein ungen zu Grunde gingen. Wie insbesondere in den Versuchen 37 und 38 stïrzten die Thiere sofort nach der Herausnahme aus dem Apparate um und sind nach einem kurzen Schrei, den das Thier ausstösst, todt. Der Thorax steht dabei in maximaler Inspirationsstellung, die Herzaction hat vor Aussetzen der Athmung aufgehört. In den Fällen, in welchen das letale Ende nicht so plötzlich erfolgt, beobachtete man bochgradige Dyspnoe und bedeutend gestörte Herzthätigkeit. Die Herztöne sind unregelmässig schwach, oft kaum zu hören und werden dureh glucksende und quatschende Nebengeräusche undentlich. In den Versuchen 40 und 42 traten auch Lähmungserscheinungen des Hinterthieres auf, wie wir noch bei Besprechung der folgenden Versuchsreihe B mebrere solehe 
Beispiele seben werden. Die Hunde der Experimente 41-43, die längere Zeit bis 15 Minuten am Leben blieben, wurden zum Zwecke der Gasanalyse getödtet; man kann jedoch mit Rücksicht auf das Resultat des Versuchs 45 sowie insbesondere späterer Angaben, nach denen sich der Hund wieder vollkommen erholte, nicht von vorneherein mit Sicherheit angeben, ob sich der Zustand dieser Thiere trotz der bedrohlichen Erscheinungen nicht doch noch vollkommen gebessert hätte.

Die Section aller hier verwendeten Hunde zeigte freie Gasblasen reichlich im ganzen Gefässsystem; insbesondere war ihre Wirkung am Herzen auffallend, indem dasselbe meist ballonartig gebläht war und neben frei gewordenem Gas nur spärliche Blutmengen, meist nur zwischen den Trabekeln enthielt; das Herz gab bei Percussion tympanitischen Schall und entleerte angeschnitten das eingeschlossene Gas unter börbarem Geräuscb. Die Lungen waren in allen Fällen hellrosaroth, blass, nahezu blutleer.

Wir sehen also, dass bei den hier verwendeten Hunden, die nach entsprechendem Aufenthalt von einem Ueberdruck von 4,2$4,7 \mathrm{Atm}$. in ca. $35-50$ Sec. decomprimirt.wurden, dieser rasche Druckabfall sofort eine schwere Schädigung des Organismus setzte, die in der Mehrzahl der Fälle, hier in $64 \%$, den sofortigen oder nach wenigen Minuten erfolgenden Tod bewirkte, indem die freigewordenen Blutgase direkt, primär die Herz- und Lungenthätigkeit ausser Funktion setzen, ohne dass es zu lokalen Störungen, zu Lähnungen in bestimmten Gebieten gekommen war.

B. Asphyktische 8ymptome nnd Lähmungserseheinungen.

Versueh 46.

H und Nr. XXIX.

\begin{tabular}{c|c|c|c|c}
\hline Z. & $\begin{array}{c}\text { Dr. i. } \\
\text { A. }\end{array}$ & $\begin{array}{c}\text { Aussen- } \\
\text { temper. }\end{array}$ & $\begin{array}{c}\text { T. in dem } \\
\text { Apparate }\end{array}$ & Hg. \\
\hline $9 \mathrm{~h}$ & 0 & $+17^{\circ}$ & $+17^{0}$ & $85 \%$ \\
$95^{\prime}$ & 4,2 & & $+25^{\circ}$ & $96 \%$ \\
$105^{\prime}$ & 4,2 & & & $90 \%$ \\
$105^{\prime} 30^{\prime \prime}$ & 0 & & $+15^{\circ}$ & $82 \%$
\end{tabular}

Der Hund stürzt wenige Minuten nach Verlassen des Apparates zusammen. Mühsame keuchende Athmung mit maximalen Inspirationsbe- 
wegungen des Thorax. Herzaction unregelmässig, frequent, Pulzfrequenz 180, glucksende Geräusche über dem Herzen hörbar. Der Hund, der sich mehrmals vergeblich zu erheben sucht, stürzt immer wieder auf die linke Seite; plötzlich treten heftige Manégebewegungen, Drehung des Kopfes und des Vorderthieres nach links auf. Dieser Zustand dauert 10 Minuten, dann liegt das Thier bew usstlos da. Nach einer halben Stunde langsame Erholung. Herzaction bedeutend verlangsamt, nicht arythmisch; Athmung langsam, regelmässig. Das Thier wird durch Chloroform getödtet.

Se ct i o $\mathrm{s}$ b e f u n d: Lungen nahezu blutleer, vereinzelte punktförmige Hämorrhagien an der Pleura. Herz: Der rechte Ventrikel dilatirt, enthält neben einem Blutgasgemisch freie Gasblasen; der linke Ventrikel contrahirt, linke Aurikel von schäumigem Blut erfüllt, in den Coronararterien des Herzens index ganzeuses, auch in den Coronarvenen Gasblasen. Hyperämie der Abdominalorgane; das System der Vena portae zeigt reichlich bei Fingerdruok bewegliche Gasblasen in den Gefässen.

Mikroskopisch: Am Zupfpräparat, in den Capillaren des Hirnes, mehr in der grauen Substanz, sowie in den Capillaren des Rückenmarkes die Blutsäule durch Gas oft stellenweise ganz verdrängt, oder die Blutsäule durch Gasbläschen unterbrochen. In den Venen der Hirn- und Rückenmarkshäute zahlreiche Gasblasen, auch ihre Arterien sind gasführend; ebenso lassen sich in den Gefässgebieten einzelner Organe Gasblasen mikroskopisch nachweisen; häufig findet man förmliche Gasperlen von verschiedener Grösse in den Gefässen, dieselben erfüllen entweder das Lumen ganz oder sind an den Randpartien der Blutsäule àngehäuft.

Versuch 47.

H u n d No. VI (Weibchen, 9 Kilo).

\begin{tabular}{|c|c|c|c|c|c|}
\hline $\mathrm{Z}$. & $\begin{array}{c}\text { Dr. i. } \\
\text { A. }\end{array}$ & A. $\mathrm{T}$. & Sch. T. & $\begin{array}{l}\text { Sch. } \\
\text { Hg. }\end{array}$ & Bar. Hg. \\
\hline $\begin{array}{ll}10 \mathrm{~h} & 4^{\prime} \\
10 & 9^{\prime} \\
10 & 10^{\prime} \\
10 & 14^{\prime} \\
10 & 39^{\prime} \\
10 & 40^{\prime}\end{array}$ & $\begin{array}{l}0 \\
3,5 \\
4,5 \\
4,5 \\
4,5 \\
0\end{array}$ & $\begin{array}{l}+2,5^{\circ} \\
+3,5^{\circ}\end{array}$ & $\begin{array}{r}+8^{0} \\
+140 \\
+150 \\
+14^{0} \\
+130 \\
+\quad 9^{0}\end{array}$ & $\begin{array}{l}80 \% \\
90 \% \\
85 \%\end{array}$ & $764 \mathrm{~mm} 76 \%$ \\
\hline $\begin{array}{ll}10 \mathrm{~h} & 41^{\prime} \\
10 & 45^{\prime} \\
10 & 47^{\prime} \\
11 & 32^{\prime} \\
11 & 15^{\prime} \\
11 & 16^{\prime}\end{array}$ & $\begin{array}{l}0 \\
2,0 \\
3,5 \\
4,5 \\
4,5 \\
0\end{array}$ & $+6^{\circ}$ & $\begin{array}{l}+15^{\circ} \\
+17^{0} \\
+15^{0} \\
+19^{\circ} \\
+10^{\circ}\end{array}$ & & \\
\hline
\end{tabular}

Der Hund wird nach einem Aufenthalt von 20 Minuten um $10 \mathrm{~h} 40^{\prime} \mathrm{Vm}$. rasch ausgeschleust und gleich wieder unter erhöhten Druck gebracht, ohne 
nach der ersten Decompression in der Kammer irgend welche Ercheinungen gezeigt zu haben.

$11 \mathrm{~h} 16^{\circ}$ abermals rasch ausgeschleust und in das ärztliche Zimmer gebracht, zeigt er anfänglich keine Erscheinungen.

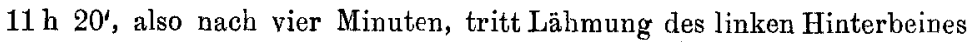
auf, zugleich setzt sehr bedeutende Dyspnoë, 69 Respirationen pro Minute, ein.

$11 \mathrm{~h} 30^{\prime}$ stürzt das Thier zusammen, Respirationen 132 pro Miuute. Alle vier Extremitäten gelähmt. Reflexe gesteigert.

$11 \mathrm{~h} 33^{\prime}$ vorübergehende Streckkrämpfe in den Extremitäten und der Nackenmuskulatur.

$11 \mathrm{~h} 40^{\prime}$ die Dyspnoë lässt nach, es treten keine Krämpfe mehr auf.

$1 \mathrm{~h}$ Mittags befindet sich das Thier bis auf einc geringe Schwäche in den Hinterbeinen wieder wohl; um

$3 \mathrm{~h} \mathrm{Nachm.} \mathrm{ist} \mathrm{das} \mathrm{Thier} \mathrm{vollkommen} \mathrm{wieder} \mathrm{hergestellt.}$

Versuch 48 .

H u nd No. X.

\begin{tabular}{|c|c|c|c|c|}
\hline Z. & $\begin{array}{c}\text { Dr. i. } \\
\text { A. }\end{array}$ & A. T. & Sch. T. & Bar. Hg. \\
\hline $\begin{array}{rr}9 \mathrm{~h} 20^{\prime} \\
9 & 21^{\prime} \\
9 & 25^{\prime} \\
9 & 45^{\prime} \\
10 & 15^{\prime} \\
10 & 16^{\prime}\end{array}$ & $\begin{array}{l}0 \\
3,5 \\
4,5 \\
4,5 \\
4,5 \\
0\end{array}$ & +20 & $\begin{array}{c}+\mathbf{1}^{\mathbf{0}} \\
\max . \\
+10^{0} \\
\min . \\
0\end{array}$ & $765 \mathrm{~mm} 80 \%$ \\
\hline
\end{tabular}

Nach 10 Minuten treten Lähmungserscheinungen auf, die beiden hinteren Extremitäten in maximaler Streckstellung. Das Thier macht Brechbewegungen. Wenige Augenblicke darauf stürzt es plötzlich nieder; heftigste Dyspnoë, 145 R. pro Minute; complete Lähmung der hinteren und vorderen Extremitäten, gurgelnde Geräusche über dem Herzen, Herząction sehr frequent, unregelmạıssig. Zeitweise lässt die Starrheit der Beine nach. Reflexe hochgradig gesteigert; werden active oder passive Bewegungen gemacht, so treten sofort Streckkrämpfe auf. - Das Thier scheint sterbend; aus dem Munde fliesst reichlich Speichel, die Augen sind starr.

Von Zeit zu Zeit lässt die Dyspnoë etwas nach, der Hund vermag dann mit der rechten Vorderpfote einige Bewegungen zu machen, die sofort wieder von Streckkrämpfen unterbrocben werden. Die linke vordere Extremität sowie beide Hinterbeine bleiben constant spastisch gelähmt. Dieser Zustand dauert mit wachsender Intensität bis Abends $10 \mathrm{Uhr}$ an, im weiteren Verlauf wird das Thier somnolent und stirbt noch in der Nacht.

Sections bef und:

Nach Eröffnung der Schädelhöhle keine Gasblasen in den Gefässen der Hirnhäute erkennbar, ebenso keine Gasblasen in den Gefässen der Rücken- 
markshaut. Die Meningen durchsichtig; die Cerebrospinalflüssigkeit scheint vermehrt.

Herz: In beiden Ventrikeln geronnenes Blut.

Lungen: Rechts mehrere kleine, links eine fast den ganzen Unterand Mittellappen einnehmende Hämorrhagie. Im übrigen das Lungengewebe beiderseits blutreich.

Leber, Nieren und Därme hyperämisch; makroskopisch in den Gefässen nirgends Gasblasen nachzuweisen.

Die mikroskopische Untersuchung der gehärteten Organstücke lässt im Inhalt der kleinen Arterien und Venen, sowie der präcapillaren Gefässe vereinzelt blasenförmige Hohlräume nachweisen.

\section{Versuch 49.}

H und No. XV ,Scheck" (Männchen 9 Kilo).

\begin{tabular}{|c|c|c|c|c|c|}
\hline Z. & $\begin{array}{c}\text { Dr. i. } \\
\text { A. }\end{array}$ & A. T. & Sch. T. & $\begin{array}{l}\text { Sch. } \\
\text { Hg. }\end{array}$ & Bar. Hg. \\
\hline 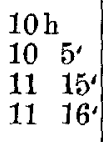 & $\begin{array}{l}0 \\
4,5 \\
4,5 \\
0\end{array}$ & +130 & $\begin{array}{l}+13^{0} \\
+17^{0} \\
-6\end{array}$ & $\begin{array}{l}80 \% \\
90 \% \\
80 \%\end{array}$ & $740 \mathrm{~mm} 80 \%$ \\
\hline
\end{tabular}

Circa 10 Minuten nach dem Ausschleusen tritt plötzlich complete Paraplegie ein; der Hund, der bisher herumlief, fällt auf das Hintertheil und vermag die Hintereine nicht mehr zu bewegen. Dyspnoïsche Athmung, jedoch nicht von besonderer Heftigkeit. Im Laufe des Nachmittages, nach 5 Uhr, stirbt der Hund; Dyspnoë, sowie zeitweise unregelmässige Herzaction bestanden bis zum Tode.

S e cti o n s b e f u nd: Kleine punktförmige Hämorrhagien im Zwerchfell und in den Lungen. Der übrige Befund ergibt nichts Pathologisches.

\section{Versuch 50.}

Hund No. V.

\begin{tabular}{|c|c|c|c|c|c|}
\hline Z. & $\begin{array}{c}\text { Dr. i. } \\
\text { A. }\end{array}$ & A. T. & Sch. T. & $\begin{array}{l}\text { Sch. } \\
\text { Hg. }\end{array}$ & Bar. Hg. \\
\hline 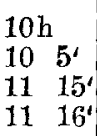 & $\begin{array}{l}0 \\
4,5 \\
4,5 \\
0\end{array}$ & +130 & $\begin{array}{c}\max \\
+16^{0} \\
\min - \\
+6\end{array}$ & $\begin{array}{l}86 \% \\
90 \% \\
86 \%\end{array}$ & $740 \mathrm{~mm} 89 \%$ \\
\hline
\end{tabular}

1.2 Minnten nach dem Ausschleusen complete Paraplegie der Hinterbeine. Stuhl geht ab; asphyctische Erscheinungen; Dyspnoë, frequente, un- 
regelmässige Herzaction. Glucksende Geränsche über dem Herzen börbar. Das Thier stirbt um 2 Uhr.

Section am Morgen des nächsten Tages: Lungen blass mit vereinzelten kleinen Hämorrhagien.

Herz: Rechter V entrikel dilatirt, enthält schlaumiges, mit mehreren grossen Gasblasen untermengtes Blut, desgleichen der rechte Vorhof. Im linken Atrium Blut, einzelne Gasbläschen zwischen den Trabekeln des linken Auricel; das linke Herz contrahirt; Gasblasen in den erweiterten Stämmen der grossen Körpervenen, weniger Gasblasen in System der Vena portae; in den Arterien besonders des unteren Körperabschnittes ganz vereinzelt hie und da Gasindices; Leber blutreich, Nieren blass, cyanotisch.

\section{Versuch 51.}

H and No. XXXV.

\begin{tabular}{|c|c|c|c|c|}
\hline Z. & $\begin{array}{c}\text { Dr. i. } \\
\text { A. }\end{array}$ & A. T. & Sch. T. & $\begin{array}{l}\text { Sch. } \\
\text { Hg. }\end{array}$ \\
\hline $\begin{array}{ll}8 \mathrm{~h} & \\
8 & 10^{\prime} \\
10 & 10^{\prime} \\
10 & 10^{\prime} 30^{\prime \prime}\end{array}$ & $\begin{array}{l}0 \\
4,5 \\
4,5 \\
0\end{array}$ & $+20^{\circ}$ & $\begin{array}{l}+20^{\circ} \\
+24^{\circ} \\
+16^{\circ}\end{array}$ & $\begin{array}{l}82 \% \\
97 \% \\
95 \% \\
80 "\end{array}$ \\
\hline $\begin{array}{ll}10 & \text { h } 40^{\prime} \\
10 & 42^{\prime} \\
11 & 10^{\prime} \\
11 & 10^{\prime} 30^{\prime \prime}\end{array}$ & $\begin{array}{l}0 \\
4,2 \\
4,2 \\
0\end{array}$ & & & \\
\hline
\end{tabular}

Sofort nach dem erstmaligen Ausschleusen legt sich das Thier ruhig hin. Respiration sehr frequent, über 100, mühsam; der Hund lässt die Zunge heraushängen, maximale tiefe Inspirationen. Herzaction frequent.

Nach 10 Minuten hat sich das Thier erholt und wird abermals eingeschleust. 10 Minuten nach der zweiten schnellen Decompression treten Manégebewegungen auf und das Thier.wird bewusstlos, wobei der Kopf nach links geschleudert wird. Nachdem es sich einigemale, stets mit dem Kopf auf den Boden aufschlagend, herumgedreht hat, bleibt es an einer Stelle ruhig liegen, und ist nach einer Stunde verendet.

Section: Herz: Im rechten Ventrikel einzelne grössere Gasblasen, neben dunkelschwarzem Blut; in der Arteria Pulmonalis sowie den Pulmonalvenen dunkelflüssiges Blut. Der linke Ventrikel contrahirt, im linken Vorhof nur Blut vorhanden, keine freien Gasbläschen. In den Mesenterialgefässen sowie in einzelnen Körperarterien da und dort Gasblasen nacbzuweisen: Lungen blauroth, zeigen keine Ecchymosen. 
Kaltes, klares Wetter.

\section{Versuch 52 . \\ H u n d Nr. VI.}

Das Thier befindet sich vollkommen normal. Keinerlei Schwäche in den Hinterbeinen erkenubar.

\begin{tabular}{|c|c|c|c|c|c|}
\hline$Z$ & $\begin{array}{c}\text { Dr i. } \\
\text { A. }\end{array}$ & A. T. & Sch. T. & $\begin{array}{l}\text { Sch. } \\
\mathrm{Hg} \text {. }\end{array}$ & Bar. Hg. \\
\hline 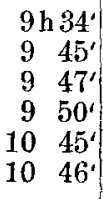 & $\begin{array}{l}0 \\
2 \\
3 \\
4,5 \\
\mathbf{4}, 5 \\
0\end{array}$ & $-5^{0}$ & $\begin{array}{l}-20 \\
\max \\
+100 \\
\min .+1\end{array}$ & $\begin{array}{l}80 \% \\
90 \% \\
94 \% \\
77\end{array}$ & $765 \mathrm{~mm} 80 \%$ \\
\hline
\end{tabular}

5 Minuten nach dem Ausschleusen tritt heftige Dyspnoë, Respirationsfrequeuz 130 pro Minute auf, zugleich Lähmung der hinteren Extremitäten.

Die Auscultation am Herzen crgiebt glucksende Geräusche über demselben. Die Herztöne nicht klar unterschcidbar. Die Dyspnoë bleibt auf derselben Höhe. Herzaction frequent, Puls der Art. cruralis kaum fühlbar. Nas Thier wird mittelst Chloroform getödtet.

Sectionsbefund. Herz: In beiden Ventrikeln schaumiges, mit grösseren und kleineren Gasblasen gemischtes Blut. Desgleichen in den beiden Vorhöfen.

In den grossen Gefässstämmen schaumiges Blut, in den Mesenterialgefässen perlschnurartig angeordnete Gasblasen. Lungen blass, anämisch, nicht gedunsen, ohne Hämorrhagien. Die Nieren erscheinen makroscopisch nicht verändert, Därme nicht gebläht. Befund völlig dem gleichend, wie er nach dem nächsten Versuch 53 erhoben wurde. Gehirn und Rückenmark werden in toto herausgenommen. Mikroscopischer Befund in anderem Zusammenhang.

Versuch 53.

Hund Nr. VIII, "Pintsch" (7 Kilo).

\begin{tabular}{|c|c|c|c|c|c|}
\hline Z. & $\begin{array}{c}\text { Dr. i. } \\
\text { A. }\end{array}$ & A. T. & Sch. T. & $\begin{array}{l}\text { Sch. } \\
\text { Hg. }\end{array}$ & Bar. Hg. \\
\hline $\begin{array}{ccc}9 \mathrm{c} & 50^{\prime} \\
9 & 57 \\
10 & 8 \\
10 & 10^{\prime} \\
10 & 50^{\prime} \\
10 & 51^{\prime}\end{array}$ & $\begin{array}{l}0 \\
2 \\
4,5 \\
4,7 \\
4,7 \\
0\end{array}$ & $\left.-5,5^{0}\right)$ & $\begin{array}{l}+30 \\
\max \\
+12^{\circ} \\
+10^{\circ} \\
+50\end{array}$ & $\begin{array}{l}72 \% \\
96 \% \\
90 \% \\
80 \%\end{array}$ & $765 \mathrm{~mm} 80 \%$ \\
\hline
\end{tabular}

8 Minuten nach dem Ausschleusen fällt der Hund wie vom Blitz getroffen um. Lähmung aller Extremitäten, heftigste Dyspnoë 120 Resp. pro Minute; Garguillement aber dem Herzen, stirbt nach 10 Minuten. 
Sectionsbefund: Panniculus adiposus reichlich entwickelt. Bei Er. öfnung des Thorax quillt schaumiges Blut aus den Intercostalgefässen. Pericard rcichlich mit Fett umwachsen. Das Herz ballonförmig gebläht; der rechte wie der linke Ventrikel hochgradig dilatirt.

Beim Anschneiden des abgebundenen linken sowohl wie des rechten Ventrikels unter Wasser entweicht Luft in grossen Blasen mit hörbarem Geräusch, ausserdem eine geringe Menge schaumigen Blutes. Aus der Aorta sowie Cava ascendens und descendens quillt schaumiges Blut.

Die Blutsäule der Coronararterien von Gasindices unterbrochen. In den Coronarvenen Gasblasen. Lungen blass, lufthaltig. Die Leber auf der Schnittfläche wie eine ödematöse Lunge beschaffen, entleert massenhaft schaumiges Blut. In den Mesenterialgefässen perlschnurartig angeordnete Luftblasen reichlich zu finden. Am Zupfpräparat kann man auch in den feinen Arterien und Venen das Vorhandensein freier Blutgase erkennen.

Rückenmark und Gehirn werden in toto herausgenommen und behufs mikroscopischer Untersuchung in Müller'sche Flüssigkeit eingel'egt. Makroscopisch an ihnen nur das Vorhandensein zahlreicher Gasblasen in den Gefässen ihrer Häute wahrnehmbar.

Versueh 54 .

Drei Meerschweinchen.

\begin{tabular}{|c|c|c|c|c|c|}
\hline$Z$. & $\begin{array}{c}\text { Dr. i. } \\
\text { A. }\end{array}$ & A. T. & Sch. T. & $\begin{array}{l}\text { Sch. } \\
\mathrm{Hg} .\end{array}$ & Bar. $\mathrm{Hg}$. \\
\hline $\begin{array}{cc}9 \mathrm{~h} & 50^{\prime} \\
9 & 51^{\prime} \\
9 & 52^{\prime} \\
9 & 55^{\prime} \\
10 & 3^{\prime} \\
10 & 20^{\prime} \\
11 & 20^{\circ} \\
11 & 21^{\prime}\end{array}$ & $\begin{array}{l}0 \\
1,0 \\
2,5 \\
3,5 \\
4,5 \\
4,5 \\
4,5 \\
0\end{array}$ & $|+2,50|$ & $\begin{array}{r}+7,50 \\
+11,0^{0} \\
+15,0^{0} \\
+140 \\
+160 \\
+150 \\
+150 \\
+160\end{array}$ & $\begin{array}{ll}86 & \% \\
85 & " \\
87 & " \\
89 & " \\
89 & " \\
96 & " \\
96 & " \\
70 & "\end{array}$ & $767 \mathrm{~mm} 73 \%$ \\
\hline
\end{tabular}

Von den drei Thieren wurde das eine nach dem Ausschleusen todt im Apparate vorgefunden, das zweite starb nach 5 Minuten, das dritte wurde an den Hinterbeinen gelähmt, es schleift dieselben nach, Stuhl geht unwillkürlich $a b$, stirbt in 20 Minuten.

Sectionsbefund des zweiten Meerschweinchens: Nach Eröffnung der Brusthöhle zeigt sich das Herz vollgefüllt mit Gasblasen und sehr stark gebläht. In der rechten Auricel sowie im rechten Vorhofe sieht man die Gasblasen durch die dünne Wand durchscheinen. Der liuke Ventrikel contrahirt, fast blutleer. In den Coronargefässen perlschnurartig angeordnete Gasblasen; ferner Gasblasen in der Aorta und Vena cava, ebenso in den Arterien und Venen der Extremitäten, in den Lungenvenen und Lungenarterien. Die Lungen blass anämisch, am freien Rande der linken einzelne bis hirsekorngrosse Hämorrhagien. Leber sehr blutreich; Nieren hyperämisch, 
entleeren so wie die Leber reichlich am Durchschnitte feinschaumiges Blut. Bei Fröffnung des Rückenmarkscanales und der Schädelhöhe in den Gefässen der Meningen, sowie im Sichelblutleiter und dem Sinus der Schädelbasis reichliche Gasblasen, desgleichen solche in feineren Blutgefässen, mit der Lupo erkennbar.

Beim ersten Meerschweinchen: Derselbe Befund. Freies Gas in der Blutsäule aller Gefässe. Das dritte Thier wurde nicht seciert.

Auch die meisten Thiere dieser Versuchsreihe, Versuch 43-51 inclusive sowie Versuch 53 und 54 (im ganzen 8 Experimente), starben innerhalb längstens 12 Stunden nach der Decompression unter dem Bilde der Asphyxie, wenn dabei auch bereits die Scbädigung des nervösen Centralapparates durch die circulirenden Gasblasen und die dadurch bewirkten functiouellen Störungen lebenswichtiger Centren in Betracht gezogen werden miissen, worauf die localen Störungen, die in sämmtlichen Versuchen aufgetretenen Herderscheischeinungen, hinweisen.

Neben der Asphyxie waren es in den Versuchen 46 and 51 hauptsächlich cerebrale Erscheinungen: die Manége bewegungen und die Bewusstlosigkeit, welche in den Vordergrund traten.

In den Experimenten 47, 48, 52 und 53 traten Lähmungen aller vier Extremitäten nahezu gleichzeitig mit den asphyctischen Erscheinungen auf.

Im Versuche 49 waren die Lungenherzerscheinungen nur geringe, es erfolgte complete Paraplegie der Hinterbeine, das Thier sturb erst nach 6 Stunden; der Hund Nro. VI hatte ebenfalls nur geringe asphyctische Beschwerden, und die in allen vier Extremitäten von Lähmung gefolgten Streckkrämpfe waren nur vorïbergehend und schwanden im Verlauf von $3-5$ Stunden, nach welcher Zeit sich das Thier vollkommen erholt hatte. Von den drei Meerschweinchen starb das eine sofort, das andere erst nach fünf Minuten, bei dem dritten endlich trat Lähmung des Hinterthicres auf und das Thier erlag nach ca. 20 Minuten.

In Gegensatz zu der Versuchsreihe A traten mit Ausnabme bei dem einen Meerschweinchen im Versuche 54, die Erscheinungen erst einige Zeit nach dem Druckabfall anf, welche 6 bis $20 \mathrm{Mi}$ nuten betrug. Wir wollen an dieser Stelle nur noch daran erinnern, dass auch das Auftreten freier Gasblasen im Gefässsystem erst einige Zeit nach der Decompression beobachtet wurde. Man vergleiche diesbezitglich die Versuchsreihe $\mathrm{C}$. 
Die Sectionsresultate ergaben im Wesentlichen den gleichen Befund wie in der vorigen Reihe $\mathrm{A}$; bei allen Meerschweinchen wurden Lungenecchymosen constatirt.

In dem Versuche 48, den Hund betreffend, der erst nach 12 Stunden starb, konnten makroskopisch keine freien Gase im Gefässsystem nachgewiesen werden; der Hauptmenge nach nur im venösen System wurden sie beobashtet bei der Section des Hundes Nro. V, wenn auch ganz vereinzelt Gasblasen in den Arterien noch nach drei Stunden zu finden waren. Bei dem über eine Stunde nach dem Experiment verstorbenen Thiere fanden sich ebenfalls spärlich Gasindices in einigen Körperarterien, daneben aber auch noch mehrere grössere Gasblasen im rechten Ventrikel.

Wir gehen nun zu jenen Versuchen über, bei welchen Allg e meinstörungen nicht oder nur eben angedeutet vorhanden waren, während die Localerschein ungen das Bild dominiren. Dieselben können entweder dauernde oder wenigstens länger, Wochen, andauernde Symptomencomplexe betreffen, oder es können, wie wir sehen werden, auch ausgesprochene Erscheinungen nach kurzer Zeit, schon nach Verlauf weniger Stunden wieder schwinden.

Wir beginnen mit der ersten Gruppe.

\section{Bleibende Lähmungen ${ }^{1}$ ).}

Versuch 55.

H und Nr. I.

Das Thier wurde vor dem Versuche gefüttert und getränkt und befindet sich vollkommen wohl.

Klares, scbönes Wetter. Bis knapp vor dem Experimente hielt sich der Hund im ärztlichen Inspectionszimmer auf. Temperatur in demselben $+20^{\circ} \mathrm{C}$. Hygrometerstand $60 \%$.

1) Eine Serie von Momentaufnahmen, welche das Auftreten und die Aufeinanderfolge der Lähmungserscheinungen an den Versuchsthieren deutlich veranschaulichen, werden wir in einer zusammenfassen-

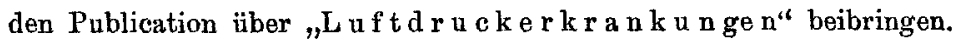




\begin{tabular}{|c|c|c|c|c|c|}
\hline Z. & $\begin{array}{c}\text { Dr. i. } \\
\text { A. }\end{array}$ & A. T. & Sch. T. & $\begin{array}{l}\text { Sch. } \\
\mathrm{Hg}\end{array}$ & Bar. \\
\hline \begin{tabular}{rc}
9 & \multicolumn{3}{c}{$40^{\circ}$} \\
9 & $45^{\prime}$ \\
9 & $46^{\prime}$ \\
9 & $47^{\prime}$ \\
9 & $50^{\prime}$ \\
10 & $40^{\circ}$ \\
10 & $41^{\prime}$
\end{tabular} & $\begin{array}{l}0 \\
2,0 \\
3,0 \\
4.0 \\
4,7 \\
4,7 \\
0\end{array}$ & $-6^{0}$ & $\mid \begin{array}{rr}-4 & 0 \\
+7 & 0 \\
+8 & 0 \\
+11^{0} \\
0 & 0\end{array}$ & $\begin{array}{l}80 \% \\
95 " \\
80 \%\end{array}$ & $764 \mathrm{~mm}$ \\
\hline
\end{tabular}

$10 \mathrm{~h} \mathrm{32}$ bellt der Hund laut im Apparate und hustet, geht dabei herum, wie man sich durch das Fenster der Schleuse überzeugen kann.

10 h $40^{\prime}$ werden die beiden Ausschleushähne geöffnet. Nach Entfernen der Thïre springt der Hund aus dem Apparat, sein Fell dampft; er bleibt ca. 10 Min. im Freien und wird dann in das Inspektionszimmer gebracht; er ist völlig munter. Nach 5 Min. bleibt er stehen und beginnt mit den Hinterbeinen zu zittern. Auf Anrufen kommt er herbei, scheint jedoch schwer zu gehen. Er bleibt dann plötzlich mit gespreizten Hinterbeinen stehen, Stuhl geht unwillkürlich ab. Der Hund versucht nunmehr sich zu setzen, ohne dass ihm dies gelingt. Die Hinterbeine werden beim Gehen steif gehalten, der Gang wird unsicher; den linken Hinterfuss vermag er nicht mehr zu heben, sondern schleift ihn beim Gehen nach. Die Zehen werden am Boden nachgezogen. Einige Secunden später treten Streckkrämpfe im rechten Fuss auf, der Hund beginnt beftig zu schwanken, Rückgrat stark gekrümmt, die Vorderbeine werden weit auseinander gespreizt - plötzlich fällt er mit dem Hintertheil auf eine Seite um. Die beiden hinteren Extremitäten sind jetzt in spastischem Zustand und werden nach vorne gestreckt; sie können weder activ noch passiv flectirt werden; die Sensibilität sowohl an den Extremitäten wie auch in der Lumbosacralgegend vollständig erloschen. Tiefe Nadelstiche werden nicht gefühlt; der Urin fliesst spontan ab. Nach einiger Zeit lassen die Streckkrämpfe nach, das Thier vermag sich mit den Vorderleib völlig normal zu bewegen; es macht jedoch fruchtlose Aufstehversuche. Endlich legt es sich nieder und bleibt ruhig, ohne die geringsten Schmerzensäusserungen in dieser Lage.

Nach einer Stunde, während welcher Zeit sich in den Erscheinungen nichts geändert hat, wird der Hund mittelst Chloroformnarcose getödtet.

Sectionsbefund. Herz: Der rechte Ventrikel mässig gebläht, entleert beim Einschneiden reichlich grossblasig schaumiges Blut; im linken Ventrikel schaumiges Blut; die Coronararterien enthalten kleine Gasindices, in den Coronarvenen einzelne Gasblasen, auch in den Vorhöfen, mehr im rechten, Blut mit Gasblasen gemischt.

Lungen mässig blutreich, einzelne grössere und kleinere dunkelrothe Hämorrhagien in denselben; in ihren grösseren Gefässen da und dort Gasblasen zu schel.. Ecchymosen am Zwerchfell. In den grossen Venenstämmen 


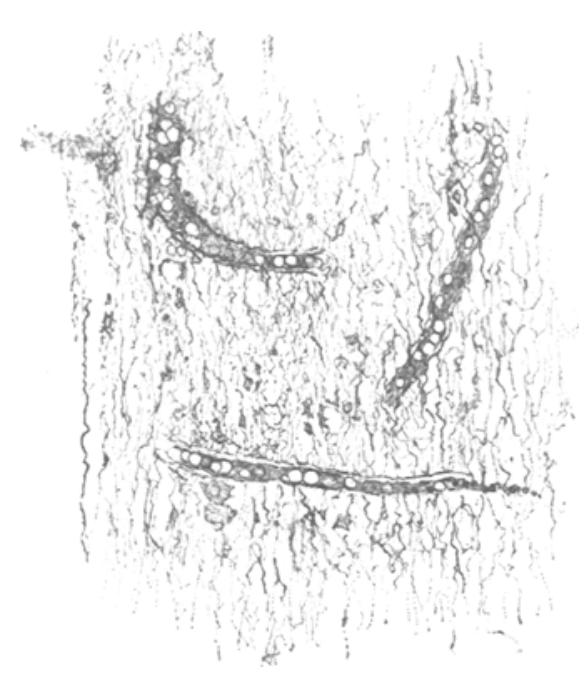

Fig. 11. Bei starker Vergrösserung Lä ng sschnitt aus dem Rückenmark eines $11 / 2$ Stunden nacb der Decompression verstorbenen Hundes. (Härtung in Müller'scher Flüssigkeit, Färbung mit Rubin.) Blasenförmige Hohlräume im Inbalt der Gefässe. grössere und kleinere Gasblasen in der Blutsäule schwimmend; auch in den Körperar. terien da und dort Gasblasen im Gefässlumen. Eingeweide blass, nicht hyperämisch; in den Mesenterialgetässen luftführender Inhalt; Därme nicht gebläht.

Gehirn sowie Rückenmark werden in toto $\mathrm{zu}$ späterer mikroscopischer Untersuchung herauspräparirt und in Müller'sche Flüssigkeit eingelegt. Die mikroscopische Untersuchung des gehärteten Rückenmarkes lässt blasenartige Hohlräume im Inhalt der Gefässe nachweisen, Gerinnungsfiguren, die wir als durch das Vorhandensein von Gasblasen im Blute bedingt ansehen müssen ${ }^{1}$ ). (Fig. 11.)

Versueh 56.

Hund Nr. VII.

\begin{tabular}{|c|c|c|c|c|c|}
\hline Z. & $\begin{array}{c}\text { Dr. i. } \\
\text { A. }\end{array}$ & A. T. & Sch T. & $\begin{array}{l}\text { Sch. } \\
\mathrm{Hg} .\end{array}$ & Bar. Hg. \\
\hline $\begin{array}{rr}9 \mathrm{~h} & 20^{\prime} \\
9 & 21^{\prime} \\
9 & 30^{\circ} \\
10 & 15^{\prime} \\
10 & 16^{\prime}\end{array}$ & $\begin{array}{l}0 \\
3,5 \\
4,5 \\
4,5 \\
0\end{array}$ & +20 & $\begin{array}{c}+10 \\
\max \\
+10^{\circ} \\
\min . \\
0^{\circ}\end{array}$ & $\begin{array}{l}83 \% \\
95 n \\
85 "\end{array}$ & $765 \mathrm{~mm} 57 \%$ \\
\hline
\end{tabular}

Nach dem Ausschleusen beginnt der Hund beim Laufen zu schwanken, der rechte Hinterfuss wird zeitweise nachgeschleppt, beginnende Lähmung des Beines. Die Lähmung ist keine complette, es besteht nur Steifheit der Hinterbeine. Nach 10 Minuten bleibt er mit gespreizten hinteren Extremitäten stehen. Es bestehen keine Blasen-, keine Mastdarmstörungen.' Nach 18 Minuten vorübergehende Besserung, der jedoch nach mehreren Minuten nunmehr

1) Die Differentialdiagnose derselben gegenüber äbnlichen seltenen Befunden bei anderen Umständen wird uns noch ausführlich beschäftigen, ebenso wie wir in einer weiteren Untersuchung den Gerinnungsformen des Blutes nach verschiedenen Todesarten unsere Aufmerksamkeit schenken. 
eine complette Lähmung des rechten sowie eine Parese des linken Hinterbeines folgt. Der Gang des Thieres ist jetzt schwankend; während es zu laufen sucht, stolpert es mit den Hinterbeinen über jedes Hinderniss, zieht dieselben einige Schritte lang nach, schwankt und stürst mitunter nieder. Das Thier frisst und trinkt nach Gewohnheit.

Krankheitsverla uf. 2. Tag: Die Lähmung besteht unverändert fort. Das Thier vermag nicht mehr über die nur etwas erhöhte Schwelle des Stalles zu gelangen; es frisst und trinkt auch nicht mehr.

Am 5. Tag keine Besserung der Lähmungserscheinungen, das Thier scheint bedeutend abgemagert. Es liegt schwer krank da; seine Temperatur ist erhöht, die Athmung frequent and dyspnoisch.

In der Nacht vom 6. auf den 7. Tag stirbt der Hund.

Se ctions bef und. Pneumonie im rechten Mittel- und Unterlappen; die hepatisirten Hurde betreffen Stellen älterer Hämorrhagien, die sich auch noch über die infiltrirten Parthien hinas erstrecken. Linkerseits an den Lungenlappen, besonders in ihren vorderen Antheilen, Hämorrhagien und pneumonische Herde.

In der Blase ca. $50 \mathrm{~cm}^{3}$ gelblichen, trüben, nicht übelriechenden Harnes. Ihre Schleimhant leicht injicirt. Die linke Niere im Vergleich zur rechten dunkler blauroth. Leber dunkel schwarzbraun, mässig blutreich. An den übrigen Organen nichts Abnormes. Befund von Rückenmark und Gehirn folgt in anderem Zusammenhang.

\section{Versuch 57. \\ H und Nr. II.}

Das Thier ist vollkommen gesund.

\begin{tabular}{|c|c|c|c|c|c|}
\hline Z. & $\begin{array}{c}\text { Dr. i. } \\
\text { A. }\end{array}$ & A. T. & Sch. T. & $\begin{array}{l}\text { Sch. } \\
\mathrm{Hg} \text {. }\end{array}$ & Bar. \\
\hline $\begin{array}{ll}10 \mathrm{~h} & 25^{\prime} \\
10 & 28^{\prime} \\
10 & 32^{\prime} \\
10 & 35^{\prime} \\
10 & 48^{\prime} \\
10 & 49^{\prime} \\
11 & 35^{\prime} \\
11 & 56^{\prime}\end{array}$ & $\begin{array}{l}0 \\
0,5 \\
3,0 \\
4,7 \\
4,5 \\
4,7 \\
4,7 \\
0\end{array}$ & $-1^{0}$ & $\begin{array}{r} \\
+160 \\
+150 \\
+60\end{array}$ & $\begin{array}{c}73 \% \\
80 \% \\
90 " \\
90 "\end{array}$ & $765 \mathrm{~mm}$ \\
\hline
\end{tabular}

Als der Druck 2 Atm. erreicht hatte, winselte das Thier im Apparat. Bei $4,5 \mathrm{Atm}$. hustet und bellt es.

5 Min. nach dem Ausschleusen beginnt der Hund das rechte Hinterbein aufzuziehen; gleich darauf steht er mit krampfhaft gestreckten Hinterbeinen da und stürzt plötzlich nieder. Beide hinteren Extremitäten in Streckstellung in allen Gelenken, unbeweglich. ITrin fiesst unwillkürlich ab. Er rutscht hierauf mit Hülfe der Vorderbeine auf dem Boden umher, ohne 
irgendwelche Schmerzensäusserungen zu zeigen. Beide Beine sind vollkommen anästhetisch. Nach 20 Minuten verschwindet der spastische Zustand, die Lähmung an den IIinterbeinen ist nummehr eine complete, die Reflexe sind gesteigert. Bei Bewegungsversuchen tritt sofort wieder Spasmus ein, um von nun ab constant zu bleiben. Dargebotene Speisen frisst das Thier gierig und trinkt viel Wasser, es zeigt dabei keine Beschwerden. 12 Uhr. Das Thier liegt ruhig ohne Zeichen von Unbehagen. Stuhl geht spontan ab.

$\mathrm{K} \mathbf{r}$ ankheitsverla uf. $2 \mathrm{~h} 40^{\circ} \mathrm{Nachm}$. winselt das Thier und giebt Schmerzensäusserungen von sich.

Um 3 h Nachm. liegt es vollkommen ruhig da und frisst nach Gewohnheit, Stuhl und Urin gehen unwillkürlich ab. Die Hinterpfoten fühlen sich wärmer an als die Vorderpfoten, Temp. $38,8^{\circ} \mathrm{C}$.

Am 6. Tage ist der Zustand des Thieres der gleiche. Es scheint keinerlei Schmerz zu haben, frisst nach Gewohnheit. Temp. 38,50.

Am 12. Tage Status idem Die Muskulatur am Gesässe scheint geschwunden, die Dornfortsätze treten im Lendenantheil scharf hervor, ebeuso die Beckenknochen. Die Prüfung mit dem electrischen Strom gicbt keine sicheren Resultate. Stuhl und Urin gehen unwillkürlich ab.

Da das Thier nicht ruhig liegt, so tritt am 16. Tage starkes Ekzem am Hintertheile und beginnender Decubitus auf, der dem Thiere heftige Schmerzen verursacht. $9 \mathrm{~h} 45^{\prime}$ Morg. wird der Hund durch Chloroform getödtet.

Se ction 10 Uhr Abends. - An den inneren Organen keine auffallenden Veränderungen. Gehirn und Rückenmark werden in toto herausgenommen. - Die Untersuchung ergiebt: multiple herdweise Nekrosen der grauen und weissen Substanz des Rückenmarks.

Versuch 58.

Hund Nr. III (Männchen, 4,5 Kilo).

Das Thier befand sich vor dem Experimente im ärztlichen Inspectionszimmer $+19^{\circ} \mathrm{C}$.

\begin{tabular}{|c|c|c|c|c|c|}
\hline Z. & $\begin{array}{c}\text { Dr. i. } \\
\text { A. }\end{array}$ & A. $\mathrm{T}$. & Son. T. & $\begin{array}{l}\text { Soh. } \\
\text { Hg. }\end{array}$ & Bar. Hg. \\
\hline $\begin{array}{cc}10 \mathrm{~h} & 25^{\prime} \\
10 & 28^{\prime} \\
10 & 32^{\prime} \\
10 & 35^{\prime} \\
10 & 48^{\prime} \\
10 & 49^{\prime} \\
11 & 35^{\prime} \\
11 & 3 x^{\prime}\end{array}$ & $\begin{array}{l}0 \\
0,5 \\
3,0 \\
4,7 \\
4,5 \\
4.7 \\
4,7 \\
0\end{array}$ & $-1^{0}$ & $\begin{array}{l}+9^{\circ} \\
+16^{\circ} \\
+17^{\circ} \\
+16^{\circ} \\
+15^{0} \\
+60\end{array}$ & $\begin{array}{l}90 \\
90\end{array}$ & $765 \mathrm{~mm} 73 \%$ \\
\hline
\end{tabular}

Während des maximalen Ueberdruckes wurde von Zeit zu Zeit Luft abgelassen und durch frische in der Weise ersetzt, dass der Druck in der Kammer nicht unter $4,5 \mathrm{Itm}$. während des Zu- und Abströmens sank. 
Nach dem Ausschleusen wird das Thier ins Freie gelassen. Es springt vollkommen wohl herum (Schneefall $-1 \%$. Nach 5 Minuten wird es ins ärztliche Zimmer gebracht, woselbst der Hund durch 15 Minuten keine Erscheinungen zeigt. Ganz plötzlich jedoch stürzt das Thier dann nieder und es treten Streckkrämpfe in den Hinterbeinen auf. Die hinteren Extremitäten werden steif nachgeschleift. Nach weiteren 10 Minuten fällt das Thier völlig um, es treten auch tonische Krämpfe in den vorderen Extremitäten ein. (Fig. 12.) Athmung oberflächlich, Herzaction unregelmässig, sehr frequent. Das Thier scheint sterbend.

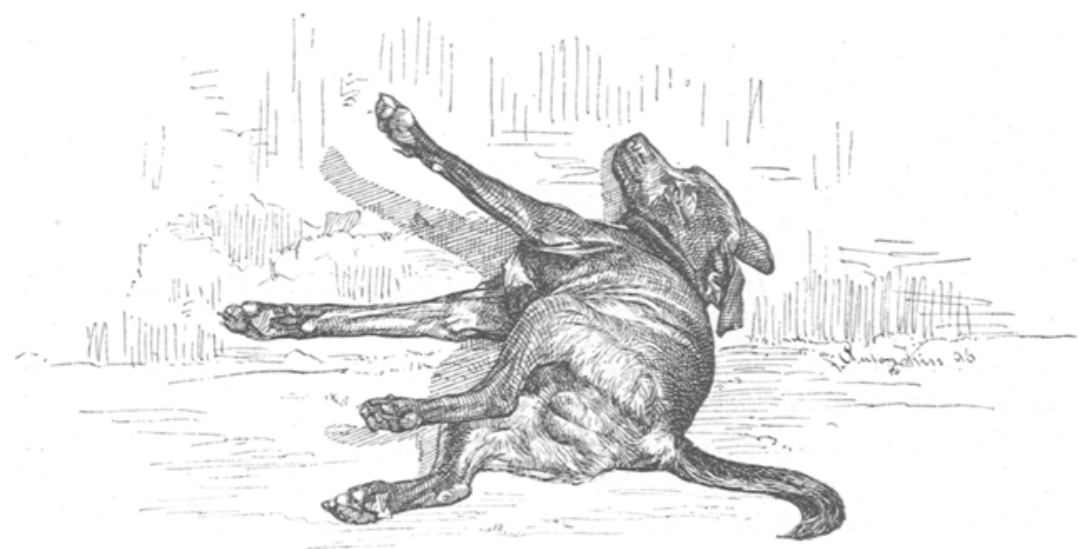

Fig. 12. Nach einer Momentaufnahme vom Versuchsthiere Nr. III Lähmung des Hinterthieres, Streckkrämpfe in den vorderen Extremitäten.

Nach weiteren $15 \mathrm{Min}$. erholt es sich, bewegt die vorderen Extremitäten, fällt jedoch gleich wieder um und verharrt in liegender Stellung. Die Atbmung und die Herzthätigkeit bessern sich. - Das Thier nimmt weder Nahrung noch Wasser zu sich; Temperatur an den Hinterpfoten angleich. Um 12 Uhr liegt es ruhig ohne Zeichen von Schmerzen am Boden.

$\mathrm{Kr}$ a $\mathrm{nk}$ hitsverla uf. $12 \mathrm{~h} 25^{\circ}$ lassen die Streckkrämpfe an den vorderen Extremitäten nach, $12 \mathrm{~h} \mathrm{40}$. Würgen mit folgendem Erbrechen. $12 \mathrm{~h} 55^{\circ}$ kurzes stossweises Athmen und Zuckungen am ganzen Leibe. $1 \mathrm{~h} 25^{\prime}$ haben sich die Lähmungserscheinungen an den vorderen Extremitäten soweit gebessert, dass der Hund sich aufrichtet. Die Steifheit der Hinterbeine schwindet temporär. Von $2 \mathrm{~h} 45^{\prime}$ liegt das Thier wieder mit vollkommen gelähmten Hinterbeinen ruhig ohne Zeichen von Schmerz da. Stuhl and Urin gehen unwillkürlich ab. Die Sensibilität in den hinteren Extremitäten geschwunden, Reflexe erloschen; die Temperatur an den Hinterpfoten erscheint gegen die an den Vorderpfoten erböht. Das Thier frisst und trinkt wie gewöhnlich.

Am 6. Tage Statut idem. Temp. 38,50.

Am 13. Tage scheint die Muskulatur der Lendengegend abgemagert, 
Die Dornfortsätze treten scharf hervor. Die linke vordere Extremität scheint schwächer, so dass er sich auf das rechte Vorderbein stützt,

Am 17. Tage Status idem. Der Fund liegt rubig da, frisst und trinkt wie gewöhnlich. Kein Ekzem.

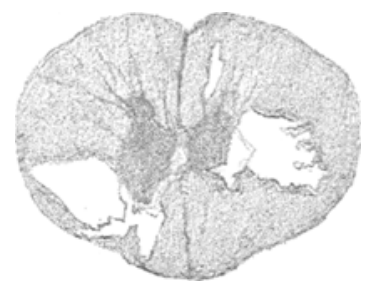

Skizze, bei schwacher Vergrösserung.

Sehnitt durch das untere Dorsalmark des rasch von 4,5 Atmosphären Ueberdruck decomprimirten Hundes, Abgrenzung der nekrotischen Herde durch beginnende reaktive Gliawucherung.

Nach 34 Tagen tritt starkes Ekzem und Decubitus am Hinterthiere auf. Am selben Tage $6 \mathrm{Uhr}$ Abends, also nach fast 5 Wochen, stirbt der Hund.

Sectionsbefund: Ausgebreiteter Decubitus im Bereich des Gesässes und beider Oberschenkel.

Am Gehirn makroscopisch keine Veränderung erkennbar; das Rückenmark zeigt im unteren Abschnitt des Dorsalmarkes eine bläulich durchscheinende Farbe. Behufs mikroscopischer Untersuchung werden beide Organe in Müller'scbe Flüssigkeit conservirt. Befund: Multiple heerdweise Necrosen mit consecutiver Höhlenbildung.

An den Lungen einzelne alte Hämorrhagien; am Herzen keine Veränderungen. Därme normal; Incontinentia alvi et urinae nachweisbar; Blase leer; ihre Schleimhaut verdickt, gewulstet und geröthet.

Das wichtigste Ergebniss dieser vier Versuche sind die mehr minder rasch nach der Decompression aufgetretenen bleibenden Lähmungserscheinungen. Unser diesbezügliches Material ist damit keineswegs erschöpft, indem Fälle mit nervösen Störunge $n$, deren Verlauf durch längere Zeit beobachtet werden konnte, auch in der Versuchsreihe $\mathrm{V}$ uiber die Wirkung der "Recompression" enthalten sind, die man Ergänzung der mitgetheilten Experimente vergleiche.

Die Lähmungserscheinungen waren in den Versuchen 55,56 , 57 complete Paraplegien des Hinterthieres mit Blasen-Mastdarmstörungen; nur in Versuch 58 trat auch vorübergehende Paraplegie der Vorderbeine auf. Auch hier ist wieder der Umstand bervorzuheben, dass die Symptome erst nach einer längeren Pause, 5 bis 20 Minuten nach dem Aussehleusen, und dann meist plötzlich ein- 
setzen. Nach dem letzten Experiment traten anfallsweise asphyctische Erscheinungen auf. Der Hund vom Versuch 56 starb an einer intercurrenten croupösen Pneumonie, die übrigen Thiere wurden nach verschieden langer Zeit getödtet, ohne dass sich im Symptomenbilde eine Besserung gezeigt bätte. Bei den Versuchsthieren II und III trat im Laufe der Erkrankung Decubitus auf. Bei dem eine Stunde nach der Laesion getödteten Hunde, konnten freie Blutgase im ganzen Gefässsystem nachgewiesen werden. Bezüglich des pathologisch anatomischen Befundes im Ruickenmark sei hier nur kurz hervorgehoben, dass disseminirte Nekrose mit subsequenter Höhlenbildung bei den Thieren die Wochen gelebt hatten, festgestellt werden konnte. Ein genanes Eingehen auf diese Verbältnisse wird Gegenstand weiterer Mittheilungen sein.

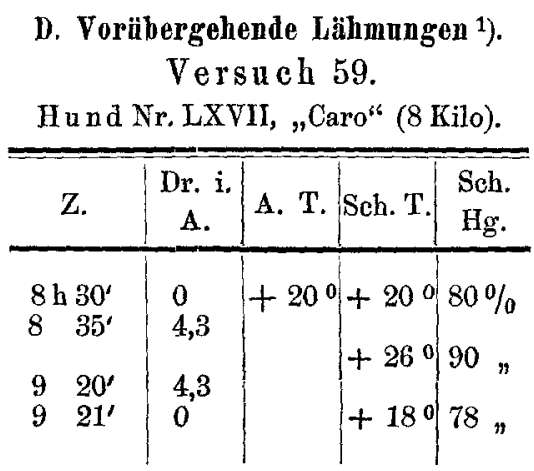

Der Hund verlässt die Schleuse ganz wohl und läuft herum. Nach circa 5 Min. fängt er laut zu heulen an und zieht das linke Hinterbein auf; er beisst sich in dasselbe. In der Folge keine weiteren Erscheinungen. Das Thier wird später neuerdings zo Versuchen verwendet.

\section{Versuch 60.}

H u n d Nr. VII, ,Mops““ (Männchen, 6 Kilo).

\begin{tabular}{|c|c|c|c|c|c|}
\hline Z. & $\begin{array}{c}\text { Dr. i. } \\
\text { A. }\end{array}$ & A. T. & Sch. T. & $\begin{array}{l}\text { Sch. } \\
\text { Hg. }\end{array}$ & Bar. Hg. \\
\hline $\begin{array}{ll}10 & \mathrm{~h} 4^{\prime} \\
10 & 8^{\prime} \\
10 & 10^{\prime} \\
10 & 39^{\prime} \\
10 & 40^{\prime}\end{array}$ & $\begin{array}{l}0 \\
2,5 \\
4,5 \\
4,5 \\
0\end{array}$ & +30 & $\begin{array}{r}+90 \\
+150 \\
+130 \\
+\quad 80\end{array}$ & $\begin{array}{l}76 \% \\
90 \% \\
85 \%\end{array}$ & $764 \mathrm{~mm} 76 \%$ \\
\hline
\end{tabular}

1) Vergleiche auch hierzu den Abschnitt $V$, „Re compression mit den daselbst geschilderten Lähmungserscheinungen. 
68 Richard Heller, Wilhelm Mager, Hermann von Schrötter:

Bei einem Drucke von 4,2 wiuselt der Hund und bellt laut.

$10 \mathrm{~h} 40^{\circ}$ ausgeschleust tritt nach $10 \mathrm{Min}$. eine Parese des linken Hinterfusses auf. Der Hund legt sich nieder und macht den Eindruck, als ob er Schmerzen empfinden würde.

$11 \mathrm{~h} 3^{\prime}$ steht er wieder auf, kratzt sich mit dem rechten Hinterfusse. Von da $a b$ schwinden die Erscheinungen; $2 \mathrm{~h} \mathrm{Nachm.} \mathrm{ist} \mathrm{er} \mathrm{gesund.}$

\section{Versuch 61.}

Hund Nr. VII.

\begin{tabular}{|c|c|c|c|c|c|}
\hline $\mathrm{Z}$. & $\begin{array}{c}\text { Dr. i. } \\
\text { A. }\end{array}$ & A. ' . & Sch. T. & $\begin{array}{l}\text { Sch } \\
\mathrm{Hg} .\end{array}$ & Bar. Hg. \\
\hline $\begin{array}{cc}10 h \\
10 & 6^{\prime} \\
10 & 8^{\prime} \\
11 & \\
11 & 1^{4}\end{array}$ & $\begin{array}{l}0 \\
2,0 \\
4,5 \\
4,5 \\
0\end{array}$ & $-4^{0}$ & $\begin{array}{l}+20 \\
+70 \\
+110 \\
+90 \\
+\quad 40\end{array}$ & $\begin{array}{l}70 \% \\
90 \% \\
92 \% \\
91 \% \\
80 \%\end{array}$ & $761 \mathrm{~mm} 65 \%$ \\
\hline
\end{tabular}

Nach dem Ausschleusen in das ärztliche Inspectionszimmer gebracht, stellen sich nach 10 Minuten leichte paretische Erscheinungen ein:

Steifheit des linken Hinterbeines alterirend mit Beugekrämpfen desselben. Der Hund schleift durch einige Sekunden die Hinterbeine nach; er vermag nicht auf den Sessel zu springen.

Die Erscheinungen sind bis 12 Uhr Mittags vollkommen znrückgegangen. Sein weiteres Schicksal s. Versuch 56.

\section{Versuch 62.}

Hund Nr. XVIII, „Müller" (Männchen, 5 Kilo).

\begin{tabular}{cc|c|c|c|c|c}
\hline Z. & $\begin{array}{c}\text { Dr. i. } \\
\text { A. }\end{array}$ & A. T. & Sch. T. & $\begin{array}{c}\text { Sch. } \\
\text { Hg. }\end{array}$ & Bar. Hg. \\
\hline $10 \mathrm{~h}$ & 0 & +10 & +10 & $740 \%$ & $748 \mathrm{~mm} 74 \%$ \\
10 & 5 & 4,5 & & +120 & $80 \%$ & \\
10 & $45^{\prime}$ & 4,5 & & & & \\
10 & $46^{\prime}$ & 0 & & +10 & $74 \%$ &
\end{tabular}

Einige Minuten nach dem Ausschleusen treten paretische Symptome von Seiten der Hinterbeinen auf. Der Hund hält das linke Hinterbein in starrer Beugestellung, winselt laut und beisst sich mehrmals in dasselbe. Nach einer Viertelstunde beruhigt sich das Thier, geringe Schwäche des linken Hinterbeines; im Verlaufe von 3 Stunden schwinden die Erscheinungen vollkommen. Das Thier ist nachmittags vollkommen wieder hergestellt. 
Versuch 63.

$\mathrm{H}$ und Nr. IX.

\begin{tabular}{rr|c|c|c|c|c}
\hline Z. & $\begin{array}{c}\text { Dr. i. } \\
\text { A. }\end{array}$ & A. T. & Sch. T. & $\begin{array}{c}\text { Sch. } \\
\text { Hg. }\end{array}$ & Bar. Hg. \\
\hline $9 \mathrm{~h} 34^{\prime}$ & 0 & $-5^{\circ}$ & -2 & 0 & $80 \%$ & $765 \mathrm{~mm} 80 \%$ \\
9 & $45^{\prime}$ & 2,0 & & $\max$. & & \\
9 & $47^{\prime}$ & 3,0 & & +10 & 90 & \\
9 & $50^{\prime}$ & 4,5 & & $\min$. & $94 \%$ & \\
10 & $45^{\prime}$ & 4,5 & & +1 & 0 & \\
10 & $46^{\prime}$ & 0 & & & $85 \%$
\end{tabular}

8 Minuten nach dem Ausschleusen treten vorübergehend paretische Erscheinungen, Steifheit der Hinterbeine, sowie leichte Dyspnoë auf. Der Hund befindet sich jedoch nach einer halben Stunde wieder vollkommen wohl.

Versuch 64.

Hund Nr. XII, "Feher" (9 Kilo).

\begin{tabular}{|c|c|c|c|c|c|}
\hline$Z$. & $\begin{array}{c}\text { Dr. i. } \\
\text { A. }\end{array}$ & A. T. & Sch. T. & $\begin{array}{l}\text { Sch. } \\
\mathrm{Hg} .\end{array}$ & Bar. Hg. \\
\hline 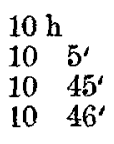 & $\begin{array}{l}0 \\
4,5 \\
4,5 \\
0\end{array}$ & +1 & $\begin{array}{l}+10 \\
+120 \\
+10\end{array}$ & $\begin{array}{l}74 \% \\
80 \% \\
74\end{array}$ & $748 \mathrm{~mm} 74 \%$ \\
\hline
\end{tabular}

15 Minuten nach der Decompression treten tonische Streckkrämpfe in beiden Hinterbeinen auf, die besonders in der ersten halben Stunde bäufig sinä, das Thier vermag sich nicht zu setzen; Gehen ist erst nach einer Stunde mit Mühe möglich. Im Laufe des Nachmittags schwinden die Erscheinungen vollkommen.

\section{Versuch 65.}

H u nd Nr. IV, „Muri" (Männchen. 6 Kilo).

Der Hund wurde vor dem Experiment gefüttert und befand sioh im ärztlichen Inspectionszimmer bei $19^{\circ} \mathrm{C}$.

\begin{tabular}{|c|c|c|c|c|c|}
\hline $\mathrm{Z}$. & $\begin{array}{c}\text { Dr. i. } \\
\text { A. }\end{array}$ & A. T. & Sch. T. & $\begin{array}{l}\text { Sch. } \\
\text { Hg. }\end{array}$ & Bar. Hg. \\
\hline $10 \mathrm{~h} 25$ & 0 & $-1^{0}$ & +90 & $73 \%$ & $763 \mathrm{~mm} 73 \%$ \\
\hline 1028 & 0,5 & & $+16^{\circ}$ & & \\
\hline $10 \quad 32$ & 3,0 & & $1+170$ & 90 n & \\
\hline $10 \quad 35$ & 4,7 & & & & \\
\hline $1048^{\prime}$ & 4,5 & & & & \\
\hline $10 \quad 49^{\prime}$ & 4,7 & & $+16^{0}$ & & \\
\hline $1135^{\circ}$ & 4,7 & & $+15^{0}$ & & \\
\hline $1136^{\circ}$ & 0 & & $+6^{0}$ & 90 n & \\
\hline
\end{tabular}


20 Minuten nach dem Ausschleusen zieht das Thier das rechte Hinterbein auf und winselt. Nach weiteren 10 Minuten treten vorübergehend Streckkrämpfe in den hinteren Extremitäten auf. Gerufen kommt er mühsam herbei, indem er die Bewegung der Hinterbeine nicht coordiniren kann.

$11 \mathrm{~h} 45^{\prime}$ legt er sich nieder und winselt laut, die hinteren Extremitäten sind steif und anästhetisch.

$12 \mathrm{~h}$ Status idem. Der Hund winselt unaufhörlich.

$1 \mathrm{~h} 3^{\prime}$ steht das Thier auf, dreht sich mehrmals um seine Achse, legt sich hierauf wieder nieder; Steifheit besteht an den Finterbeinen in geringem Grade weiter.

$1 \mathrm{~h} 10^{\prime}$ steht das Thier auf, befindet sich vollkommen wohl, läuft herum; das linke Hinterbein ist etwas schwächer. Der Urin geht während des Herumlaufens unwillkürlich ab.

Am nächsten Tage ist das Thier, bis auf eine geringe Schwäche im linken Hinterbein, - der Hund kann nicht auf den Stuhl springen -, wieder . hergestellt; Harnentleerung normal. Nach zwölf Tagen alle Symptome vollständig geschwonden.

Versueh 66.

H u n d Nr. X, (Männchen, 6 Kilo).

\begin{tabular}{|c|c|c|c|c|c|}
\hline $\mathrm{Z}$. & $\begin{array}{c}\text { Dr. i. } \\
\text { A. }\end{array}$ & A. $\mathrm{T}$. & Sch. T. & $\begin{array}{l}\text { Sch. } \\
\text { Hg. }\end{array}$ & Bar. Hg. \\
\hline 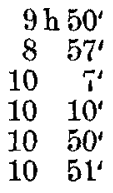 & $\begin{array}{l}0 \\
2 \\
4,5 \\
4,7 \\
4,5 \\
0\end{array}$ & $-5^{0}$ & $\begin{array}{r}+3^{0} \\
+12^{0} \\
+13^{0} \\
+\quad 9^{0}\end{array}$ & $\begin{array}{l}72 \% \\
96 \% \\
90 \%\end{array}$ & $768 \mathrm{~mm} 80 \%$ \\
\hline
\end{tabular}

5 Minuten nach der Decompression erbricht der Hund heftig. Nach 10 Minuten beginnende Lähmungserscheinungen am rechten Hinterbein, kurze Zeit darauf auch am linken. Die Beine werden mühsam nachgeschleppt. Der Hund legt sich nieder und verharrt bis $12 \mathrm{Chr}$ in dieser Stellung. Im Laufe des Tages schwinden die Symptome, Tags darauf ist das Thier vollkommen gesund.

\section{Versuch 67.}

Hund Nr. IV.

Das Thier befindet sich vollkommen wohl. Nebeliges Wetter. 


\begin{tabular}{|c|c|c|c|c|c|}
\hline $\mathrm{Z}$. & $\begin{array}{c}\text { Dr. i. } \\
\text { A. }\end{array}$ & A. T. & Sch. T. & $\begin{array}{l}\text { Sch. } \\
\text { Hg. }\end{array}$ & Bar. Hg. \\
\hline $\begin{array}{rr}9 \mathrm{~h} & 50^{\prime} \\
9 & 55^{\prime} \\
10 & 3^{\prime} \\
10 & 5^{\prime} \\
10 & 20^{\prime} \\
10 & 40^{\prime} \\
11 & 20^{\prime} \\
11 & 21^{\prime}\end{array}$ & $\begin{array}{l}0 \\
3,5 \\
4,5 \\
4,7 \\
4,6 \\
4,5 \\
4,5 \\
0\end{array}$ & $+2,50$ & $\begin{array}{l}+7,5^{0} \\
+11,0^{0} \\
+13,5^{0} \\
+150\end{array}$ & $\begin{array}{l}80 \% \\
90 \% \\
96 \% \\
80 \%\end{array}$ & $767 \mathrm{~mm} 73 \%$ \\
\hline
\end{tabular}

10 Minuten nach dem Ausschleusen tritt Contractur des linken Hinterbeines mit gleichzeitigem Streckkrampf des rechten auf; nach weiteren $5 \mathrm{Mi}$ nuten winselt das Thier laut, setzt sich mühsam nieder, steht jedoch gleich wieder auf. Die Contractur bleibt bis 1 Uhr bestehen.

Um 2 Ubr ist das Thier wieder vollkommen normal.

Allen den in der Versuchsreihe 59-67 inclusive beschriebenen Erscheinungen von Seiten des Rückenmarkes ist die relativ kurze Dauer gemeinsam, nach welcher eine vollständige Wiederherstellung der gestörten Functionen eintrat, nach der im Beginne an sich schwere Symptome wieder schwandea.

In den Versuchen 59,60,62 und 67 waren nur je eine und zwar eine hintere Extremität, in allen Fällen das linke Hinterbein befallen; in den übrigen Versuchen trat unter wechselnden Bildern und in verschiedener Reihenfolge der paraplegische Typus deutlich hervor; im Experiment 63 waren die paretisehen Erscheinungen der Hinterbeine von Dyspnoe begleitet.

Am schwersten war der Hund IV befallen, indem die Symptome bei diesem erst am nächsten Tage geschwunden waren, am raschesten hatten sie sich bei den Thieren LXVII and IX zuriickgebildet.

Auf die Reihenfolge sowie das Eintreten und die Häufigkeit der einzelnen Symptome werden wir mit Berücksichtigung des Abschnittes $\mathrm{C}$ nach Besprechung der Recompressions-Versuche noch einzugehen haben.

\section{E. Verbalten des Blutdruekes nach rascher Decompression.}

Nachdem wir nunmehr die direct $z$ u beobachtenden Erscheinungen nach der Decompression geschildert haben, wollen wir daran anschliessend einige Versuche über das Verhalten des Blutdruckes nach raschem Abfall des Barometerdruckes an- 
fügen, die überdies eine Ergänzung zu unseren anderweitig mitzutheilenden Experimenten über den Einfluss der Luftdruckänderung (Compression) auf den Blutdruck unter physiologischen Bedingungen bilden.

Diese Versuche stellen uns, wie wir mit Sicherheit sagen können, Ụntersuchungen über den Blutdruck bei Vorhandensein von freien Gasen im Gefässsystem dar und dienen dazu, die Wirkung dieser letzteren auf die Herzthätigkeit zu studiren.

Aus äusseren Gründen war es uns leider nicht mebr möglich, diesbezüglich über ein reicheres Material zu verfügen; die folgenden Experimente schliessen sich jedoch enge an die von uns eben veröffentlichten Beobachtungen über die Effecte künstlicher $\mathrm{L} \mathrm{uft}$ e mbolie auf den Organismus an und werden durch die hierbei gewonnenen Erfahrungen erklärt.

Aus den schon im Capitel III besprochenen Gründen mussten wir uns auch hinsichtlich dieser Versuche in der experimentellen Technik einschränken und dieselbe vereinfachen. Wir konnten zu den Versuchen nicht das $L_{\text {u }} \mathbf{d}$ wi g'sche Manometer und Kymo. grapbion verwenden. Wir haben vielmehr das handliche und für unsere Experimente einzig brauchbare v. B a s ch'sche Sphygmamanometer verwendet; dasselbe kann sowohl unter dem herrsehenden Luftdruck als auch im Compressionsapparate unter Druckerhöhung ohne weiteres benutzt werden, indem mit dem ansteigenden Luftdruck der Blutdruck, gleichzeitig auch der Druck im Manometer und im Versuchsthier die entsprechende Zunahme erfährt, sodass der Stand des Zeigers am Messinstrument, welches man durch das Fenster des Apparates ganz gut beobachten kann, stets bloss den Blutdruckswerth anzeigt ${ }^{1}$ ).

1) Alle anderen Methoden wären complicirt gewesen und hätten erst die Herstellung eigens für diesen Zweck construirter Instrumente nothwendig gemacht.

Man hätte das erwähnte Rohr c an seinem inneren Ende mit der Arterie carotis des Versuchsthieres in Verbindung mit seinem äusseren Ende an ein sehr empfindliches Manometer anzuschalten gehabt, das neben einer Haupt. theilung in Atmosphären, bis 5 Atmosphären Ueberdruck, noch eine Theilung in je $10 \mathrm{zu} 10 \mathrm{~mm} \mathrm{Hg}$ hätte besitzen müssen, um nach hergestelltem Gleich: gewicht in der Kammer und im Instrument noch den von Herzen aufgebrachten Druck anzuzeigen.

Die Ludwig'sche Manometerröhre dementsprechend umzugestalten (zu verlängern) wäre wohl nicht gut möglich gewesen. 
Versuch 68.

Hund Nr. LIX.

Nach dem Einbinden der Canüle (Cocaïnanästhesie) beträgt der Blutdruck $95-110 \mathrm{~mm} \mathrm{Hg}$.

Compression in 4 Min., der Blutdruck am Ende derselben stationär geblieben; die pulsatorischen Schwankungen zwischen $95-105 \mathrm{~mm} \mathrm{Hg}$; nach $3 / 4$ stündigem Aufenthalt in der Schleuse bei 4,0 Atm. Druck sinkt der Blutdruck um ein Geringes und hält sich zwischen $90-100 \mathrm{~mm} \mathrm{Hg}$.

Decompression in 50Sec., der Blutdruck steigt am Ende derselben um ca. $10 \mathrm{~mm} \mathrm{Hg}$. und bleibt durch etwa 5 Minuten auf diesem Niveau. Nach dieser Zeit erfolgt unter mehreren starken, unregelmässigen Druckschwankungen ein rasches Ansteigen des Blutdruckes, frequente Herzaction, mehrere grosse, dann rasch aufeinanderfolgend kleine Pulse. Der Druck beträgt zu dieser Zeit $150 \mathrm{~mm} \mathrm{Hg}$; kurz darauf folgt ein Absinken des Druckes und derselbe schwankt in den nächsten Minuten zwischen 115 und $140 \mathrm{~mm} \mathrm{Hg}$; nach weiteren 3 Minuten, während welcher Zeit Steifigkeit an den Hinterbeinen des Thieres zu bemerken ist, gelangt der Blutdruck auf das Niveau von 110115; nach 10 Minuten zeigt das Manometer $100 \mathrm{~mm} \mathrm{Hg}$. Das Thier wird vom Brette genommen: Entfernung der Canüle; Ligatur der Carotis, geringes Nachschleppen der Hinterbeine, nach 1 Stunde hat sich der Hund wieder erholt; am nächsten Tage befindet er sich wohl.

\section{Versueh 69. \\ E $\mathrm{u}$ i $\mathrm{d} \mathrm{Nr}$. LXXI.}

Bei einem mittelgrossen Hund wird die rechte Art. femoralis mit dem v. Basch'schen Sphygmomanometer in Verbindung gebracht und ein Blutdruck von $140 \mathrm{~mm} \mathrm{Hg}$. gemessen; spec. Gewicht des BJates 1058. Der Hund wird hierauf auf 4,7 Atm. Ueberdruck eingeschleust und während des $3 / 4$ stündigen Verweilens ein Blutdruckswerth von $135-145 \mathrm{~mm} \mathrm{Hg}$, verzeichnet.

Decompression in 56 Sec. Das Thier befindet sich Anfangs wie vor dem Versuche; nach ca. 2 Minuten treten plötzlich klonische und tonische Streckkrämpfe an allen vier Extremitäten ein und fast gleichzeitig beobachtet man am Manometer ein Ansteigen des Blutdruckes gegen 180; in grossen Pulsen sinkt derselbe dann wieder rasch auf $150 \mathrm{~mm}$ und im weiteren Verlauf staffelweise immer mehr und mehr ab, sodass er Werthe von 70-80 erreicht; unregelmässige Druckschwankungen, frequente Herzaction, tiefe Athemzüge. Die Streckkrämpfe haben aufgehört; der Blutdruck sinkt mehr und mehr. Der Hund wird durch Chloroform getödtet.

Section: In den Arterien die Blutsäule stellenweise auf grössere und kleinere Strecken von Gasindices unterbrochen; ganz besonders ản den Arterien des Netzes ist dies deutlich zu sehen, aber auch die grossen Körper. arterien zeigen grossblasigen Inhalt; im gesammten Venensystem reichlich schaumiges Blut. Besonders die rechte Herzkammer von schaumigem 
Blutgasgemisch prall erfüllt; im linken Atrium grosse Gasblasen zwischen den Trabekeln; die linke Herzkammer nahezu contrahirt. Das specifische Gewicht der leichtesten Blutstropfen aus dem rechten Herzen beträgt 1040; das specifische Gewicht des Blutes aus dem linken Vorhof ist ebenfalls bedeutend geringer geworden und wird mit ca. 1042 bestimmt.

\section{Versue h 70 . \\ Hund Nr. LXX.}

Nach der unter Cocaïnanästhie vorgenommenen Operation liegt der Hund ruhig am Brette und verharrt in dieser Stellung, ohne Abwehrbewegungen zu machen, während der folgenden ca, $11 / 2$ Stunden andauernden Experimente.

Vor der Compression Blutdruck gemessen in der Arteria carotis sinistra $100-120 \mathrm{~mm} \mathrm{Hg}$.

Dauer der Compression 5 Min, vorübergehende Steigerung des Blutdruckes auf $130 \mathrm{~mm}$; während des Aufenthaltes in 4,5 Atm. durch 1/2 Stunde, ausser vorübergehender A mplitudenänderung in den pulsatorischen Schwankungen des Blutdruckes wie zum Beginn des Versuches $120 \mathrm{~mm} \mathrm{Hg}$; Decompressionszeit 15 Minuten, Ausschläge von 100 auf $130 \mathrm{~mm} \mathrm{Hg}$, soust keine Veränderung.

Nach 10 Minuten neuerliche Compression; Aufenthalt im Apparate durch 20 Minuten. Das gleiche Verhalten im Blutdruck wie nach dem ersten Einschleusen. Decompressionszeit 6 Minuten: Zunahme der pulsatorischen Schwankungen, geringe Steigerung des Blutdruckes auf $140 \mathrm{~mm} \mathrm{Hg.}$ (die Temperaturabnabme im Apparate beträgt $9^{\circ} \mathrm{C}$.); dann sinkt wieder der Druck auf $115 \mathrm{~mm}$; nach 10 Minuten neuerliche Compression auf $4,5 \mathrm{Atm}$. Nachdem das Thier über eine halbe Stunde im Apparate verweilt hat, Dec o mpression in 50 Secunden. Der Blutdruck steigt gegen das Ende dex Decompression auf $135 \mathrm{~mm} \mathrm{Hg}$, an und bleibt auf dieser Höhe unter wechselnden pulsatorischen Schwankungen; wenige Augenblicke hierauf folgt ein momentanes rapides Ansteigen auf $150 \mathrm{~mm} \mathrm{Hg.,} \mathrm{das} \mathrm{rasch} \mathrm{von} \mathrm{starkem}$ Druckabfall um etwa $70 \mathrm{~mm}$ gefolgt wird; das Thier beginnt schwer zu athmen und ist unruhig, Herzaction mit der aufgelegten Hand nur undeutlich fühlbar; eben nur angedeutete, pulsatorische Schwankungen.

Der Hund wird rasch wieder eing e s chle ust.

Durch das Fenster des Apparates kann man beobachten, dass das Thier sich wieder ruhig verhält; der Blutdruck, der unter den Stand von $90 \mathrm{~mm} \mathrm{Hg}$. gesunken war, beginnt nahezu gleichzeitig mit dem erreichten maximalen Luftdruck wieder anzusteigen, und nimmt, nach ca. zwei Minuten wieder abgelesen, einen Stand von 120-135 $\mathrm{mm} \mathrm{Hg}$. ein ; regelmässige, deutliche, langsame Pulse. Diesen Stand behält das Quecksilber im wesentlichen während des iber $1 / 2$ Stunde andauernden Verweilens unter dem Druck von 4,5 Atm. Der Hund wird hieranf langsam in 15 Minuten decomprimirt, und nach vollendetem Druckabfall durch Chlornform getödtet. 
Section: In den Mesenterialgefässen hie und da grössere und kleinere Gassäulchen erkennbar; sonst allenthalben normale Verbältnisse.

Wie wir dies in einem physiologischen Theil unserer zusammenfassenden Untersuchungen noch genau auseinandersetzen werden, hat es sich auch bei den drei hier abzuhandelnden Versuchen 68,69 und 70 gezeigt, dass der Blutdruck während der Compression und unter bedeutend erhöhtem Luftdruck (4,5 Atmosphären) $n a h e z u$ unverändert blieb, (das eine Thier wurde rasch hintereinander zweimal recomprimirt), hingegen ein Ansteigen des Blutdruckes wäbrend oder mehr minder rasch nach der Decompression erfolgte.

Im Versuche 68 trat eine Blutdrucksteigerung um circa $50 \mathrm{~mm}$ $\mathrm{Hg}$ nach dem Druckabfall unter gleichzeitigem Auftreten von Streckkrämpfen ein, eine nabezu gleich grosse Zunahme anch im Experimente 69.

Dieses Ansteigen des Blutdruckwerthes nach der Decompres. sion haben wir uns durch das Vorhandensein von freien Gasblasen im Gefässsystem zu erklären, durch welche für die Circulation Widerstände gesetzt werden, indem der Durchtritt des Blatluftgemisches insbesondere durch die engen Bahnen der Capillaren eine vermehrte Arbeitsleistung vor allem des linken Herzens beansprucht. Dass dieselbe nicht gleich nach der Decompression, sondern erst nach einigen Minuten besonders deutlich wird, bängt wahrscheinlich damit zusammen, dass es erst einiger Zeit bedarf, bis die im Beginne feinen Bläschen anwachsen, sich sammeln und dadurch erst die Fortbewegung des Blutes mehr and mehr erschweren. Diese Drucksteigerung war jedoch in beiden Versuchen in dem einzelnen Falle in verschieden kurzer Zeit von einem bedeutenden Absinken des Blutdruckes gefolgt.

Beim Hunde LIX, der am wenigsten durch die Decompression geschädigt wurde, erfolgte ein Abfall des Blutdruckes bis auf den Stand wie vor dem Versuche; das Thier, das Lähmungserscheinungen an den hinteren Extremitäten gezeigt hatte, erholt sich wieder, so dass wir uns bei Vergleichung dieses Experimentes mit den folgenden vorstellen müssen, dass die Elimination des freien Stickstoffes hier in günstiger Weise vor sich ging obne schwere Störung der Herzthätigkeit oder des vasomotorischen Centrums zu setzen, als deren Ausdruck ein weiteres Absinken des Blutdruckes hätte erfolgen mïssẹn. 
Dies trat im Versuche 69 ein; der Druck sank hier nach der voribergehenden Steigernng auf $180 \mathrm{~mm} \mathrm{Hg}$ um mehr als 100 $\mathrm{mm} \mathrm{Hg}$ und das Thier ging in kurzer Zeit an den Folgen der Luftembolie, beschleunigt durch die Chloroformnarkose, zu Grunde.

Die Section ergab auch das Vorhandensein von freiem Gas im ganzen Gefässsystem.

Das im Arterien- und Venensystem circulirende Gas schädigte hier in so eingreifender Weise die Herzthätigkeit, dass nach der vorübergehenden bedeutenden Steigerung des Blutdruckes rasch ein rapides Absinken desselben im grossen Kreislauf erfolgte, das wir uns in Uebereinstimmung mit den Angaben von Couty und $\mathrm{H}$ a $\mathfrak{u}$ e $\mathbf{r}$ als insbesondere durch die behinderte Speisung des linken Ventrikels mit der nothwendigen Blutfluissigkeit sowie anch durch die functionelle Schädigung des vasomotorischen Centrums bedingt vorstellen mïssen. Ebenso wie wir dies in dem gleich za besprechenden Experiment 70 anzunehmen haben, trat beim Versuchsthier 69 die Wirkung des Vorhandenseins von Luft im Arteriensystem zurïck gegenüber der rasch hervortretenden Störung im rechten Ventrikel gegeniber dem Moment der venösen Luftembolie mit ihren Folgen.

Bei dem Hund des' letzten Versuches dieser Reihe war die Blutdruckssteigerung gleich nach der zweiten Decompression nur eine geringe, es kam rasch darauf allerdings zu einer erheblicheren Druckzunahme anf $150 \mathrm{~mm} \mathrm{Hg}$, die aber sofort von einem schnellen Absinken des Druckes mit Verschwinden der pulsatorischen Schwankungen gefolgt war. Unter der zu dieser Zeit bewerkstelligten neuerlichen Compression hebt sich jedoch das gesunkene Blutdrucksniveau wieder und die Pulse werden wieder deutlich. Wie wir im Abschnitte $V$ des genaueren seben werden, wurde durch die Recompression eine Resorption der freien Blutgase bewirkt, mit deren Rückaufnahme ins Blut der Blutdruck wieder ansteigen und der Zustand des Thieres sich bessern musste.

\section{F. Keine Erseheinungen.}

Versuch 71.

Zwei Hunde Nr. LI und LVI.

Versuch in der Sanitätsschleuse.

Zwei mittelgrosse Hunde werden in 10 Minuten auf einen Ueberdruck von $1 \mathrm{Atm}$. comprimirt und über eine Stunde im Apparate belassen. Nach 
der in 5 Secunden erzielten Decompression springen beide Thiere vollständig munter aus der Schleuse heraus. Beide Thiere zeigen weder nach 5 Minuten, das eine auch in der Folgezeit keinerlei Erscheinungen ${ }^{1}$ ).

Die nach 10 Minuten vorgenommene $\mathrm{Se}$ et i on des einen durch Chloroform getödteten Thieres zeigt freie Gasblasen vereinzelt im System des rechten Herzens; Lunge von normalem Blutgehalt; im übrigen keinerlei pathologische Erscheinungen. Die Gehörorgane wurden bei diesen Experimenten nicht untersucht.

\section{Vers u oh 72 .}

H u n d LII.

Sanitätsschleuse.

Der Hund wird in 2 Minuten auf einen Druck von 1,2 Atm. comprimirt und eine Stunde lang im Apparate belassen. Das Thier läuft in der Kammer herum und befindet sich wohl. Nach der Decompression, die in 4 Secunden vollzogen ist, zeigt der Hund normales Verhalten und keinerlei Erkrankungssymptome. Auch in der folgenden Zeit tritt keine Aenderung im Befinden ein.

\section{Versueh 73.}

H u nd Nr. I (Männchen, 5 Kilo).

Dem Hunde wurden vor dem Einschleusen beide Ohren fest verstopft, um die Druckverhältnisse zwischen Mittelohr und äusserem Gehörgang zu verändern.

\begin{tabular}{|c|c|c|c|c|}
\hline Z. & $\begin{array}{c}\text { Dr. } i . \\
\text { A. }\end{array}$ & A. T. & Sch. T. & $\begin{array}{l}\text { Sch. } \\
\text { Hg. }\end{array}$ \\
\hline $\begin{array}{l}10 \mathrm{~h} \\
103^{\prime} \\
1133^{\prime} \\
1134^{\prime}\end{array}$ & $\begin{array}{l}0 \\
2,5 \\
2,5 \\
0\end{array}$ & $-1^{0}$ & $\begin{array}{r}+\quad 40 \\
+11^{0} \\
+\quad 6^{0} \\
+\quad 2^{0}\end{array}$ & $\begin{array}{l}80 \% \\
90 \% \\
95 \% \\
85 ”\end{array}$ \\
\hline
\end{tabular}

Bei steigendem Drucke schüttelt das Thier wiederholt den Kopf; im übrigen befindet es sich wohl.

Nach dem Ausschleusen keinerlei Krankheitserscheinungen.

\section{Versuch 74. \\ $\mathrm{H}$ u n d Nr. I.}

Das Thier ist vollkommen wohl.

1) Auch bei rascher Decompression von einem Ueberdruck von $0,5 \mathrm{Atm}$. und 0,8 Atm. zeigten Thiere keine Störungen des Allgemeinbefindens. 


\begin{tabular}{|c|c|c|c|c|c|}
\hline $\mathrm{Z}$. & $\begin{array}{c}\text { Dr. i. } \\
\text { A. }\end{array}$ & A. T. & Sch. T. & $\begin{array}{l}\text { Sch. } \\
\text { Hg. }\end{array}$ & Bar. Hg. \\
\hline $\begin{array}{rr}9 \mathrm{~h} \\
9 & 3^{\prime} \\
9 & 15^{\circ} \\
10 & 30^{\circ} \\
10 & 31^{\prime}\end{array}$ & $\begin{array}{l}0 \\
2,7 \\
2,7 \\
2,7 \\
0\end{array}$ & $-2^{0}$ & $\begin{array}{l}+1^{0} \\
+5^{0} \\
+9^{0} \\
+8^{0} \\
+6^{0}\end{array}$ & $\begin{array}{l}90 \% \\
90 \% \\
95 " \\
95 " \\
85 \%\end{array}$ & $742 \mathrm{~mm}$ \\
\hline
\end{tabular}

Während des Einschleusens winselt der Hund, scheint sich aber sonst vollkommen wohl $\mathrm{zu}$ befinden.

Während der Decompression läuft das Thier unruhig herum, schüttelt den Kopf; heftiges Zittern der Hinterbeine. Dichter Nebel während der Decompression, lässt ihn nicht weiter beobachten.

Der Hund wird herausgelassen. Starkes Zittern der Hinterbeine, sonst keine Erscheinungen; er befindet sich wohl.

\section{Versuch 75.}

Hund Nr. I.

$11 \mathrm{~h} \mathrm{40}$ abermals eingeschleust.

\begin{tabular}{|c|c|c|c|c|}
\hline Z. & $\begin{array}{c}\text { Dr. } \\
\text { A. }\end{array}$ & A. T. & Sch. T. & $\begin{array}{l}\text { Sch. } \\
\text { Hg. }\end{array}$ \\
\hline $\begin{array}{ll}11 \mathrm{~h} & 40^{\prime} \\
11 & 41^{\prime} \\
11 & 55^{\prime} \\
11 & 56^{\prime}\end{array}$ & $\begin{array}{l}0 \\
3,5 \\
3,5 \\
0\end{array}$ & $\begin{array}{c}0^{0} \\
-\end{array}$ & $\begin{array}{l}+6^{0} \\
+9^{0} \\
+9^{0} \\
+6^{0}\end{array}$ & $\begin{array}{l}85 \% \\
90 \% \\
85 "\end{array}$ \\
\hline
\end{tabular}

Der Hund duckt sich zusammen und winselt stark. Nach dem Einschleusen tritt abermals heftiges Zittern der Hinterbeine auf, der Hund hustet und schüttelt fort und fort den Kopf.

Auftreten von heftiger Diarrhöe, nach $1 / 2$ Stunde verlieren sich alle diese Erscheinungen, der Hund frisst gut und trinkt sehr grosse Mengen von Wasser.

\section{Versuch 76.}

Hund Nr. XXX.

\begin{tabular}{|c|c|c|c|c|}
\hline Z. & $\begin{array}{c}\text { Dr. i. } \\
\text { A. }\end{array}$ & A. T. & Sch. T. & $\begin{array}{l}\text { Sch. } \\
\text { Hg. }\end{array}$ \\
\hline 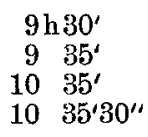 & $\begin{array}{l}0 \\
4,2 \\
4,2 \\
0\end{array}$ & $+18^{\circ}$ & $\begin{array}{l}+18^{0} \\
+25 \\
+18\end{array}$ & $\begin{array}{l}87 \% \\
90 \% \\
87 \%\end{array}$ \\
\hline
\end{tabular}

Das Thier bleibt nach dem Ausschleusen vollkommen gesund. 
Versuch 77.

Hund Nr. XVIII.

\begin{tabular}{|c|c|c|c|c|c|}
\hline Z. & $\begin{array}{c}\text { D. i. } \\
\text { A. }\end{array}$ & A. T. & Sch. T. & $\begin{array}{l}\text { Sch. } \\
\text { Hg. }\end{array}$ & Bar. Hg. \\
\hline 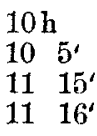 & $\begin{array}{l}0 \\
4,5 \\
4,5 \\
0\end{array}$ & $+13^{0}$ & $\begin{array}{l}-3^{0} \\
+17^{0} \\
+6^{0}\end{array}$ & $\begin{array}{l}86 \% \\
90 \% \\
86 \%\end{array}$ & $740 \mathrm{~mm} 86 \%$ \\
\hline
\end{tabular}

Das Thier zeigt nach dem Ausschleusen keinerlei Erscheinungen.

Die nach 20 Minuten vorgenommene S etion zeigt vereinzelte Gasblasen im System des rechten Herzens, insbesondere der Vena cava descendens; hie und $\mathrm{da}$ in den feineren Arterien des Mesenteriums Gasindices. Bei der mikroscopischen Untersuchung können in den präcapillaren Gefässen des Rückenmarkes sowie der Pia mater zahlreiche Gasbläschen nachgewiesen werden.

\section{Versuch 78. \\ H u n d Nr. LIII.}

Ein 6 Kilo schwerer Hund wird in 5 Minuten auf einen Druck von 3,5 Atm. comprimirt und 5 Minuten unter diesem Druck belassen; das Thier zeigt rasch, in ca. 1 Minute decomprimirt, keinerlei pathologische Erscheinungen; es läuft herum und befindet sich vollkommen wohl.

\section{Versueh 79. \\ H u n d Nr. LIII.}

Neuerliche Compression des Thieres am nächsten Tage auf einen Druck von $4 \mathrm{Atm}$.

Es wird 10 Minuten im Apparate belassen und nach dieser Zeit in $\mathbf{5 1}$ Secunden entschleust; nach Verlassen der Kammer zeigt das Thier keinerlei Krankheitserscheinungen.

Tödtung desselben nach 10 Minuten durch Chloroform.

S e c tion: Vereinzelte freie Gasblasen im Blute des rechten Herzens, Der übrige Befund ergibt normale Verhältnisse.

\section{Versuch 80.}

$2 \mathrm{H} \mathrm{unde} \mathrm{Nr.} \mathrm{LII} \mathrm{und} \mathrm{LIV.}$

Die Hunde, beide ca. 7 Kilo schwer, werden in 4 Minuten auf einen Druck von 4,5 Atm. comprimirt und verbleiben 10 Minuten im Apparat. Darnach werden sie in 1 Minute decomprimirt.

Sie zeigen keinerlei Erscheinungen und laufen munter in der Baracke herum.

Nach 10 Minuten wird das eine Thier (LIV) in Chloroformnarkose ge: tödtet. Die Section ergibt: 
Nirgends im Gefässsystem freie Gase. Lungen und Adominalorgane zeigen keinen abnormen Befund.

Das andere lebend gebliebene Thier bietot auch in der Folgezeit keinerlei Erkrankungssymptome dar.

\section{Versueh 81 . \\ Hund Nr. LV.}

Ein 5 Kilo schwerer Hund wird in 2 Minuten auf den Druck von 2,8 Atm. eingeschleust und 15 Minuten im Apparate belassen. Das Thier wird hierauf in 40 Secunden decomprimirt (Temperaturabfall während des Druckabfalles 90 C.) und zeigt keinerlei Erscheinungen.

Die nach 5 Minuten vorgenommene Section ergibt allenthalben normale Verhältnisse; freie Gasblasen in den Gefässen nirgends nachweisbar ${ }^{1}$ ).

Versuch 82.

Hund Nr. IV.

\begin{tabular}{|c|c|c|c|c|c|}
\hline Z. & $\begin{array}{c}\text { Dr. i. } \\
\text { A. }\end{array}$ & A. T. & Sch. T. & $\begin{array}{l}\text { Sch. } \\
\text { Hg. }\end{array}$ & Bar. Hg. \\
\hline $\begin{array}{ll}10 h \\
10 & 5^{\prime} \\
10 & 7^{\prime} \\
10 & 8^{\prime} \\
11 & \\
11 & 1^{\prime}\end{array}$ & $\begin{array}{l}0 \\
1,5 \\
3,5 \\
4,5 \\
4,5 \\
0 \\
\end{array}$ & $-4^{0}$ & $\begin{array}{r}+\quad 20 \\
+\quad 70 \\
+11^{0} \\
+120 \\
+\quad 90 \\
+\quad 4^{0}\end{array}$ & $\begin{array}{l}90 \% \\
92 n \\
80 n\end{array}$ & $759 \mathrm{~mm} 65 \%$ \\
\hline $\begin{array}{rr}11 & 2^{\prime} \\
11 & 5^{\prime} \\
11 & 15^{\prime} \\
11 & 16^{\prime}\end{array}$ & \begin{tabular}{|l|}
0 \\
4 \\
4,5 \\
4,5
\end{tabular} & & $\begin{array}{r}+4^{0} \\
+14^{0} \\
+14^{0} \\
+10^{\circ}\end{array}$ & $\begin{array}{l}85 \\
88 \\
90 \\
88 \\
88\end{array}$ & \\
\hline
\end{tabular}

Um 11 Uhr wird der Hund rasch entschleust und dann abermals wieder comprimirt, sobald der Druck auf 4,5 Atmosphären gestiegen war, wird mit dem langsamen Ausschleusen begonnen; dasselbe dauert 30 Minuten.

Nach der Decompression verhält sich das Thier vollkommen normal und zeigt keinerlei Erscheinungen.

Der Hund bleibt auch weiterhin vollkommen gesund.

1) Auch bei Hunden, die 1, 3 und 5 Minuten unter Ueberdrücken von 1,0, 2,0 und 3,0 Atm. zugebracht hatten, traten (mit Ausnahme am Gehörorgane) niemals Erscheinungen ein; auch zwei diesbezüglich vorgenommene Sectionen ergaben negativen Befund. 
Experimentelle Untersuchungen etc. des Luftdruckes auf den Organismus. 81

\section{Versue h 83 .}

Hund Nr. VII.

Das Thier befindet sich vollkommen wohl.

Spec. Gewicht des Blates (aus der Pfote entnommen) beträgt 1058.

\begin{tabular}{|c|c|c|c|c|c|}
\hline Z. & $\begin{array}{c}\text { Dr. i. } \\
\text { A. }\end{array}$ & A. T. & Sch. T. & $\begin{array}{l}\text { Sch. } \\
\text { Hg. }\end{array}$ & Bar. Hg. \\
\hline $\begin{array}{rr}9 \mathrm{~h} & 50^{\prime} \\
9 & 55 \\
10 & 3^{\prime} \\
10 & 5 \\
11 & 20 \\
11 & 21 \\
\end{array}$ & $\begin{array}{l}0 \\
3,5 \\
4,5 \\
4,7 \\
4,6 \\
0\end{array}$ & +20 & $\begin{array}{c}\max . \\
+150 \\
\min . \\
+\quad 90\end{array}$ & $\mid \begin{array}{c}80 \% \\
96 \% \\
70 \%\end{array}$ & $767 \mathrm{~mm} 73 \%$ \\
\hline $\begin{array}{ll}11 & 30 \\
11 & 31^{\prime}\end{array}$ & $\begin{array}{l}0 \\
4,5\end{array}$ & & & & \\
\hline
\end{tabular}

Compression auf 4,7 Atm., rasche Decompression: $10 \mathrm{Min}$. danach treten keinerlei krankhafte Erscheinungen auf. Das Thier wird neuerdings auf 4,5 $\mathrm{\Lambda tm}$. eingeschleust und nach erreichtem maximalen Druck äusserst langsam decomprimirt. Sowohl gleich nach Verlassen des Apparates, wie auch in der Folgezeit treten keine pathologischen Symptome auf; spec. Gewicht des Blutes 1058.

\section{Versuch 84. \\ Hund Nr. VI.}

Das Thier ist völlig normal, frisst und trinkt gut.

\begin{tabular}{|c|c|c|c|c|c|}
\hline Z. & $\begin{array}{c}\text { Dr. i. } \\
\text { A. }\end{array}$ & A. T. & Sch. T. & $\begin{array}{r}\text { Sch. } \\
\text { Hg. }\end{array}$ & Bar. Hg. \\
\hline $\begin{array}{rr}9 \mathrm{~h} 50^{\prime} \\
9 & 52^{\prime} \\
9 & 55^{\prime} \\
10 & 3^{\prime} \\
10 & 5^{\prime} \\
10 & 40^{\prime} \\
11 & 20^{\prime} \\
11 & 21^{\prime} \\
\end{array}$ & $\begin{array}{l}0 \\
2,5 \\
3,4 \\
4,5 \\
4,7 \\
4,5 \\
4,5 \\
0 \\
\end{array}$ & $+3^{0}$ & $\begin{array}{l}+110 \\
+130 \\
+150 \\
+\quad 90\end{array}$ & $\begin{array}{l}80 \% \\
89 \% \\
96 \% \\
70 \% \\
\end{array}$ & $767 \mathrm{~mm} 73 \%$ \\
\hline $\begin{array}{cc}11 & \mathrm{~h} \\
11 & \\
11 & 31 \\
11 & 45 \\
12 & 5 \\
12 & 20\end{array}$ & $\begin{array}{l}0 \\
4,5 \\
2 \\
1 \\
0\end{array}$ & & $\begin{array}{l}+110 \\
+120 \\
+100\end{array}$ & $\begin{array}{l}93 " \\
90 " \\
89\end{array}$ & \\
\hline
\end{tabular}

Der Hund wurde um $11 \mathrm{~h} 21^{\prime}$ rasch entschleust; keine Erscheinungen. Um $11 \mathrm{~h} \mathrm{31}$ ' wurde er wieder comprimirt und gleich daranf langsam ausgeschleust. 
Das Thier äussert weder beim ersten noch heim zweiten Versuch Zeichen von Unbehagen.

Um 12 h 20' verlässt der Hund vollkommen vohl die Schleuse, er urinirt nach Verlassen derselben und frisst sofort dargereichte Nahrung, trinkt aber auffallend viel.

\section{Versueh 85.}

H u a d N r. XXXIX.

Das Thier ist vor dem Versuche vollkommen wohl.

\begin{tabular}{|c|c|c|c|c|c|}
\hline Z. & $\begin{array}{c}\text { Dr. i. } \\
\text { A. }\end{array}$ & A. $\mathrm{T}$. & Seh, T. & $\begin{array}{l}\text { Sch. } \\
\mathrm{Hg} .\end{array}$ & Bar. Hg. \\
\hline $\begin{array}{ll}10 \mathrm{~h} \\
10 & 8^{\prime} \\
11 & 0^{\prime} \\
11 & 1^{\prime}\end{array}$ & $\begin{array}{l}0 \\
4,5 \\
4,5 \\
0 \\
\end{array}$ & $-5^{0}$ & $\begin{array}{r}+2^{0} \\
+12^{0} \\
+9^{0} \\
+4^{0}\end{array}$ & $\begin{array}{l}90 \% \\
92 \% \\
80 \%\end{array}$ & $759 \mathrm{~mm} 65 \%$ \\
\hline $\begin{array}{cc}11 \mathrm{~h} & 2^{\prime} \\
11 & 6^{\prime} \\
11 & 15^{\prime} \\
11 & 45^{\prime}\end{array}$ & $\begin{array}{l}0 \\
4 \\
4,5 \\
0\end{array}$ & & $\left\{\begin{array}{l}+4^{0} \\
+14^{0} \\
+10^{\circ}\end{array}\right.$ & $\begin{array}{l}80 " \\
85 " \\
90 " \\
88^{\prime \prime}\end{array}$ & \\
\hline
\end{tabular}

Nach dem Verlassen der Schleuse treten keinerlei krankhafte Erscheinungen auf; die vor dem Versuch sowie die nach der zweiten Decompression vorgenommene Bestimmung des specifischen Gewichtes des Blutes ergab dieselben Zahlenwerthe.

\section{Versuch 86.}

$\mathrm{H}$ und $\mathrm{Nr}$. XXXrX.

Vor dem Versuch wird das specifische Gewicht des Blutes, aus der Pfote entnommen, mit 1055 bestimmt.

Das Thier wird in 5 Minuten auf den Druck von $3,5 \mathrm{Atm}$. comprimirt und eine Stunde in der Kammer belassen; nach dieser Zeit wird es langsam in 35 Minuten decomprimirt.

Der Hund befindet sich wohl; er wird 5 Minuten nach Verlassen des Apparates getödtet; die Section ergibt allenthalben normale Verhältnisse; nirgends im Gefässsystem freie Gasblasen, das specif. Gewicht des Blutes nach der Decompression 1055, zeigt somit keine Veränderung ${ }^{1}$ ).

\section{Versuch 87.}

Kaninchen. Caisson.

Seit zwei Tagen befindet sich ein Kaninchen im Caisson unter einem Drucke von 2,3 Atm. und 2,4 Atm.

1) Weitere diesbezügliche Experimente zeigten auch bei Drüekén von 4,0 und 4,5 Atmosphären und nachfolgender langsamer Decompression niemals das Auftreten von Krankheitserscheinungen bei den Versuchsthieren. 
Beim Einschleusen zeigte sich das Thier sehr erschreckt, legte die Ohren zurïck und duckte sich im Caisson in eine Ecke.

Nach kurzer Zeit wurde es wieder munter, lief herum und frass ganz gut.

Nach dem Ausschleusen am 3. Tage, das 15 Minuten dauerte, befand es sich ganz wohl and zeigte keinerlei Erscheinungen.

Die bald nach der Decompression vorgenommene Section ergab normale Verhältnisse.

\section{Versuch 88.}

$\mathrm{Z}$ we i Kaninchen. Druck 2,4 Atm. Caisson.

Um $12 \mathrm{Uhr}$ werden zwei Kaninchen in den Caisson gebracht und um 4 Uhr Nachmittags in 18 Minuten ausgeschleust.

Sofort nach der Decompression wird das eine Thier in Wasser von $35^{\circ} \mathrm{C}$., das andere in Eiswasser gebracht.

Beide Thiere verhalten sich nahezu gleich und zeigen keine krankhaften Erscheinungen ${ }^{1}$ ).

\section{Versuch 89.}

K a n in chen. Druck 2,6 Atm. Caisson.

Ein Kaninchen sollte die Procedur des Ein- und Ausschleusens mehreremale durchmachen. Es wurde daher um $10 \mathrm{~h}$ Vormittags eingeschleust, verblieb bis $2 \mathrm{~h}$ Nachmittags im Druck und wurde um $2 \mathrm{~h}$ Nachmittags in $5 \mathrm{Mi}$ nuten ausgeschleust. Abends befand es sich wieder von $10 \mathrm{~h}-2 \mathrm{~h}$ im Druck und wird danach wieder in 5 Minuten decomprimirt. Am Morgen ist das Thier sehr niedergeschlagen, sitzt ruhig und hat die Ohren zurückgelegt, frisst aber gut.

Am anderen Tage wird es um $10 \mathrm{~h}$ Vormittags wieder unter Druck gebracht und um $2 \mathrm{~h}$ Nachmittags in der gleichen Zeit wie früher ausgeschleust. Um $4 \mathrm{~h} \mathrm{Nachmittags} \mathrm{wird} \mathrm{es} \mathrm{durch} \mathrm{Chloroforminhalation} \mathrm{getödtet.}$

Section. Im abgebundenen Herzen, sowie in den Gefässen keine Gasblase mehr. Beide Lungen besonders an ihrem freien Rande stark ecchymosirt. Gehirn und Rückenmark zeigen makroskopisch keine Veränderungen.

\section{Versueh 90.}

\section{Kaninchen.}

Ein Kaninchen mit offener Nase sowie ein Kaninchen mit fest verstopften beiden Nasen]öchern werden eingeschleust.

1) Auch Kaninchen, die rasch decomprimirt wurden, verhielten sich bedeutenden Temperaturwechseln gegenüber nach dem Ausschleusen gleich. 


\begin{tabular}{|c|c|c|c|c|}
\hline $\mathrm{Z}$. & $\begin{array}{c}\text { Dr. i. } \\
\text { A. }\end{array}$ & A. T. & Sch. T. & $\begin{array}{l}\text { Sch. } \\
\text { Hg. }\end{array}$ \\
\hline 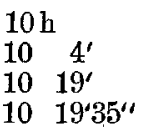 & $\begin{array}{l}0 \\
2,6 \\
2,6 \\
0\end{array}$ & $+3^{0}$ & $\begin{array}{l}+3^{0} \\
+6^{\circ} \\
+7,8^{0} \\
+3^{\circ}\end{array}$ & $\begin{array}{l}90 \% \\
97 \% \\
90 \%\end{array}$ \\
\hline
\end{tabular}

Die Thiere zeigen nach dem Druckabfall keine Krankheitserscheinungen. Die abgehackten Köpfe werden zur Untersuchung des Gehörorgans weiter verwendet.

\section{Versuch 91 .}

$\mathrm{K}$ a $\mathrm{n}$ in chen. Druck 2,6 Atm. Caisson.

Um $10 \mathrm{~h}$ Vormittags wird ein Kaninchen eingeschleust, hierauf $\mathrm{um}$ $2 \mathrm{~h}$ mittelst der Materialschleuse rasch decomprimirt und, nachdem es keine Krankheitserscheinungen gezeigt hatte, nach 21/2 Stunden durch Chloroforminhalation getödtet. Die S ection ergab: Nach Eröffnung des Thorax wird das Herz unterbunden, von den grossen Gefässen abgeschnitten und unter Benzol gebracht. Es sinkt unter. Beim Einschneiden in beide Ventrikel entleeren sich entsprechende Mengen von Blut, die sich auf dem Boden des Gefässes gleichmässig ausbreiten, ohne einzelne Kugeln zu bilden. Aus den Ventrikeln tritt kein Gas aus. In der Aorta descendens sowie in der Vena cava und in den grossen Gefässen der Extremitäten sind keine Gasblasen sichtbar. Die Lungen lufthaltig, zeigen an ihren Convexitäten beiderseits vereinzelte punktförmige Ecchymosen. Im rechten Mittellappen am unteren freien Rande sowie an dessen Spitze Hämorrhagien von der Grösse einer Linse, ebenso solche am unteren Rande des rechten Unterlappens; desgleichen Hämorrhagien am Ober- und Unterlappen der linken Lunge; am Zwerchfell sowie am Herzen keine Ecchymosen vorhanden. Am Gehirn und an der Medulla spinalis makroskopisch keine Veränderungen.

\section{Versuch 92 .}

$$
\text { Zwei Kaninchen. }
$$

Heftiger Regen und Nebel.

\begin{tabular}{|c|c|c|c|c|c|}
\hline $\mathrm{Z}$. & $\mid \begin{array}{c}\text { Dr. i. } \\
\text { A. }\end{array}$ & A. T. & Sch. T. & $\begin{array}{l}\text { Sch. } \\
\mathrm{Hg} .\end{array}$ & Bar. Hg. \\
\hline $\begin{array}{rr}9 \mathrm{~h} 45^{\prime} \\
9 & 46^{\prime} \\
9 & 47^{\prime} \\
11 & 57^{\prime} \\
11 & 58^{\prime}\end{array}$ & $\begin{array}{l}0 \\
1 \\
2,7 \\
2,7 \\
0\end{array}$ & $+4^{0}$ & $\begin{array}{r}+\quad 4^{0} \\
+\quad 6^{0} \\
+10^{0} \\
+\quad 5^{0}\end{array}$ & & $751 \mathrm{~mm} 80 \%$ \\
\hline
\end{tabular}

Beim Einströmen der Luft ducken sich die Thiere und legen die Obren zurück. Nachdem der Druck constant geworden ist, scheinen sie sich voll- 
kommen wohl zu befinden und laufen in der Schleuse herum. Auch während der Decompression zeigen sie nichts besonderes.

Nach dem Ausschleusen weder Lungenherzerscheinungen noch Symptome von Seiten des nervösen Apparates.

Zum Zwecke des Studiums der Veränderungen am Gehörorgane werden beide Thiere mittelst Chloroform getödtet. Befund des Gehörorganes wird in anderem Zusammenhange des Genaueren mitgetheilt werden.

Versuch 93.

Drei Kaninchen.

\begin{tabular}{|c|c|c|c|c|c|}
\hline Z: & $\begin{array}{c}\text { Dr. i. } \\
\text { A. }\end{array}$ & A. T. & Sch. T. & $\begin{array}{l}\text { Sch. } \\
\text { Hg. }\end{array}$ & Bar. Hg. \\
\hline $\begin{array}{cc}10 \mathrm{~h} \\
10 \\
10 & 5^{\prime} \\
10 & 35^{\prime} \\
10 & 36^{\prime}\end{array}$ & $\begin{array}{l}0 \\
2 \\
4,0 \\
4,0 \\
0\end{array}$ & $\left|-1^{0}\right|$ & $\left|\begin{array}{r}+50 \\
+100 \\
0\end{array}\right|$ & $\begin{array}{l}85 \% \\
96 \% \\
80\end{array}$ & $771 \mathrm{~mm} 80 \%$ \\
\hline
\end{tabular}

Nach dem Ausschleusen zeigen die Thiere keiverlei Erscheinungen ${ }^{1}$ ). Sie wurden zum Zweck der Untersuchung des Gehörorganes nach $1 / 2$ Stunde durch einen Schlag auf den Kopf getödtet. Befund des Gehörorgans an anderer Stelle.

\section{Versuch 94 .}

Ein Kaninchen und eine Taube

Druck 2,5 Atm. Caisson.

Um $10 \mathrm{~h}$ Vormittags warde ein Kaninchen und eine Taube eingeschleust. Um $12 \mathrm{~h}$ Mittags wurden beide Thiere mit dem Materiale entscbleust und dauerte der Druckabfall 2 Minuten 21 Sekunden. Beide Thiere lebten. Die Taube schien krank zu sein, zitterte und hatte die Federn aufgestellt. Das Kaninchen legte die Ohren zurück and sass gedrückt und theilnamslos da.

Am nächsten Tage haben sich die Thiere vollständig erholt und zeigten keinerlei Erscheinungen.

\section{Versuch 95 .}

Zwei Meerschweinchen.

Sanitätsschleuse.

Während man bei einem Ueberdruck von 1,94 Atmosphären in der Recompressionskammer mit anderen Versuchen beschäftigt ist, wurden zwei

1) Auch mehrere Experimente bei Drücken von 3,5, 4,5 und 4,7 Atmosphären lehrten, dass auch bei längerem Aufenthalt dieser Thiere und rasch bewerkstelligtem Druckabfall keine Erscheinungen auftraten; in mehreren Fällen konnten nichtsdestoweniger Gasblasen nachgewiesen werden. 
mitgenommene Meerschweinchen mittelst der Medicamentenschleuse in 2 Secunden entschleust. Die Thiere zeigen nach der Decompression keinerlei Erscheinungen und werden nach 8 Tagen getödtet.

Die Untersuchung der Gehörorgane folgt in anderem Zusammenhang.

\section{Versuch 96 .}

Meerschweinchen.

Ein Meerschweinchen wird in 1,5 Minuten eingeschleust; maximaler Ueberdruck 4,5 Atm. Das Thier bleibt 15 Minuten im Apparat. Ausschleuszeit 1 Minute 30 Secunden.

Es zeigt keinerlei Erscheiungen. Nach ò Stunden wird es durch Chloroforminhalation getödtet.

Section: Lungenechymosen. In der linken Bulba eine kleine Hämorrhagie makroskopisch sichtbar; folgt des Genaueren an anderer Stelle.

\section{Versueh 97.}

Meerschweinchen.

Fin Meerschweinchen wird in 5 Minuten auf einen Druck von 4,5 Atmosphären comprimirt und sofort darnach in 30 Secunden decomprimirt. Nach der Herausnahme aus dem. Apparate zeigt es keine Erscheinungen; Hörvermögen bei Händeklatschen anscheinend normal.

Nach 4 Stunden wird das Thier durch Chloroforminhalation getödtet.

Die Section ergibt: Reichliche Ecchymosen in den Lungen. Am Gehörorgan makroskopisch kein pathologischer Befund. Die übrigen Organe normal.

\section{Versuch 98.}

\section{Zwei Meerschweinohen.}

Einem Meerschweinchen werden beide Nasenlöcher mit Watte und Collodium verstopft, dasselbe dann in 4 Minuten eingeschleust. Es verbleibt 25 Minuten unter einem Drucke von 4,5 Atm. und wird in 1 Minute entschleust. Nach der Decompression scheint das Thier das Hörvermögen eingebüsst zu haben, da es beim ZusammenkJatschen der Hände, selbst ganz nahe am Ohre, nicht wie es sonst und bei anderen Thieren der Fall ist, zusammenschreckt und die Ohren spitzt. Es sitzt vollkommen ruhig im Käfig; nach 2 Stunden hört es wieder. Nach weiteren 2 Stunden wird es mittelst Chloroform getödtet. Die Untersuchung des Gehörorganes zeigt makroskopisch in beiden Bullen Blutungen in der Schleimhaut derselben. Mikroskopischer Befund folgt an anderer Stelle.

Das zweite Thier zeigt nach der Decompression keinerlei Erscheinungen und befindet sich wohl. 


\section{Versuch 99.}

T a u ben, Caisson.

Druck: 2,5 Atm.

Decompression auf $0,4 \mathrm{Atm}$.

Druckanstieg auf 2,5 Atm.

Decompression in 20 Minuten zum normalen Atmosphärendruck.

Um 6 h Vormittagss werden zwei Tauben eingeschleust. Die eine Taube sitzt unten im Caisson ängstlich und gedrückt, während die andere munter ist. Sie überleben die Senkung des Caissons um $10 \mathrm{~h}$ Vormittags, bei welcher die Druckverminderung 2,1 Atm. betrug. Die Tauben werden lebend in 20 Min. ausgeschleust und zeigen ausser Apathie und geringer Reaction gegen äussere Reize keine Erscheinungen. Sie werden durch Chloroforminhalation getödtet und secirt.

Die Section ergab: Bei der einen Taube Ecchymosen am Brustbein; bei beiden Thieren Ecchymosen im Schädel- sowie in den Wirbelknochen. In den Knochen der Extremitäten nichts Abnormes. In den Lungen vereinzelte hirselkorngrosse Ecchymosen; an den anderen Organen nichts abnormes.

\section{Versuch 100.}

$\mathrm{T}$ a u be. Druck 2,5 Atm. Caisson.

Eine Taube wird eingeschleusst und verhält sich beim Einschleussen folgendermaassen: Am Schlusse der Druckerhöhung sträulten sich ihre Feder, sie athmete schwer und liegt endlich bewegungslos, wie todt, da. Nach einiger Zeit erholte sie sich. Sie blieb 4 Stunden unter Druck.

Nach der Decompression in 50 Sec. zeigte sie sich apathisch; sonst nichts zu bemerken.

\section{V e r s u c h 101. \\ 3 Tauben.}

Drei Tauben werden in 5 Minuten auf einem Drucke von 4,2 Atm. comprimirt.

Im Drucke verhalten sich die Thiere wie in ihrem Käfig im Freien. Zeit des Verweilens $3 / 4$ Stunden, hierauf Decompression in 30 Secunden. Die Thiere zeigen sofort nach der Decompression und auch in der Folgezeit keinerlei Erscheinungen.

Section: Keine Ecchymosen in den Lungen, zahlreiche Ecchymosen in der Crista sterni. Befund des Gehörorganes an anderer Stelle.

Versueb 102.

Frosch. Druck 2,3 Atm. Caisson.

Ein Frosch wird curarisirt und um $4 \mathrm{~h} 30^{\prime}$ Nachm. in den Caisson gebracht und um $6 \mathrm{~h}$ ausgeschleust. Unter dem Miskroscop werden zunächst 
die Schwimmbäute betrachtet. In denselben circulirt das Blut normal; keine Gasblasen sichtbar. Das Peritoneum zeigt Stasen in den venösen Gefässen, nirgends aber sind Gasblasen zu sehen. Das Herz wird ausgeschnitten und pulsirt, in Oel gebracht, fort, ohne dass Gasentwicklung zu beobachten wäre.

\section{Versuch 103 \\ Frosch.}

Ein Frosch mit freigelegtem Mesenterium, am Präparierbrettchen fixirt, wird in 5 Minuten auf einen Druck von 4,7 Atm. gebracht; bleibt 1 Stunde unter Druck und wird in 50 Secunden ausgeschleust. Unter dem Mikroscope zeigt die Blutbewegung in den Gefässen keine Veränderung; keine Gasblasen sichtbar, auch das Herz enthält keine solchen.

\section{Versuch 104. \\ Frosch.}

Ein Frosch wird in 10 Minuten bis zu 4,2 Atm. comprimirt; bleibt 40 Minuten unter Druck und wird dann in 55 Secunden entschleust.

Aus der Schleuse genommen wird das Mesenterium unter dem Mikroscop beobachtet. Es zeigen sich keine Veränderungen in der Blutcirculation keine freien Gase in der Blutbahn.

Versuch 105.

Sechs Fische.

In einem $1 / 2$ Meter hohen Glascylinder werden 6 Goldfischchen in 5 Minuten eingeschleust und bleiben 20 Minuten unter einem Drucke von 4,5 Atm. Decompressionszeit 15 Minuten.

Während des Aufenthaltes in comprimirter Luft halten sich die Thiere meist am Grunde des Gefässes und zeigen auch nach dem Ausschleusen keine Aenderung in ihrem Verbalten.

Hierauf nochmals bis 4,5 Atm. comprimirt und nach 20 Minuten Verweilens in 30 Secunden entschleust, bieten die Thiere kein abnormes Verhalten.

Wie Eingangs gesagt, hat diese Gruppe von Experimenten das Gemeinsame, dass die Versuchsthiere nach dem Aufenthalte in comprimirter Luft vollkommen wohl blieben und keinerlei Krankheitserscheinungen darboten. Wie wir nebst den Versuchen 71, 72, 73 und 74 häufig zu sehen Gelegenheit hatten, zeigen $\mathrm{Hu}$ de nach rascher Decompression von Drücken unter 3,0 Atmosphären niemals pathologische Symptome, sie vertragen die Decompression ohne Nachtheil, wenn wir hiebei auch annehmen müssen, dass nach dem Druckabfall freie Gasblasen im Blute 
kreisen, die wir ja sogar nach der Decompression von 1,2 Atm, Ueberdruck nachzuweisen in Stande waren (s. Versuch 25a).

Fassen wir die Versuche 76 und 77 ins Auge, so fällt der Umstand auf, dass die verwendeten Hunde, obwohl sie genau denselben Bedingungen bei den Experimenten unterworfen worden waren, wie jene Thiere, die nach der Decompression schwerere oder leichtere Symptome darboten, durch den raschen Druckabfall in keiner Weise geschädigt wurden.

Dieses Ausbleiben von pathologischen Erscheinungen haben wir uns nicht etwa als die Folge des Nichtauftretens von freigewordenen Gasblasen im Blute vorzustellen, indem uns ja die Versuche 71 nnd 77 gezeigt haben, dass solche auch im Gefässsystem, insbesondere des rechten Herzens, wenn auch in geringerer Menge vorhanden waren. Es sind vielmehr individuelle Momente, die bier in Betracht kommen, unter welchen die Abgabe des Gasüberschusses durch die Langen so beschleunigt und erleichtert wird, so dass es nicht zu patbologischen Erscheinungen kommt. Fiir die Bedeutung individueller Momente spricht anch die Beobachtung, dass Thiere wit fettreichem Panniculus adiposus, die auch dann bei der Section reiche Fettentwicklung am Mesenterium und am Pericard zeigten, häufiger gerade den schwersten Erscheinungen unterworfen waren als musculöse magere Thiere; ob auch bei Hunden die Race von einem gewissen Einfluss ist, dariüber lässt sich nichts Sicheres sagen ${ }^{1}$ ).

Gewiss müssen wir aber nach unserem grossen Thatsachenmaterial annehmen, dass diese Fälle Ausnahmen darstellen, indem ja in der Mehrzahl der Beobachtungen Versuchsthiere, Hunde, die eine entsprechend lange Zeit, uiber eine halbe Stunde in einem Ueberdruck von 3-5 Atm. zugebracht hatten und in einer Minute decomprimirt wurden, schwere Allgemeinerscheinungen oder nervöse Störungen darboten, als deren Ursache das Vorhandensein von freien Gas im Gefässsystem in bedeutenderer Menge nach. gewiesen wurde.

1) Erwähnt sei hierzu noch ein nicht näher beschriebener Versuch:

Drei Hunde wurden gleichzeitig durch 1 Stunde 10 Minuten unter Druck gebracht und dann rasch entschleust. Von diesen drei Thieren zeig te das eine vonüber. gehende paretische Erscheinungen, das zweite complete Paraplegie der Hinterbeine mit Blasen- und Mastdarmlähmung, das dritte hatte vorübergehende Dyspnoë, befand sich aber nach einer Stunde vollkommen wohl. 
Unzweifelhaft geht aber aus den nunmehr zu besprechenden Versuchsergebnissen hervor, dass für das Zustandekommen von Erscheinungen drei Umstände massgebend sind: die Höhe des Druckes, die Dauer des Aufenthaltes in demselben und die Raschheit der Decompression. Fehlt einer dieser Factoren oder ist sein Werth gegeniiber den beiden anderen kein entsprechender, so wird es nicht zu schädlichen Folgen kommen.

Wie uns die Versuche $78-81$ and 75 am Hunde, welche alle bei bedeutendem Ueberdrucke angestellt worden sind, zeigen, war es hier die kurze Dauerdes Aufenthaltes in comprimirter Luft - bis 15 Minuten, die trotz rascher Decompression das Auftreten einer grösseren Menge freien Gases in der Blutmasse und damit das Auftreten pathologischer Symptome verhinderte.

Die Sectionsbefunde der Thiere 80 und 81 ergaben auch das Fehlen von Gasblasen in den Gefässen; im Versuche 79 konnten dieselben noch in der rechten Herzkammer in geringer Menge nachgewiesen werden.

Was die Geschwindigkeit des Druckabfalles anlangt, so lebren die Versuche 86 und die dort mitgetheilten Erfahrungen, sowie die Versuche $82-85$ inclusive an Hunden, dass bei Drücken iuber 3 Atmosphären, in den meisten Versuchen kamen Druckerhöhungen von 4,5 Atm. in Anwendung, dann keine Erscheinungen eintraten, wenn die Decompression langsa m vor sich ging. Es hat sich ergeben, dass gewiss eine Dauer von $30 \mathrm{Mi}$ nuten für das Absinken des Druckes genügt, damit die Thiere nicht geschädigt werden, auch hat die Section im Versuche 86 nach dieser Zeit keine freien Gase mehr nachweisen lassen. Ein grosses Material würde es natürlich erfordern, wollte man für die einzelnen Drücke diese untere Grenze des Genaueren bestimmen, indem es gewiss, gerade mit Rücksieht auf das schon Gesagte, berechtigt ist, anznnehmen, dass in manchen Fällen auch Zeiten von 5-20 Minuten ausreichend sein werden, um die Elimination der Blutgase in der Raschheit zu ermöglichen, dass keine $\mathrm{Er}$ scheinungen auftreten.

Die Versuche $82-85$ inclusive lehren uns aber auch noch des Ferneren, dass rascher Druckabfall ohne nachtheilige Folgen ${ }^{1}$ ) ver-

1) Von den "rein mechanischen" Schädigungen des Gehörorganes wird an anderer Stelle die Rede sein. 
tragen wird, wenn man, ohne das Eintreten von Krankheitssymptomen abzuwarten, die Thiere schnell wieder unter den früheren Druck bringt. Es wird hierbei einerseits, wie wir in Kenntniss der früheren Versuchsreihen sagen können, die Decompression in diesem Falle keine nachtheiligen Folgen haben, weil die Zeit zur Enthindung von Gasblasen zu kurz ist und andererseits nicht hinreichend war, um es zur Bildung einer grösseren Menge freien Gases kommen zu lassen, welche ja dann Erscheinungen bewirkt bätte. Angenommen, es wäre während der so kurz dauernden Decompression bereits zum Anftreten von freiem Stickstoff in einzelnen Gefässbezirken gekommen, so musste derselbe bei der rasch folgenden Recompression, Versuche 82 und 85 (nach einer Minute), gleichsam im Status nascendi wieder resorbirt werden und konnte in den Fällen, Versuche 83 und 84 (nach neun Minaten), noch keine die Gewebe schädigende Wirkung entfaltet haben. In allen vier Experimenten waren dann nach der zweiten langsam bewerkstelligten Decompression die eventuell vorhandenen Gasblasen sicher geschwunden. Man vergleiche hierzu auch die folgende Reihe von Experimenten, insbes. die Versuche 109 und 111.

Die mit Kaninchen vorgenommenen Versuche 87 bis 93 inclusive sowie die dort mitgetheilten Erfahrungen (s. die Anmerkung) ergaben das bemerkenswerthe Resultat, dass diese Thiere selbst nach der raschen Decompression von 4,5 Atm. niemals Erscheinungen zeigten (Vers. 93); dass sie daher bei viel geringeren Drücken 2,5 Atm. und nachfolgendem langsamen Druckabfall (520 Minuten) keine Krankheitssymptome darboten ist selbstverständlich.

Anders gestalten sich die Verhältnisse bei den Meerschwe inehen. Wenn aucb die Thiere in den Experimenten 95 und $98{ }^{1}$ ) keine Erscheinungen zeigten und die Druckveränderung ohne Schädigung vertrugen, so wissen wir doch aus den Ergebnissen des Versuches 54 , nach welchem alle drei Meerschweinchen (Ueberdruck 4,5 Atm., Aufenthalt ca. 11/2 Stunden, Decompression innerhalb einer Minute) wehr minder rasch, dass eine nach Auftreten einer Paralyse der Hinterbeine, starben, dass diese Thiere gegen die Einwirkungen solcher Druckveränderungen, wie wir sie bei unseren Experimenten

1) Die Versuche 96 und 97 wurden aus anderen Gesichtspunkten angestellt. 
angewendet haben, sich nicht refractär verhalten und somit empfindlicher sind als Kaninchen.

Von Vögeln haben wir Tauben in das Bereich unserer Untersuchungen gezogen, Versuche 99, 100, 101 und feststellen können, dass diese Thiere durch Druckveränderungen bis $4,5 \mathrm{Atm}$. and rasche Decompression nicht geschädigt werden ${ }^{1}$ ) und sich nach dem Experiment vollkommen wohl befanden, wenn auch bei zwei Thieren Ecchymosen in der Diploë des Knochens nachgewiesen wurden (Vers. 99 und 101).

Frösche, bei welchen, wie man weiss, die Hautathmung eine sebr bedeutende ist, vertrugen die Experimente ohne jegliche Folgen wie dies zum Theil sehon in Abschnitt I gesagt wurde; insbesondere sei erwähnt, dass sie während und nach einer raschen Decompression niemals aufgebläht wurden ${ }^{2}$ ). Andererseits können die bier beziiglich des Einflusses der Druckänderung auf die Blutcirculation gemachten Beobachtungen als Ergänzung des dort Gesagten dienen.

Wollte man mit Rücksicht auf das Mitgetheilte, abgesehen von den letztgenanntenVersuchen 102-105 inclusive eine E $\mathrm{mp}$ fin dlic hkeits scala für Aenderungen des Barometerdruckes bis 4,5 Atm. aufstellen, so kämen nach unserer Erfahrung als die wenigst empfindlichen Thiere die Tauben und Kaninchen an die erste Stelle, dann wïrden die Meerschweinchen und dann die Hunde folgen, die bei der Decompression von $3,5 \mathrm{Atm}$. an, schon schwere Symptome zeigen. Der Menseh erweist sich, wie wir nach dem vorliegenden grossen Beobachtungsmaterial sagen können, am allerempfindlichsten gegen die Effecteder Decompression, indem selbst nach 15 bis 20 Minuten andauernder Druckverminderung von einem Ueberdruck von 2 Atm. schwere Erscheinungen, ja der Tod ${ }^{3}$ ) eintreten kann, eine Thatsache, die mit den Erfahrungen über die Folgen der Luftembolie aus anderen Ur-

1) Natürlich wieder von den Veränderungen am Gehörorgan abgesehen.

2) Philippon konnte dieses Phänomen nach der Decompression beobachten, wenn er den Stickstoff der Luft durch Stickoxydul ersetzte.

3) Wir selbst verfügen über die $O b d u c t i o n$ eines solchen Falles; der betreffende Arbeiter hatte noch mebrere Stunden nach dem Ausschlensen gelebt. Die nach ca. 12 Stunden vorgenommene Section ergab, wie sicher festgestellt werden konnte, freies Gas im rechten Herzen. Der übrige Befund an anderer Stelle. 
sachen, Lufteintritt in die Venen bei chirurgischen Operationen, gut im Einklange steht.

Anhangsweise sei noch des Versuches 105 mit Fischen gedacht, auf welehe, wie zu erwarten stand, der rasche Druckwechsel von 1,0 auf 4,5 Atm. obne Einfluss war.

\section{Recompression.}

Die Experimente dieses Abschnittes waren von dem Gesichtspunkt geleitet zu untersuchen, ob thatsächlich die nach der Decompression aufgetretenen Erscheinungen dadurch beeinflusst werden können, dass man die Thiere nach kürzerem oder längerem Zuwarten wieder in den erhöhten Luftdruck zurückbringt. Es ist dies ein Verfahren, welches zuerst von Hop pe-Seyler nach seinen Versuchen über die Wirkung starker Luftverdünnung vorgeschlagen unter dem Namen Recompression, vielfach bei den nach rascher Druckverminderung auftretenden Erkrankungen (sog. Pres sionserscheinungen) praktisch in Verwendung gezogen wird und dessen Werth experimentell festzustellen wir im folgenden bemüht waren. Die in diesem Abschnitt mitgetheilten Versuchsergebnisse können als Ergänzung der Versuchsreihe „Lähmungserschein ungen" betrachtet werden.

\section{Versuch 106. \\ Hund Nr. XXXXII. \\ Sanitätsschleuse.}

Ein mittelgrosser, junger Hund wird in einer halben Stunde auf einen Druck von $2 \mathrm{Atm}$. comprimirt und nach einstündigem Verweilen durch die Medicamentenschleuse momentan entschleusst. Nachdem der Hund 20 Minuten ausserbalb der Schleuse zugebracht hatte, ohne irgendwelche Krankheitserscheinungen darzubieten, wird er abermals innerhalb weniger Secunden durch die Medicamentenschleuse unter Drucis gesetzt. In der Schleuse scheint das Thier etwas schlechter zu hören, zeigt aber sonst keine Symptome.

Nach weiterem Verweilen von einer halben Stunde wird der Druck langsam in $8 / 4$ Stunden herabgesetzt, und das Thier 5 Minaten nach vollendeter Decompression getödtet.

Die S ectio n ergibt überall normale Verhältnisse, keine Ecchymosen in den Lungen; nirgends sind Gasblasen in den Gefässen nachzuweisen. 


\section{V e r s a h 107. \\ Hund Nr. LVII.}

Fin mittelgrosser Hund wird in 5 Minuten eingescbleust, $3 / 4$ Stunden im Apparate unter einem Druck von 4,5 Atm. belassen und nach der Decompression, die in 50 Secunden vollzogen ist, durch Thoraxstich getödtet.

Im Gefässsystem allenthalben freie Gasblasen in der bereits beschriebenen Form und Vertheilung nachweisbar. Das todte Thier wird sofort auf den früheren Druck recomprimirt und eine halbe Stunde in dem Ueberdruck von 4,5 Atm. belassen. Nach dieser Zeit wird es in einer halben Stunde decomprimirt. An der Vertheilung, der Zahl und der Form der Gasblasen in den Arterien und Venen hat sich nichts geändert, indem selbst an jenen Stellen, wo die Blutgase als feine Bläschen nebeneinander gehäuft durch die Gefässwand durchscheinend und die höchste Kuppe auf der Blutflüssigkeit einnehmend zu sehen waren, keine Veränderung, kein Grösserwerden derselben beobachtet werden konnte.

\section{Vers u c h 108.}

Hund Nr. XI, ,Burschel" (8 Kilo).

\begin{tabular}{|c|c|c|c|c|c|}
\hline Z. & $\mid \begin{array}{c}\text { Dr. i. } \\
\text { A. }\end{array}$ & A. T. & Sch. T. & $\begin{array}{l}\text { Sch. } \\
\mathrm{Hg} \text {. }\end{array}$ & Bar. Hg. \\
\hline $\begin{array}{rr}9 \mathrm{~h} & 34 \\
9 & 45^{\prime} \\
9 & 47 \\
9 & 50^{\prime} \\
10 & 45^{\prime} \\
10 & 46^{\prime}\end{array}$ & $\begin{array}{l}0 \\
2 \\
3 \\
4,5 \\
4,5 \\
0\end{array}$ & -50 & $\begin{array}{c}-20 \\
\max . \\
+10 \\
\min . \\
+\quad 10\end{array}$ & $\begin{array}{l}80 \% \\
90 \% \\
94 \% \\
87 \%\end{array}$ & $765 \mathrm{~mm} 80 \%$ \\
\hline
\end{tabular}

Bald nach dem Ausschleusen treten dyspnoische sowie beginnende Lähmungserscheinungen, Unmöglichkeit activer Bewegung der Hinterbeine, Streckkrämple, gesteigerte Pieflexe auf. Nach kurzer Zeit ist die Lähmung der Hinterbeine eine vollständige.

Recompression nach 10 Minuten.

\begin{tabular}{|c|c|c|c|c|}
\hline Z. & $\mid \begin{array}{c}\text { Dr. i. } \\
\text { A. }\end{array}$ & A. T. Sch. T. & $\begin{array}{l}\text { Sch. } \\
\text { Hg. }\end{array}$ & Bar. Hg. \\
\hline $\begin{array}{l}10 \mathrm{~h} 56^{\prime} \\
10 \quad 59^{\prime} \\
11\end{array}$ & $\begin{array}{l}0 \\
3 \\
4,5\end{array}$ & & & \\
\hline $1120^{\prime}$ & $\begin{array}{l}\text { Langsa } \\
\text { (ca. } 1\end{array}$ & $\begin{array}{l}\text { nes Entschl } \\
\text { tunde) auf } \\
\text { Baromet }\end{array}$ & $\begin{array}{l}\text { sen } \\
\text { en h } \\
\text { stand }\end{array}$ & $\begin{array}{r}12 \mathrm{~h} 25^{\prime} \\
\text { rschenden }\end{array}$ \\
\hline
\end{tabular}

Der Hund wird eingeschleust. Die heftige Dyspnoë, die unregelmässige Herzaction, der ganze Symptomencomplex der Asphyxie ist nach der Decompression geschwunden; die Lähmung jedoch bleibt bestehen. 
$6 \mathrm{~h} 40^{\prime}$ Nachm. Paraplegie der Hinterbeine. Das Thier liegt ruhig im Stall; es hat nicht urinirt.

Am nächsten Morgen wird der Hund todt im Stalle gefunden.

Section: Die Lungen zeigen an mehreren Stellen bis bohnengrosse Eechymosen. Am Herzen sowie an den übrigen Organen nichts Pathologisches nachweisbar. Das Gefässsystem zeigt $\mathrm{makroscopisch} \mathrm{normale}$ Blutfüllung; Blase stark dilatirt.

Die mikroscopische Untersuchung des gehärteten Rückenmarkes folgt in anderem Zusammenhang.

\section{Versuch 109.}

Hund Nr. XXXVI.

Das Thier war vor dem Versuch vollkommen gesund.

\begin{tabular}{|c|c|c|c|c|}
\hline$Z$. & $\begin{array}{c}\text { Dr. i. } \\
\text { A. }\end{array}$ & A. T. & Sch. T. & $\begin{array}{l}\text { Sch. } \\
\mathrm{Hg}\end{array}$ \\
\hline 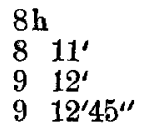 & $\begin{array}{l}0 \\
4,5 \\
4,5 \\
0\end{array}$ & $12^{\circ}$ & $\begin{array}{ll}11 & 0 \\
20^{\circ} & 0 \\
18 & 0 \\
10^{0} & 0\end{array}$ & $\begin{array}{l}78 \% \\
92 \% \\
80 "\end{array}$ \\
\hline
\end{tabular}

Neuerliche Compression.

\begin{tabular}{|c|c|c|c|c|}
\hline $\begin{array}{l}9 \mathrm{~h} 17^{\prime} \\
9\end{array}$ & 0 & $12^{\circ}$ & $10,5^{\circ}$ & \\
\hline $\begin{array}{rr}9 & 19^{\prime} \\
10 & 39^{\prime}\end{array}$ & 4,5 & & $18^{\circ}$ & $\begin{array}{l}90 \\
90\end{array}$ \\
\hline $1039^{\prime} 40^{\prime \prime}$ & $0^{x, 0}$ & & $10^{\circ}$ & 80 \\
\hline
\end{tabular}

5 Minuten nach der ersten Decompression zeigt der Hund keinerlei Erscheinungen. Abermals auf einen Druck von 4,5 Atm. gebracht und rasch decomprimirt läuft das Thier wenge Minuten herum, bleibt dann mit ausgespreizten Hinterbeinen und gestrecktem Schweife stehen, Harn und Faeces gehen ab; dann stïrzt es, leise winselnd, mit gelähmten Hinterbeinen zusammen. Zugleich hochgradige Dyspnoë, die Zunge hängt aus dem Maule heraus, Speichel fliesst reichlich ab. Die Lähmung ergreift nunmehr auch die vorderen Extremitäten. Der Hund wird recomprimirt.

Recompression.

\begin{tabular}{|c|c|c|c|c|}
\hline Z. & $\begin{array}{c}\text { Dr. i. } \\
\text { A. }\end{array}$ & A. T. & Sch. T. & $\begin{array}{l}\text { Sch. } \\
\text { Hg. }\end{array}$ \\
\hline $\begin{array}{l}11 \mathrm{~h} \\
11 \\
11 \\
11 \\
11 \\
11 \\
4^{\prime}\end{array}$ & \begin{tabular}{|l}
0 \\
4,4 \\
4,4
\end{tabular} & $20^{\circ}$ & $\begin{array}{l}19^{0} \\
28^{\circ} \\
26^{\circ} \\
20^{\circ}\end{array}$ & $\begin{array}{l}72 \% \\
86 \% \\
80 \%\end{array}$ \\
\hline
\end{tabular}


Nach der langsamen Decompression zeigt. das Thier keine Dyspnoë mehr. Athmung und Puls regelmässig, eher verlangsamt.

Das Hinterthier ist noch immer gelähmt. Die Hinterbeine nachschleppend, sucht sich der Hund fortzubewegen; dabei hälterden Kopf gegen den Boden gesenkt, schleppt sich stets im Kreise herum, den Kopf mit der Schnauze in den Sand bohrend, und überschlägt sich fast dabei. Reflexe im Bereich der Hinterbeine erloschen, ebenso complete Anästhesie des Hinterthieres. Blase und Mastdarm gelähmt. Aufgerichtet und dann sich selbst überlassend fällt das Thier bei jedem Bewegungsversuch mit den vorderen Extremitäten, mit dem Kopfe voran stets nach der rechten Seite.

Nach 2 Tagen wird der Flund getödtet.

Section: Herz und Gefässsystem bieten nichts pathologisches; Lungen blutreich, an einzelnen Stellen stecknadelkopfgrosse Ecchymosen.

An den Abdominalorgauen normaler Befund. Am Gehirn und Rückenmark makroscopisch nichts abnormes wahrnehmbar.

G e hör organ: Trommelfell beiderseits dunkelblauroth verfärbt. Die Bulla jeder Seite von schwarzbraun gefärbtem coagulirten Blute erfüllt.

Versuch 110.

II und $\mathrm{Nr}$. IV.

\begin{tabular}{|c|c|c|c|c|c|}
\hline Z. & $\begin{array}{c}\text { Dr. i. } \\
\text { A. }\end{array}$ & A. $\mathrm{T}$. & Sch. T. & $\begin{array}{l}\text { Sch. } \\
\text { Hg. }\end{array}$ & Bar. Hg. \\
\hline $\begin{array}{rr}9 \mathrm{~h} & 20^{\circ} \\
9 & 21^{\prime} \\
9 & 25^{\prime} \\
10 & 15^{\prime} \\
10 & 16^{\circ}\end{array}$ & $\begin{array}{l}0 \\
3,5 \\
4,5 \\
4,5 \\
0\end{array}$ & +20 & $\mid \begin{array}{c}+20 \\
\max . \\
+10^{0} \\
\min .0\end{array}$ & $\begin{array}{l}85 \% \\
95 " \\
92 " \\
97 " \\
85 "\end{array}$ & $765 \mathrm{~mm} 83 \%$ \\
\hline
\end{tabular}

Nach dem Ausschleusen läuft der Hund 10 Minuten lang ohne Erscbeinungen umher. Dann tritt plötzlich heftige Dyspsnoë, 120 Respirationen pro Minute, augleich spastische Lähmung der Hinterbeine ein. Recompression.

Aufs neue, bis zu einem Drucke von 4,5 Atm. eingeschleust, schwindet, sichtlich, wie man sich durchs Fenster der Kammer überzengen kann, die Dyspnoë und die Lungen-Herzerscheinungen. Das Thier, welches wie todt dalag, richtet sich nunmehr auf die Vorderbeine auf; für kurze Zeit vermag es wieder die hinteren Extremitäten zu gebrauchen; die Läbmung wird jedoch gleich darauf im Apparat während des langsameu 40 Minuten dauernden Ausschleusens wieder manifest. Nach dem Druckabfall sind die HerzLungenerscheinungen völlig geschwunden, an den Hinterbeinen complete spastische Lähmung mit Anästhesie. Stuhl und Urin gehen unwillkürlich ab.

Krankheitsverlauf:

Am nächsten Tage bleibt die Lähmung im gleichen. Der Penis ist errigirt und es besteht Priapismus bis zum Tode des Thieres. Die elektrische Prïfung ergibt keine sicheren Resultate. Retentio urinae; Blase ausdrückbar; 
Temp. 40,30 C. Am 4. Tage frisst und trinkt der Hund. Status iden. Auch am 8. Tage hat sich der Zustand des Thieres nicht geändert, es wird photographirt. Temp. $39,2^{\circ} \mathrm{C}$. In der Nacht vom 9. auf den 10. Krankheitstag stirbt der Hund.

Section am nächsten Tage:

Abdomen aufgetrieben. Penis erigirt. Nach Eröffnung der Bauchhöhle zeigt es sich, dass die ausogedehnte Blase mehr als die Hälfte derselben einnimmt, sie ist prall gespannt. Am oberen Pol der Blase in der Ausdehnung von ca. Guldengrösse ein diphteritischer Entzündungsprozess, der eine leichte Verklebung der Blase mit den anlagernden hinaufgedrängten Dünndärmen herbeigefübrt hat. In der Blase ca. 1/2 Liter trüben Harnes. Derselbe alkalisch reagirend, zeigt deutlich Albumen; Blasenschleimhaut aufgelockert injicirt; beide Nieren aufs doppelte vergrössert, deren Becken erweitert; Nierensubstanz aufgelockert, wie schwammig. Cystitis, Pyclonephritis.

Die Lungen zeigen in allen Lappen vereinzelte Ecchymosen; das Herz und die übrigen Organe bieten nichts pathologisches. Gehirn and Bückenmark zeigen makroskopisch nichts abnormes.

Der mikroskopische Befund desselben ergibt: Multiple herdweise $N$ ekrosen insbesondere in den Seitensträngen des unteren Dorsalmarkes (Fig. $14 a b$ ).

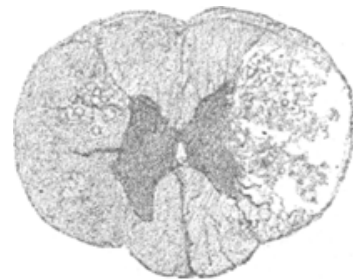

$a$

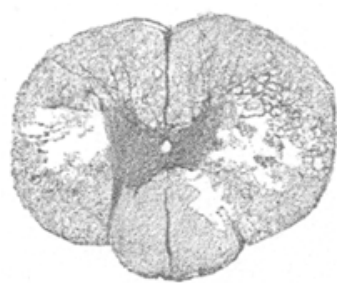

$b$

Skizzen, bei schwacher Vergrösserung.

Zwei Schnitte aus dem unteren Dorsalmark eines rasch von 4,5 Atmosphären Ueberdruck decomprimirten Hundes, der 10 Tage nach dem Experiment getödtet wurde, a Necrose des rechten Seitenstranges. $b$ Necrotische Herde in beiden Seitensträngen.

Versueb 111.

Hund Nr. V (Männchen, 9 Kilo).

\begin{tabular}{|c|c|c|c|c|c|}
\hline Z. & $\begin{array}{c}\text { Dr. i. } \\
\text { A. }\end{array}$ & A. 'Т. & Sch. T. & $\begin{array}{l}\text { Sch. } \\
\text { Hg. }\end{array}$ & Bar. Hg. \\
\hline $\begin{array}{cc}10 \mathrm{~h} & 4^{\prime} \\
10 & 9^{\prime} \\
10 & 10^{\prime} \\
10 & 39^{\prime} \\
10 & 40^{\prime}\end{array}$ & $\begin{array}{l}0 \\
3,5 \\
4,5 \\
4,5 \\
0\end{array}$ & $\begin{array}{l}+4,50 \\
+6\end{array}$ & $\begin{array}{l}+8^{0} \\
+14^{0} \\
+15^{0} \\
+13^{0} \\
+\quad 9^{0}\end{array}$ & $\begin{array}{l}76 \% \\
90 \% \\
80,\end{array}$ & $764 \mathrm{~mm} 76 \%$ \\
\hline
\end{tabular}




\begin{tabular}{|c|c|c|c|c|c|}
\hline Z. & $\begin{array}{c}\text { Dr. i. } \\
\text { A. }\end{array}$ & A. T. & Sch. T. & $\begin{array}{c}\text { Sch. } \\
\text { Hg. }\end{array}$ & Bar. $\mathbf{H g}$. \\
\hline $\begin{array}{rr}10 & 45^{\prime} \\
10 & 47^{\prime} \\
10 & 60^{\prime} \\
11 & 3^{\prime} \\
11 & 15^{\prime} \\
11 & 16^{\prime} \\
\end{array}$ & $\begin{array}{l}0 \\
3,5 \\
4,5 \\
4,5 \\
4,5 \\
0 \\
\end{array}$ & {$\left[\begin{array}{ll}+6 & 0 \\
& \\
+6 & 0\end{array}\right.$} & $\begin{array}{r}+90 \\
+15^{0} \\
+16^{0} \\
+15^{0} \\
+10^{0}\end{array}$ & $\begin{array}{l}79, \\
90, \\
80,\end{array}$ & \\
\hline $\begin{array}{ll}11 & 20^{\prime} \\
11 & 22^{\prime} \\
11 & 24^{\prime} \\
11 & 49^{\prime} \\
11 & 50^{\prime}\end{array}$ & $\begin{array}{l}0 \\
4,3 \\
4,5 \\
4,5 \\
0\end{array}$ & $\left.+\begin{array}{ll}6 & 0\end{array}\right)$ & $\begin{array}{r}+90 \\
+18^{0} \\
+\quad 17^{0} \\
+\quad 4^{0}\end{array}$ & $\begin{array}{l}\text { nicht } \\
\text { notirt }\end{array}$ & \\
\hline
\end{tabular}

Das Thier wurde um $10 \mathrm{~h} 40^{\circ}$ und um $11 \mathrm{~h} 16^{\circ}$ rasch ausgeschleust, ohne dass beide Male 5 Minuten nach der Decompression pathologische Erscheinungen aufgetreten wären.

Nach dem drittmaligen Ausschleusen um 11 h 50' länft der Hund noch durch 2 Minuten umher; dann tritt jedoch plötzlich eine Contractur im linken Hinterbein auf der bald darauf auch Contractur im rechten Hinterbeine folgt; Fäces und Urin gehen unwillkürlich $\mathbf{a b}$; der Hund fällt auf den Boden. Mit dem spastischen Zustand alternireud treten Streckkrämpfe auf, die bald von vollständiger Paraplegie beider Hinterbeine gefolgt sind.

Das Thier wird sofort recomprimirt und in 5 Minuten auf den früheren Druck gebracht, 10 Minuten lang in demselben belassen und dann langsam entschleust.

Recompression.

\begin{tabular}{ll|l|l|l|}
\hline 12 h $10^{\prime}$ & 0 & $\mid$ & $\mid$ \\
4,5 & $\begin{array}{l}\text { Von da al) langsame Decompres- } \\
\text { sion bis 12 h 55' (ca. 45 Minuten) } \\
\text { aufden äusseren Barometerdruck. }\end{array}$
\end{tabular}

Während des Ausschleusens hat sich der Zustand so weit gebessert, dass der Hund auf drei Beinen in der Kammer umher läuft, das linke Hinterbein bleibt in maximaler Beugestellung.

Nach dem Ausschleusen liegt das Thier ruhig da; bis auf die Contractur des linken Hinterbeines sind alle Lähmungserscheinungen an den Extremitäten geschwunden.

Abduction sowie Streckversuche des kranken Beines verursachen Schmerzen, das Thier winselt. Die Erregbarkeit der linken hinteren Extremität für den faradischen Strom gesteigert.

Krankheitsver la uf:

Nach zwei Tagen: Urin geht unwillkürlich ab. Die Contractur des linken Hinterbeines lässt zeitweise nach, so dass der Hund dann alle vier Extremitäten benutzen kann, jedoch ist der Gang des Thieres stolpernd, es bleibt an Gegenständen, die am Boden liegen, mit den Hinterfüssen hängen. 
Am 3. Tage ist die Incontinentia urinae geschwunden; der Hund frisst and trinkt nach Gewohnheit. Die Lähmung hat sich soweit gebessert, dass er sich nunmehr aller vier Füsse bedienen kann.

Nach 8 Tagen sind alle Erscheinungen bis auf eine Schwäche des linken Hinterbeines geschwanden.

Nach weiteren 10 Tagen Status idem.

Ein Monat nach dem Experiment ist die Schwäche in dem Hinterbeine vollständig geschwunden,

Nach weiteren 8 Tagen wird der Hund zu einer läufigen Hündin gegeben; der Coitus gelingt erst am 2. Tage, obgleich der Hund schon am ersten Tage häufig diesbezüglich fruchtlose Versuche macht, keine Erection. Das Thier bleibt am Leben.

\section{Versuch 112.}

\section{$\mathrm{H}$ und $\mathrm{Nr}$. VI.}

Das Thier ist vollkommen gesund; es frisst und trinkt nach Gewohnheit, und zeigt keinerlei Krankheitserscheinungen.

\begin{tabular}{|c|c|c|c|c|c|}
\hline$Z$. & $\begin{array}{c}\text { Dr. } i . \\
\text { A. }\end{array}$ & A. T. & Sch. T. & $\begin{array}{l}\text { Sch. } \\
\mathrm{Hg} .\end{array}$ & Bar. Hg: \\
\hline $\begin{array}{rr}9 \mathrm{~h} & 20^{\prime} \\
9 & 30^{\prime} \\
10 & 15^{\prime} \\
10 & 16^{\prime}\end{array}$ & $\begin{array}{l}0 \\
4,5 \\
4,5 \\
0\end{array}$ & +20 & $\left|\begin{array}{cc}+1 & 0 \\
\max . & 10 \\
\min . & 0\end{array}\right|$ & $\begin{array}{l}83 \% \\
90 \% \\
80 \%\end{array}$ & $765 \mathrm{~mm} 83 \%$ \\
\hline
\end{tabular}

6 Minuten nach dem Ausschleusen um 10 h 16 Min. stürzt der Hund plötzlich unter den Erscheinungen von Asphyxie und Lähmung der hinteren Extremitaten nieder; sofortige R e compression.

Recompression (2 Hunde).

\begin{tabular}{|c|c|c|c|c|c|}
\hline Z. & $\begin{array}{c}\text { Dr. i. } \\
\text { A. }\end{array}$ & A. T. & Seh. T. & $\begin{array}{l}\text { Sch. } \\
\text { Hg. }\end{array}$ & Bar. Hg. \\
\hline $\begin{array}{l}10 \mathrm{~h} 26^{\circ} \\
1027^{\circ}\end{array}$ & $\begin{array}{l}0 \\
4,5\end{array}$ & & & & \\
\hline $\begin{array}{l}10 \mathrm{~h} 28^{\prime} \\
1031^{\prime}\end{array}$ & $\begin{array}{l}0 \\
4,5\end{array}$ & $\begin{array}{l}\text { Von } \\
\text { beide } \\
\text { meter }\end{array}$ & $\begin{array}{l}\text { n lang } \\
\text { iere av } \\
\text { id bis } 1\end{array}$ & ne 1 & $\begin{array}{l}\text { ompression } \\
\text { seren Baro } \\
\text { 1 Stunde) }\end{array}$ \\
\hline
\end{tabular}

Da ein zweitus Yersuchsthier eben unter asphyctischen und LähmungsErscheinungen zusammenbricht und der Recompression bedarf, wird der bereits im Appalat befindliche Hund rasch decomprimirt, um jenen in die Schleuse bringen zu können. Während des steigenden Druckes bessert sich der Zustand des ersten Thieres, das bis dahin wie todt dalag, so weit, dass 
es nunmehr aufsteht, sich schüttelt and ohne Zeichen von Dyspnoë in der Kammer umhergeht.

Das plötzliche Ausscbleusen zum Zwecke der Recompression eines an. deren Thieres hatte somit keinen schädichen Effekt gehabt. Der Hund befindet sich nach der Recompression vollkommen wohl.

Auch der Zustand des zweiten Thieres hat sich bedeutend gebessert; nach 20 Minuten tritt jedoch abermals anfallsweise Dyspnoë auf, die aber nicht so heftig ist wie das erstemal und von keinen Lähmungserscheinungen begleitet ist.

Nachmittags 3 Uhr tritt roribergehend ein ca. 4 Minuten dauernder dyspnoischer Anfall auf., Am anderen Tage morgens befindet sich das Thier anscheinend wohl, frisst and trinkt wie gewöhnlich.

\section{Versuch 113.}

Hu nd Nr. IX "W e is s" (Männchen, 8 Kilo).

\begin{tabular}{|c|c|c|c|c|c|}
\hline Z, & Dr. i. & A. T. & Sch.T. & $\begin{array}{l}\text { Sch. } \\
\text { Hg. }\end{array}$ & Bar. Hg. \\
\hline $\begin{array}{rr}9 h 50^{\prime} \\
9 & 57^{\prime} \\
10 & 7^{\prime} \\
10 & 10^{\prime} \\
10 & 50^{\prime} \\
10 & 51^{\prime}\end{array}$ & $\begin{array}{l}0 \\
2 \\
4,5 \\
4,7 \\
4,7 \\
0\end{array}$ & $-4,5^{0}$ & $\begin{array}{c}+2 \\
\max \\
+13 \\
\min \\
+9\end{array}$ & $\begin{array}{l}72 \% \\
96 " \\
90 " \\
80 "\end{array}$ & $768 \mathrm{~mm} 80 \%$ \\
\hline
\end{tabular}

Kurz nach dem Ausschleusen zeigt der Hund beginnende paretische Erscheinungen an den hinteren Extremitäten, Steifheit der Beine, Stuhl geht unwillkürlich ab. Nach 5 Minuten tritt heftige Dyspnoë auf (140 Resp. pro Minute). Das Tbier stürzt nunmehr an allen Extremitäten vollständig ge* lähmt zusammen und scheint zu verenden.

Sofortige $\mathrm{k}$ e compression auf den früheren Druck.

\begin{tabular}{|c|c|c|c|c|c|}
\hline Z. & Dr. i. & A. T. & Sch. T. & $\begin{array}{l}\text { Sch. } \\
\text { Hg. }\end{array}$ & Bar. Hg. \\
\hline $11 \mathrm{~h}$ & $\begin{array}{l}0 \\
4,5\end{array}$ & & & & \\
\hline
\end{tabular}

Mit steigendem Druck schwindet sichtlich die Dyspnoë, das Thier steht auf und verhält sich im Apparate während des langsamen Ausschleusens vollständig ruhig.

Nach dem Verlassen desselben zeigt das Thier keinerlei lirankheits. erscheinungen, Dyspnoë und Lähmungssymptome sind geschwunden, der Hund bleibt gesund. 
Experimentelle Untersuchungen etc. des Luftdruckes auf den Organismus. 101

\section{Versuch 114. \\ Hund Nr. XLIII.}

Ein mittelgrosser Hand wird in der Experimentirkammer einem Druck von 3,5 Atm. ausgesetzt und dann nach einstündigem Aufenthalt im Apparat in $5 \mathbf{3}$ Secunden entschleust.

Ca. 12 Minuten, nachdem das Thier aus dem Apparat herausgenommen wurde, beginnt es die Hinterbeine nachzuschleppen, bleibt zeitweise stehen und athmet mehrmals auffallend tief ein; wenige Augenblicke danach tritt starke Dyspnoë auf, der Hund fällt um, die Hinterbeine gelähmt; dann treten Streckkrämpfe an den vorderen Extremitäten auf. Das Thier wird sofort wieder recomprimirt; in einer Minute ist der maximale Druck von $3,5 \mathrm{Atm}$. erreicht, der Zustand des Thieres bessert sich. Es wird durch 10 Minuten im constanten Druck belassen und dann langsam in 30 Minuten ausgeschleust. Dyspnoë sowie die Erscheinungen an den Vorderbeinen sind geschwunden; am Hinterthier ist nur mehr geringe Schwäche der Beine erkennbar.

\section{Versuch 115 .}

Hund $\mathrm{Nr}$. XLIV.

Ein mittelgrosser Hund wird in 3 Minuten auf den Druck von 4,5 $\mathrm{Atm}$. comprimirt und eine Stunde in diesem Druck belassen; rasche Decompression in 53 Secunden (Temperaturabfall während derselben $12^{\circ}$ ).

Nach zwei Minuten fällt das Thier plötzlich um und beginnt mühsam zu athmen; Herzaction frequent unregelmässig, gurgelnde Geräusche über dem Herzen zu bören, die Reflexe an den Extremitäten deutlich gesteigert, Beginn von Streckkrämpfen in den hinteren Extremitäten, das Thier wird sofort in ca. einer Minute auf 4 Atmosphären wieder eingeschleust und durch 3 Minuten im Druck belassen.

Hierauf Decompression in 25 Minuten; man kann durch das Fenster die successive Besserung des Zustandes beobachten, indem das Thier nach einiger Zeit aufsteht und im Apparat umhergeht.

Das Thier befindet sich wohl; es vermag aus der. Druckkammer herausgenommen berumzugehen, wenn auch noch eine gewisse Schwäche der Hinterbeine bemerkbar ist.

Hierauf wird der Hund nach einer Viertelstunde durch Chloroform getödtet.

Die Section ergibt im Gebiet der grossen Körpervenenstämme vereinzelte freie Gasblasen; auch im rechten Vorhof awischen den Trabekeln einzelne grosse Gasblasen sichtbar.

\section{Versuch 116.}

\section{$\mathrm{Hu}$ in $\mathrm{Nr}$. XXXVII.}

Ein Hund von 5 Kilo wird auf 4 Atm. comprimirt und nach $1 / 2$ stündigem Aufenthalt in der Kammer in einer Minute entschleusst; unter ca. 10 Mi- 
nuten nach dem Verlassen des Apparates auftretenden spastischen Erscheinungen an den Hinterbeinen erfolgt complete Lähmung der Hinterbeine, Störungen der Function des Rectums im Verlauf von weiteren 10 Minuten. Das Thier wird auf den vorigen Druck recomprimirt und $1 / 2$ Stunde in demselben belassen; es wird hierauf vorsichtig in 35 Minuten ausgeschlenst.

Keine Besserung, das Thier kriecht mühsam mit den Vorderbeinen am Boden herum und schleppt die Hinterbeine nach. Erst am zweiten Tage hat sich der Zustand so weit gebessert, dass der Hund nunmehr auch Bewegungen mit den Hinterbeinen machen kann und nach weiteren vier Tagen wieder herumzulaufen vermag.

Versuch 117.

Hund Nr. XLV.

\begin{tabular}{|c|c|c|c|c|}
\hline Z. & $\begin{array}{c}\text { Dr. i. } \\
\text { A. }\end{array}$ & A. T. & Sch. T. & $\begin{array}{l}\text { Sch. } \\
\text { Hg. }\end{array}$ \\
\hline 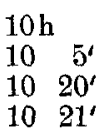 & $\begin{array}{l}0 \\
4,2 \\
4,2 \\
0\end{array}$ & $+21^{0}$ & $\begin{array}{l}+18^{0} \\
+22^{0} \\
+16^{0}\end{array}$ & $\begin{array}{l}80 \% \\
90 \% \\
78,\end{array}$ \\
\hline
\end{tabular}

Ca. 5 Minuten nach Verlassen des Apparates tritt Paralyse aller vier Extremitäten auf. Das Thier macht heftige Brechbewegungen und wird nnter zunehmender Dyspnoë asphyctisch, es liegt sterbend am Boden; gurgelnde Geräusche über dem Herzen zu hören; sofortige R e compression.

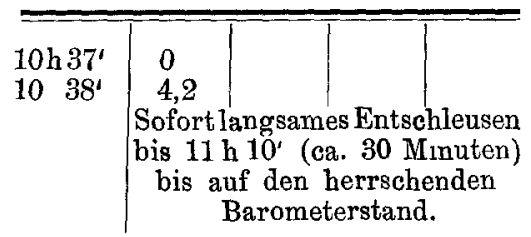

Nach rascher Recompression langsam entschleust, verlässt das Thier, dessen Krankbeitserscheinungen bereits im Apparat geschwunden waren, anscheinend wohl, denselben.

Nach einigen Minuten, während welcher Zeit der Hund umherläuft, fängt sein Gang an schwankend zu werden; das Thier taumelt und fällt zu Boden. Nach ca. einer Stunde tritt plötzlich complete Paralyse aller vier Beine auf. Asphyctische Erscheinungen kommen nicht mehr zur Beobachtung. Athmung und Puls nach der langsamen Decompression zeigen eine Abnahme der Frequenz, das Thier bleibt noch 36 Stunden am Leben.

Keine Section.

Versuch 118.

H u nd Nr. XLVI.

Ein mittelgrosser Hund wird in 4,8 A. Druck gebracht und $3 / 4$ Stunden in der Kammer belassen; er wird hierauf in 51 Secunden decomprimirt. 
Das Thier, anfangs ohne Erscheinungen, wird nach ca. 8 Minnten von den schwersten Symptomen befallen; es stürzt plötzlich um und bleibt regungslos liegen. Unregelmässige Herzaction; anfangs frequente, gleich darauf langgezogene tiefe Inspirationen; Streckkrämpfe an den Hinterbeinen.

Sofortige Recompression auf den vorigen Druck in 2 Minuten. Wie man durchs Guckloch beobachten kann, bleibt das Thier anfänglich am Boden liegen, tiefe Athemzüge deutlich zu sehen. Nach 5 Minuten hat sich der Hund erholt und kriecht im Apparate herum; er wird noch 10 Minuten in der Kammer belassen und dann in 50 Minuten ausgeschleust; das Thier verlässt die Kammer vollkommen wohl. Tödtung des Hundes.

Section.

Freie Gasblasen in den Gefässen können nicht nachgewiesen werden; auch im Herzen, dessen linker Ventrikel contrahirt ist, rothes, nicht schaumiges Blut. Lungen erscheinen in ihrem Blutgehalt nicht geändert.

\section{Versuch 119.}

H a nd N r. XLVI.

\begin{tabular}{|c|c|c|c|c|c|}
\hline Z. & $\begin{array}{c}\text { Dr. i. } \\
\text { A. }\end{array}$ & A. T. & Sch. T. & $\begin{array}{l}\text { Sch. } \\
\text { Hg. }\end{array}$ & Bar. Hg. \\
\hline $\begin{array}{cc}10 \mathrm{~h} & 25^{\prime} \\
10 & 29^{\prime} \\
11 & 29^{\prime} \\
11 & 30^{\prime}\end{array}$ & $\begin{array}{l}0 \\
4,7 \\
4,7 \\
0\end{array}$ & $15^{0}$ & $\begin{array}{l}12^{\circ} \\
18^{\circ} \\
10^{\circ}\end{array}$ & $\begin{array}{l}70 \% \\
85 \% \\
75,\end{array}$ & Barom. $760 \mathrm{~mm}$, Hyg. $70 \%$ \\
\hline
\end{tabular}

Das Thier zeigt wenige Augenblicke nach dem Druckabfall schwere Störungen; es stürzt wie vom Blitze getroffen um, streckt die Beine von sich und scheint bewusstlos; Thorax in maximaler Inspirations-Stellung.

Sofortige $R$ ecom pression jedoch nur auf 3 Atmosphären.

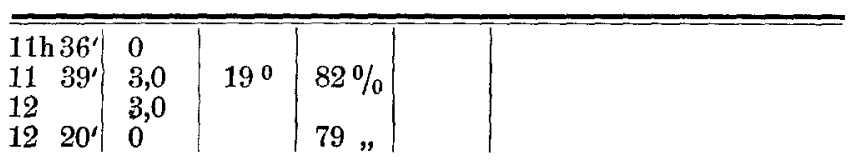

Nach dem Druckabfall erscheint der Zustand des Thieres gebessert; Bewusstlosigkeit besteht nicht mehr, es reagirt auf äussere Reize, bleibt jedoch am Boden liegen und vermag die Beine nicht zu bewegen. Athmung und Puls langsam, regelmässig.

Das Thier wird nach einer Stunde getödtet.

Section: Mehrere grosse Gasblasen im rechten Ventrikel, daneben müssige Mengen nicht schaumigen Blutes; der linke Ventrikel contrahirt. Im übrigen makroskopisch Gasblasen in den Gefässen nirgends mehr nachweisbar. Der übrige Befund ergibt normale Verbältnisse. 
104 Richard Heller, Wilhelm Mager, Hermann von Schrötter:

Versueh 120.

$\mathrm{H}$ and $\mathrm{Nr}$. XLVII.

Nach einstündigem Verweilen in einem Druck von 4,5 Atm. wird das Thier in einer Minute decomprimirt.

Bald nach dem Druckabfall tritt Dyspnoë auf und man vermag gurgelnde Geräusche über dem Herzen zu hören; der Hund schleppt sich mühsam am Boden umher, endlich bleibt er, alle vier Beine von sich gestreckt, liegen.

Recompression auf 2 Atmosphären Ueberdruck.

Man lässt das Thier eine halbe Stunde im Apparate und decomprimirt es hierauf langsam in $20^{\circ}$.

Der Hund wird aus der Schleuse genommen; er vermag sich jedoch noch immer nicht fortzubewegen und fällt bei diesbezïglichen Versuchen immer wieder zu Boden.

Nach 3 Stunden: Das Thier athmet ruhig und regelmässig; desgleichen regelmässige langsame Herzaction. Auf Anrufen reagirt es nur träge.

In der Nacht stirbt der Hund. Section wurde nicht gemacht.

Betrachten wir zunächst die Versuche 108 bis 112 inclusive. Bei allen hiebei verwendeten Thieren traten mehr minder rasch nach dem Druckabfall H e r z - L u g e ners c h ei n u n e n sowie paralytische Symptome auf.

Frihhestens nach 10 Minuten, zu welcher Zeit sämmtliche Erscheinungen manifest waren, wurden die Hunde wieder rasch in den $\mathrm{f} r$ ï h e r e n Druck gebracht und ca. 10-20 Minuten in der Kammer belassen, um dann langsam durchschnittlich in $3 / 4$ Stunden ausgeschleust $\mathrm{zu}$ werden.

In allen Versuchen konnte festgestellt werden, dass die Herz-Lungenerscheinungen nach der Recompression schwanden, die früher bestandene Dyspnoe hatte aufgebört, die gurgelnden Geräusche über dem Herzen waren geschwunden, Athmung und Herzaction der Thiere schien ungestört zu sein, indem gewöhnlich langsame tiefe Respirationen und meist verlangsamte Herzaction beobachtet wurde. Ja, man konnte sogar sehen, dass dieser Symptomencomplex schon im Apparate schwand, meist gleich im Anschlusse an den erreichten maximalen Ueberdruck, wie wir dies auch anlässlich anderer, hier nicht näher ausgeführter Versuche wahrgenommen haben ${ }^{1}$ ). Häufig jedoch, und es verdient dies be-

1) Wir erinnern diesbezüglich auch an den Versuch 70, woselbst ein Wiederansteigen des gesunkenen Blutdruckes nach der neuerlichen Compression beobachtet werden konnte. 
sonderer Erwähnung, schwinden die Störungen der Respiration und Circulation schon bei Driucken, die bedeutend geringer sind als diejenigen, von denen herab das Thier decomprimirt die schweren Erscheinungen davongetragen hatte. Man beobachtet dann wie sich ein schwer asphyctisches Thier schon während des Druckanstieges erholt und bevor noch der Druck sein Maximum erreicht hat, bereits ruhig und regelmässig athmet.

Diesbezïglich sind auch die Experimente 119 und 120 von Interesse, welche gezeigt haben, dass die Lungen-Herzerscheinungen in dem einen Falle schon nach der Recompression auf 3 Atm., in dem anderen nach dem Druckanstieg auf $2 \mathrm{Atm}$. schwanden, obwohl dieselben nach einer Decompression von $4,5 \mathrm{Atm}$. aufgetreten waren.

Anders aber verhielten sich die Symptome von Seiten des nervösen Centralapparates. Bei allen Thieren der Versuche 108-112 waren entweder gleichzeitig mit den asphyctischen Symptomen oder denselben vorangebend Lähmungserscheinungen insbesondere des Hinterthieres von verschiedener Intensität aufgetreten. Diese Symptomengruppen konnten mit Ausnabme des Falles 111 nicht zum Verschwinden gebracht werden; die Läsion im Ruickenmarke war nach 10 Minuten, nach welcher Zeit die Recompression vorgenommen wurde, bereits eine so schwere, dass die Lähmung auch nach der langsamen Decompression fortbestand, und im Versuche 108 und 109 sowie im Versuche 110 bis zum Tode des Thieres, der bei 108 am nächsten Tage, bei 109 nach 2 Tagen und bei 110 ám neunten Tage erfolgte, permanent blieb. Im Versuche 111 gestalteten sich die Verhältnisse anders. Hier war nach dem innerhalb einer Minute erfolgten Druckabfall vorerst eine Lähmung des linken Hinterbeines eingetreten, die dann rasch von einer vollständigen Lähmung des Hinterthieres gefolgt war. Recompression: Die Lähmang des Hinterbeines besteht fort, die übrigen nervösen Erscheinungen sind jedoch vollständig zurüekgegangen. Die Störung des somit zuerst und am schwersten afficirten Beines konnte durch die neuerliche Einwirkung des erböhten Luftdruckes nicht gebessert werden, die Paralyse schwand vielmehr nach und nach abnehmend erst in fünf Wochen.

Dieser Versuch wird besonders lehrreich, wenn wir ihn mit dem Experiment 114 vergleichen, auf das wir gleich werden einzugehen haben.

Vorerst wollen wir jedoch die Sectionsresultate sowie die 
106 Richard Heller, Wilhelm Mager, Hermann von Schrötter:

Todesursacbe in den erstgenannten Beobachtungen besprechen und die Erfahrungen an den Hunden LVII und XLII in Betracht ziehen. Der erste Fall hetrifft ein Thier, welehes von einem Ueberdruck von $2 \mathrm{Atm}$. plötzlich entschleust nach einer Beobachtungszeit von 5 Minuten, ohne dass pathologische Symptome auftraten, rasch recompimirt nach der darauffolgenden langsamen Decompression getödtet und secirt wurde. Die Section ergab keine freien Gasblasen in den Gefässen, was wir mit Rücksicht auf die Versuche 25, 25a und 71 als den Effect der Recompression anzusehen berechtigt sind.

Wenn auch im Versuche 108 die asphyctischen Symptome wie schon gesagt nach der Recompression geschwunden waren und sich das Thier bis auf die Lähmung anscheinend wohl befand, indem keine Störungen der Herzthätigkeit und der Respiration zu beobachten waren, so erfolgte doch nach ca. 10 Stunden das letale Ende. Wie die Section zeigte, konnten 'mit freiem Auge im Gefässsystem nirgends mehr Gasblasen nachgewiesen werden, auch kann man wohl annehmen, dass in den Capillaren der einzelnen Organe kein gasbläschenführender Inhalt mehr vorbanden war, da derselbe in Erwägung der langen Zeit bereits abgegeben sein musste. Das Kreisen des Blutgasgemisches in den Gefässen, insbesondere der nervösen Substanz, die dadurch veränderte und bedentend herabgesetzte Gewebsernährung führte durch die Schädignng lebenswichtiger Centren den Tod herbei; war ja auch die nach der Decompression aufgetretene Paraplegie keine bloss vorübergehende; die Läsion im Rückenmark vielmehr eine so intensive, dass die betreffenden Symptome nicht mehr schwanden.

Auch bei dem Versuchsthier Nro. IV hatte die Recompression keine Besserung der Erscheinungen von Seiten des Rtickenmarkes bewirkt; auch nach derselben war vollständige Paraplegie des Hinterthieres vorhanden, die Symptome, wie sie vor der neverlichen Luftdruckerhöhung auftraten, bestanden fort und waren deutlich ausgeprägt; neben der Lähmung der Hinterbeine beherrschte vor allem die Paralyse der Blase das Bild und der am nächsten Tage aufgetretene Priapismus hielt bis zum Tode des Thieres an, welcher am neunten Tage nach dem Experiment unter den Erscheinungen der Cystitis und Pyelonephritis erfolgte.

Im Versuche 111 waren keine Störungen der Herz-Lungenthätigkeit, nach der Decompression nur Erscheinungen von Seiten 
des Rückenmarkes aufgetreten; der rasche Druckabfall war von einem paraplegischen Symptomencomplex gefolgt, in dem die nervösen Bahnen des zuerst afficirten linken Hinterbeines am meisten geschädigt worden waren, so dass die Erscheinungen von Seiten dieser Extremität auch nach der Recompression bestehen blieben. Dass dic Function des rechten Beines nach der langsamen Decompression nahezn vollständig wiedertergestellt war, müssen wir nicht nothwendiger Weise als den Effect der Recompression ansehen, sondern wir können nach unseren anderweitigen Erfahrungen annehmen, dass die Störungen hier von vorne herein leichtere und daher nur voriubergehende waren und auch ohne weitere therapentische Versuche zurückgrggangen wären. Die Störungen des linken Hinterbeines bildeten sich erst allmählich zurïck und nach circa einem Monat war die Gebranchsfähgkeit des Beines wieder vollkommen hergestellt.

Im Experimente 116 war die rasehe Decompression nur von Lähmungserscheinungen des Hinterthieres gefolgt; die Recompression, erst nach dem Manifestwerden derSymptome vorgenommen, batte, wie zu erwarten stand, keine Besserung im Gefolge, wenn anch die Zeit des Aufenthaltes im erhöhten Druck and die Dauer des Druckabfalles entsprechende waren.

Auch in den Versuchen 112, 113, 114 und 115 war nach der ersten Decompression derselbe Symptomencomplex wie in den Experimenten 108-110 aufgetreten; die Recompression hat hier aber nicht bloss die Allgemeinerscheinungen zum Schwinden gebracht, es wurde durch dieselbe auch erreicht, dass die Symptome von Seiten des Rückenmarkes, die eben sich ausbildenden Lähmungen keine bleibende wurden, indem die Setzung dauernder Läsionen an den durch die gestörte Circulation mangelhaft ernährten Stellen verhindert warde.

In allen vier Experimenten, und dieser Umstand muss besonders betont werden, wurden die Thiere sogleich, nachdem die Erscheinungen aufgetreten waren, neuerlich in den frühern Druck gebracht, so dass eine Zeit von böchstens zwei Minuten zwischen dem Auftreten der ersten pathologischen Erscheinungen and dem Wiederansteigen des Luftdruckes verstrich, eine Zeit, die in der Reihe 108-112 eine viel längere, bis 10 Minuten andauernde war.

In den Versuchen 112, der eine Hund, und 113 wurde durch die Recompression vollständige Heilung erzielt. Bei dem andern 
Thier des Versuches 112, welches ebenfalls nur wenig äber eine Minute unter dem gleichen Ueberdruck wie in dem die Erscheinungen verursachenden kxperimente geathmet hatte, waren ebenfalls alle schweren Symptome geschwunden; es traten jedoch bald nach der Recompression sowie nach einigen Stunden neuerlich Anfälle von Dyspnoe auf, als Zeichen, dass vollständig normale Verhältnisse noch immer nicht im Organismus hergestellt waren, dass die Abgabe und Resorption des freien Gases noch immer nicht vollendet war and dadurch Störungen der Herztbätigkeit bedingt wurden. In weiterer Folge befand sich das Thier dann wohl und hatte keinerlei Erscheinungen mehr.

Auch des Experimentes 117 ist diesbezïglich hier Erwähnung zu thun. Die nach dem Auftreten der schweren Erscheinungen wenn auch sofort vorgenommene Recompression auf den vorigen Druck, mit dem gleich darauf erfolgten Ausschleusen in 30 Minuten waren zu kurz gewesen, um die vollständige Elimination des freien Stickstoffes zu bewirken; die Herz-Lungenerscheinungen waren allerdings geschwunden; wir müssen jedoch annehmen, dass nach der zweiten Decompression noch freie Gase in der Blutbahn kreisten, die hinreichend waren, noch nach einiger Zeit schwere Schädigungen, so die Lähmung aller vier Extremitäten hervorzurufen. Die Störungen waren so eingreifender Art, dass das Thier im Verlauf von 36 Stunden verendete.

Dass die Recompression, um ihre volle Wirlssamkeit entfalten zu können, thatsächlich durch einen entsprechenden Zeitraum ausgefuhrt werden muss, dass man insbesondere die Decompression äusserst lang sam zu bewerkstelligen hat, wenn man das Thier auch nur auf kurze Zeit in dem maximalen Ueberdruck belässt, ergibt sich aus dem Versuche 115, bei welchem durch die Section noch Gasblasen in einzelnen Bezirken des Gefässsystems nachzuweisen waren, wenn auch das Thier nach Verlassen des Apparates keine Erscheinungen mehr zeigte. Recomprimirt wurde in diesem Versuche anf 4,0 Atm. durch 3 Minuten; die Daner des Druckabfalls betrug 25 Minuten. Vergleiche hierzu auch die Experimente 116 and 120.

Der Versuch 114, welchen wir schon herangezogen baben, ergab nach der Recompression eine so bedeutende Besserung der Symptome, dass der früher an den Hinterbeinen vollständig gelähmte Hund wieder gehen konnte, wenn auch eine gewisse 
Schwäche derselben nicht zu verkennen war; die Erscheinungen von Seiten der erst nach dem Befallenwerden der Hinterbeine nur leicht geschädigten vorderen Extremitäten waren vollständig geschwunden.

Im Versuche 118 war der Erfolg der Recompression ein vollkommener. Das Thier, das in Erwägung bereits besprochener Versuchsreihen wahrscheinlich nach kürzerer oder längerer Zeit gestorben wäre, wurde durch die neuerliche Erhöhung des Luftdruckes wäbrend der Zeit von 15 Minuten und den in 50 Minuten bewerkstelligten Druckabfall gerettet und vollkommen wiederhergestellt. Auch die Section lebrte, dass wieder normale Verbältnisse für den Kreislauf geschaffen worden waren, indem das Gefüsssystem allenthalben normale Blatfillung und nirgends mehr das Vorhandensein freier Gasblasen zeigte. Denselben Erfolg hatte die Recompression auch im Versuche 106, bei weJchen die Section ebenfalls keine Gasblasen mehr zeigte, deren wenn auch symptomenloses Verhandensein nach der ersten fast momentanen Decompression wir in Rücksicht bereits besprochener Versuchsresultaten annehmen diurfen. Die neuerliche Compression hatte in diesen Fällen die vollständige Rückabsorption und Elimination des freien Stickstoffs bei der Passage des Blutes durch die Lungen ermöglicht.

Dass eine Resorption des in Form grösserer und kleinerer Blasen in den Gefässen freigewordenen Gases im todten Thier nicht erfolgt, haben wir an Versuch 107 zeigen können.

In den beideu letzten Beobachtungen dieses Abschnittes 119 und 120 wurde bei der Recompression nit Vorbedacht nieht der gleiche Ueberdruck wieder angewendet, wie in dem ersten, die Erscheinungen verursachenden Experimente, sondern es wurden geringere Drücke, in dem zweiten Falle nur die halbe Luftdruckerhöhung in Wirksamkeit gebracht. War es ja vou theoretischem Standpunkt ans denkbar, dass die Recompression auf geringeren Druck genügen könnte, um die Blutflüssigkeit von den vorhandenen freien Gasblasen zu befreien und dadurch die Ausbildung weiterer Folgezustände zu verhindern sowie anch durch Wiederherstellung normaler Circulationsbedingungen die bereits aufgetretenen Störungen zum Versebwinden zu bringen, da man wohl annebmen darf, dass selbst kurze Zeit nach der ersten Decompression eịn gewisser Gasiiberschuss bereits abgegeben worden sein kann, so dass die noch im Gefaisssystem vorbandene Menge freien 
110 Richard Heller, Wilhelm Mager, Hermann von Schrötter:

Gases eine solche ist, wie sie einer Decompression von einem geringeren Ueberdruck entsprechen wïrde.

I)as Thier XLVI zeigte nach der zweiten langsamen Decompression wohl eine Besserung der schweren Erscheinungen, die sich jedoch nur auf die Herz-Lungensymptome und dadurch auf den Allgemeinzustand erstreckte. Die Unbeweglichkeit der Beine bestand hingegen noch fort und das Thier vermochte sich nicht zu erheben. Die nach einer Stunde vorgenommene Section bewies auch, dass der Effect der Recompression kein vollständiger war, indem sich noch freies Gas im rechten Herzen vorfand. Allerdings müssen wir zu diesem Versuche noch bemerken, dass das Thier nur durch eine Minute unter $3 \mathrm{Atm}$. Druck gebracht und in 20 Minuten ausgeschleust wurde.

Beim Hunde Nr. XLVII schien die nenerliche Druckwirkung ron 2 Atmosphären in der Dauer von einer halben Stunde einen günstigen Einfluss auf die Herzthätigkeit gehabt zu haben, wie der Zustand des Thieres nach der langsamen Decompression zeigte. $\mathrm{Zu}$ einer vollen und bleibenden Wiederherstellung der schwer geschïdigten Functionen war es jedoch nicht gekommen. Die sich allmählich mehr und mehr bessernden Circulations- und Ernährungsverhältnisse waren hier nicht mehr im Stande, die gesetzten Störungen wieder auszugleichen; das Thier starb nach mebreren Stunden.

Wie wir dies schon bei Gelegenheit einer anderen Versuchsreibe gesagt haben, wïrde allerdings eine noch viel grössere Zahl von Experimenten nothwendig sein, um den Werth der Recompression für die einzelnen Fälle noch genauer zu determiniren und festzustellen, und dadurch die Werthe der anzuwendenden Druckgrössen, sowie die Dauer des Aufenthaltes und der Decompression in bestimmte Grenzen zu bringen und näher zu präcisiren; wir glauben jedoch nach den mitgetheilten Beobaclitungen die Wirksamkeit einer neuerlichen Compression genügend beleuchtet und für die einzelnen Symptomengruppen klargestellt zu haben.

Gegen die Erscheinungen von Seiten des Herzens und die Störungen des Respirationsapparates ist die Recompression ein ausgezeichnetes Mittel und wirkt geradezu lebensrettend in jenen Fällen, wo durch die Behinderung dieser lebenswichtigen Funktionen bereits schwere Allgemeinerscheinungen aufgetreten sind.

Auch bei begrenzten Störungen, bei den durch lokale Schä- 
digungen im Rückenmark bedingten Lähmungserscheinungen haben wir von der Recompressionsdaner dann günstige Erfolge gesehen, wenn das Thier gleich nach dem Auftreten derselben unter Druck gebracht wurde.

Man darf jedoch in der Beurtheilung des Werthes der Recompression bezüglich der Lähmungserscheinungen nicht zu sanguinisch sein, denn man muss sich stets ror Augen balten, dass sich auch scheinbar schwere paraplegische Symptome nach Minuten oder Stunden spontan bessern and schwinden können und andererseits wieder ausgesprochene Lähmungen mit manifesten Erscbeinungen durch den Effect der Recompression nicht zurückgehen und nur dann gebessert werden, wenn man die für den einzelnen Fall vorher nicht genau zu bestimmende "kritische“ Zeit versäumt hat.

Die Herz-Lungenerscheinungen können - und wir verfügen diesbezüglich über Beobachtungen am Mensehen - noch nach Stunden giunstig beeinflusst werden im Gegensatz zu den Lähmungserscheinungen, auf welche eine neuerliche Erhöhung des Luftdruckes nur in deren Initialstadium wirken kann.

Es braucht nach dem Gesagten wohl nicht besonders betont zu werden, dass die Recompression im Allgemeinen umso günstiger wirkt, je fribueitiger dieselbe vorgenommen wird, je länger man den Aufenthalt ausdehnt und je langsamer die daraufolgende Decompression be. werkstelligt wird.

Am Schlusse dieses Absehnittes haben wir noch einige Bemerkungen uber die an unseren Versuchsthieren beobachteten Lähmungsersch einungen nachzutragen, wobei wir nunmehr unsere gesammten diesbezüglichen Erfahrungen berïcksichtigen können.

Was zunächst bei übersichtlicher Betrachtung dieser Erscheinungen auffällt, ist die Prädilection der Störungen von Seiten der hinteren Extremitäten. Wenn anch die Paraplegie der Hinterbeine nicht immer vollständig und in beiden Beinen mit gleicher Intensität ausgebildet ist, so ist doch der paraplegische Typus der Läsion in den meisten Fällen mehr oder minder deutlich ausgeprägt, indem bloss in wenigen Fällen Symptome nur von Seiten einer Extremität allein anftraten. In der Mehrzabl der Beobachtungen war auch die Funktion der anderen alterirt. 
112 Richard Heller, Wilhelm Mrager, Hermánr von Schrötter:

Die Störung von Seiten des weniger befallenen Beines war aber dann stets eine bloss vorübergehende, und man konnte die betreffende Extremität schon beim Einsetzen der Erscheinungen als die weniger afficirte meist dadurch erkennen, dass die Art der Symptome, vorwiegend Reizerscheinungen, schon auf den weniger intensiven Grad der Läsion ibrer Bahnen schliessen liessen. Haben wir doch oft genug beobachtet, dass, während das eine Bein bereits vollkommen unbeweglich war, ein theilweiser und zeitweiser Gebrauch des andern noch möglich blieb, wenn auch die Funktion desselben in verschiedener Stärke gelitten hatte. In solchen Fällen, wo die Störung insbesondere eine bintere Extremität befallen hatte, liess sich in Bezug auf die Häufigkeit ein Ueberwiegen der einen Seite gegen die andere nicht nachweisen. Die Lähmung betraf jedoch in der Mehrzahl der Beobachtungen, insbesondere bei Decompression von höherem Ueberdruck nicht bloss die hinteren Extremitäten, sondern wir hatten es häufig mit einer vollständigen Lähmung des Hinterthieres za thun. Die Störungen der Funktionen von Blase und Mastdarm werden wohl erst später deutlich und manifest, eine diesbezügliche Störung wird jedoch bereits im Beginne in jenen Fällen mit Sicherheit angenommen werden düren, wo an dem betreffenden Versuchsthier, wie wir dies bei den entsprechenden Experimenten beschrieben haben, unwillkürlicher Stuhlabgang auf Läsionen dieser Sphäre hinweist.

Meist setzen die nervösen Störungen mit Reizerscheinungen ein, bevor es zu vollständiger Lähmung der betreffenden Extremitäten kommt.

Tonische Streckkrämpfe von wechselnder Intensität leiten die folgenden Lähmungserscheinungen ein, die im Beginn auf längere (im Versuch 58 durch $3^{1} / 2$ Stunden) oder kürzere Zeit spastischen Charakter besitzen; die Reflexe sind dann deutlich gesteigert und passive Bewegungen versetzen die Extremität in krampfhafte Streckstellung, auch scheint das Thier Schmerzen in dem befallenen Beine zu haben, indem es sich bäufig unter Winseln in dasselbe beisst.

Meist ist die Entwicklung des Bildes folgende. Das Thier springt aus dem Apparat heraus und läuft noch herum, dann plötzlich bleibt es stehen, spreizt die hinteren Extremitäten auseinander, krümmt dabei häufig auch den Rücken und zittert an den Beinen, den Schweif in die Höhe gestreckt; plötzlich geht 
noch in dieser Stellang Stuhl, oft auch Urin ab; die Beine werden immer steifer, die Zehen maximal dorsalwärts flectirt, und so versucht es der Hund, zu gehen. Er stürzt aber gleich auf eine Seite und bleibt mit gestreckten Hinterbeinen, oft auch unter gleichzeitigen asphyctischen Erscheinungen liegen, fruchtlos bemübt, mittelst der Vorderbeine am Boden weiterzukriechen.

Die Steifheit der hinteren Extremitäten lässt dann allmählich nach, das Thier versucht sich aufurichten; da treten jedoch abermals Streckkrämpfe auf und es liegt wieder mit weit von einandergespreizten, steifen Hinterbeinen am Boden. Nach wechselnder Zeit lässt der spastische Zustand nach, Extremitäten und Schweif bleiben unbeweglich; die Reflexe können aber noch lange Zeit gesteigert sein.

Auch in der sensiblen Sphäre lassen sich häufig schon in der ersten Zeit Defecte nachweisen (Versuch 55 und 58). Die den Symptomencomplex dominirenden Motilitätsstörungen bessern sich dann meist in weiterer Folge und nach Tagen oder Wochen kann das Thier seine Extremitäten wieder vollkommen wie vor dem Versuch gebrauchen. In den schweren Fällen gewinnt die sich entwickelnde Cystitis mit ihren Folgen, sowie das Auftreten von Decubitus für den Allgemeinzustand des Thieres an Bedeutung und es geht unter diesen Umständen zu Grunde, ohne das Bewegungsvermögen der Beine wieder erlangt za haben (nach 5 Wochen im Versuch 58).

Aber nicht immer sind es Reizerscheinungen, welche die Lähmungen einleiten und ihrem Manifestwerden vorangehen; wir haben Beobachtungen mitgetheilt, welche zeigen, dass das Thier in manchen Fällen and dann meist gleich im Anschluss an die Decompression plötzlich auf den Hintertheil zusammenbricht und an den hinteren Extremitäten gelähmt bleibt, ohne dass Krämpfe in denselben aufgetreten wären; wohl aber kann es hiebei vorkommen, dass vorübergehende Streckkrämpfe in den vorderen Extremitäten auftreten.

Dieses Einsetzen der Lähmungen ohne vorhergehende oder begleitende irritative Symptome ist besonders in jenen Fällen deutlich, wo die Thiere nach Verlassen des Apparates an allen vier Extremitäten paralysirt zusammenstürzen (Versuche 14, 53, 114, 117 und 119) und wie bewegungslos am Boden daliegen. Diese schweren nervösen Erscheinungen sind aber dann, wie wir 
114 Richard Heller, Wilhelm Mager, Hermann von Schrötter:

gesehen haben, auch meist mit so bedeutenden Störungen der lebenswichtigen Funktionen, Aspbyxie, verbunden, dass sie von letalem Ausgang gefolgt sind. Wir haben uns in solchen Fällen vorzustellen, dass die Läsionen der betreffenden Bahnen im Rückenmarke gleich im Beginne so eingreifende, die $\mathrm{Isch}$ a e m ie und A n a e m is i u $\mathrm{g}$ g der betreffenden Bezirke so vollständige waren, dass die von denselben versorgten Extremitäten ihre Functionen vollkommen einbüssten.

Dass es einmal zu einer bleibenden Paraplegie der vorderen Extremitäten allein gekommen wäre, haben wir in Uebereinstimmung mit anderen Autoren nie beobachten können.

Wie ja aus der Beschreibung der einzelnen Versuche zur Genüge hervorgeht, können die Bilder wechselnde sein und die Aufeinanderfolge der nervösen Symptome, die Art des Ergriffenseins der einzelnen Extremitäten in Bezug anf In- und Extensität vielfach variiren. Aber anch ihr zeitliches Auftreten kann in Rucksicht auf die Erscheinungen von Seiten des Herzens und des Respirationsapparates ein verschiedenes sein. Häufig treten beide Symptomengruppen gleichzeitig auf; man beobachtet Streckkrämpfe in den Beinen und zu derselben Zeit Dyspnoe und Störungen der Herzthätigkeit; in anderen Fällen treten nach der Decompression zuerst asphyctische Symptome auf und dann erst folgen die Lähmungserscheinungen. Es kann aber auch vorkommen, dass die Paraplegien die Reihe der Störungen eröffnen und dann erst, in solchen Fällen wohl meist leichtere, Allgemeinstörungen auftreten; es kann endlich in seltenen Fällen sogar geschehen, dass vorübergehende Dyspnoe noch zu einer Zeit auftritt, nach welcher die Lähmungserscheinungen bereits wieder geschwunden sind.

Fassen wir nunmebr nach Besprechung der einzelnen Ver. suchsreihen die gewonnenen Resultate dieser Untersuchung kurz und übersichtlich zusammen, so glauben wir nunmehr die folgenden Sätze entgiultig festgestellt zu haben, die zugleich eine Bestätigung der Anschauungen der französischen Autoren bilden können.

Die Blutvertheilung des Organismuserfährt in comprimirter Luft aus mechanischen UrsachenkeineVeränderung; man kanndaher eine solebe zurErklärng der nach der Decompression a f tretenden pathologischen Erscheinun. gen nieht heranzieben. 
Experimentelle Untersuchungen ete. des Luftdruckes auf den Orgānismus. 11วั

Nach rascber Decompression, deren Dauer für den einzelnen Fall in $\mathrm{nerhalb}$ einergewissen unteren Grenzeschwankt, kann man im Gefäs system freies Gas nachweisen.

Das aus dem Blute freigewordene Gas ist seiner Zusammensetzung nach fastausschliessliebstickstoff.

War der Aufenthalt in comprimirter Luftein genügender, und die Decompression eine entsprecbend rasche, sotreten naebderselben pathologische Erscheinugen auf. Dieselben sind nach ihrer In- und Extensität versehieden und können inzweiHauptgruppenuntersehieden werden, woron entweder jede allein oder beide gleichzeitig vorhanden sein können. Die eine fruppe umfasst die schwereren Störungen, die der Herz- und Langenthätigkeit; sie ist vorwiegend für den Allgemeinzustand des Thieres von massgebender Bedeutung und kann daher dixect zum letalen Ausgangefibren. Der anderen Gruppe gehören die Störungen seitens des Centralnervensystems, insbesondere des Riuckenmarkes an.

Alle diese Erscheinungen sind dureb das Vorbandensein von freiem Gas im Gefässystemebedingt, und es walten hiebei der Hauptsache nach dieselben Momente ror, wie nach der künstlichen Einbringung von Luft in das Gefässsystem. Was speciell die Erschein ungen von Seitendes Rückenmarks betrifft, so haben wir ans dieselbendureh das Vorhandensein von Luft in den Arterienzu erklären, wodureheszu multipler, heerdweiser Necrose in demselben ko m t.

Dienach der Decompression aufgetretenen Erscheinungen können durch neaerliche Erhö. hung des Luftdruckes zum Theile zum Schwinden gebraebt werden. Die Symptomevon Seiten des Herzens und des Respirationsapparates wer- 
116 Heller, Mager, v. Schrötter: Experimentelle Untersuchungen etc.

den unter allen Umständengünstigbeeinflusst, Lähmungsersehein ungen jedoch n ur dann, we un die Recompression rechtzeitig vorgenommen wird.

Der Erfolg derselben hängt im Allgemeinen ab ron der Kürze der Zeit, die zwischen dem ersten Auftreten der Erseheinungen und der neuerlichen Compression liegt, der Höhe des Druckes und der Dauer derselben, sowie von derzeitlichen Ausdebung, der Langsamkeit des Druckabfalles.

Auf die hier nur übersichtlich mitgetheilten Erfahrungen werden wir noch ausführlich zurückkommen. Wir werden die hier gewonnenen Resultate über die Effecte rascher Veränderungen des barometrischen Druckes des näheren mit den Ergebnissen der venösen und arteriellen Luftembolie in Beziebung zu bringen haben und der Genese der einzelnen Symptome in besonderer Berûcksichtigung der am Menschen nach der Decompression beobachteten Erscheinungen eine eingehende Interpretation w i d m en. 